IVETH YAMAGUCHI WHITAKER

\title{
GRAVIDADE DO TRAUMA E PROBABILIDADE DE SOBREVIDA EM PACIENTES INTERNADOS
}

Tese apresentada à Escola de Enfermagem da Universidade de São Paulo, para obtenção do título de Doutor em Enfermagem.

Orientadora:

Profa D ra Maria Sumie Koizumi

São Paulo

2000 
Ficha catalográfica preparada pelo Serviço de Biblioteca e Documentação da EEUSP

Whitaker, Iveth Yamaguchi

Gravidade do trauma e probabilidade de sobrevida em pacientes internados / Iveth Yamaguchi Whitaker - São Paulo: I.Y. Whitaker, 2000. $148 \mathrm{p}$.

Tese (Doutorado) - Escola de Enfermagem - Universidade deSão Paulo.

I. Título. II. Índices de gravidade do trauma. III. Morbidade.

IV. Mortalidade hospitalar. V. Pesquisa em enfermagem. 


\section{DEDICATÓRIA}

Aos meus pais, irmãos e cunhados, pelo amor à vida.

Ao Ari com amor, pelos ensinamentos e dedicação incondicional. 


\section{AGRADECIMENTOS}

À Profa. Dra Maria Sumie Koizumi, pelos ensinamentos como orientadora ao longo do mestrado e doutorado.

À Comissão de Ética para Análise de Projetos de Pesquisa-CAPPesq da Diretoria Clínica do HCFMUSP, pela autorização para realização do estudo.

Ao Dr Oduvaldo Góes, Diretor da Divisão de Arquivo Médico do HCFMUSP, pelo acesso à consulta aos prontuários dos pacientes.

Ao Prof Dr Olavo Pires de Camargo, Chefe do Corpo Clínico do IOT-HCFMUSP, por permitir o acesso aos prontuários dos pacientes.

Ao Dr Francisco Claro, Diretor do Instituto Médico Legal do Estado de São Paulo, por autorizar a consulta aos laudos de necropsia .

Ao Dr Antonio Gonçalves, Coordenador do SAMU-SP da Secretaria de Saúde do Estado de São Paulo, pelo acesso às fichas de atendimento pré-hospitar .

Ao Capitão José Luiz Borges do COBOM, por permitir a consulta ao banco de dados para obtenção das informações referente à fase pré-hospitalar.

À amiga Terezinha Dalossi Gennari, por ter compartilhado em todos os momentos, fossem eles fáceis ou difíceis, alegres ou tristes, recompensadores ou não e principalmente pela amizade inabalável.

Às Professoras Nina Granitoff, Valterli Conceição S. Gonçalves, Suely Sueko V. Zanei e Maria Nilda V. de Camargo, pela amizade, pelo incentivo e auxílio incondicional para a realização desta tese.

Às Residentes de Enfermagem Luciana de O liveira Matias e Flávia Vidal S. Tamancoldi, pela inestimável colaboração na supervisão do estágio aos alunos de enfermagem. 
A todos do D epartamento de Enfermagem da UNIFESP pelo apoio e incentivo recebido durante a realização da tese.

À D ra Clara Sette Whitaker Ferreira, pela valiosa contribuição na recuperação de dados e dos prontuários e, especialmente, pelo apoio recebido no momento importante desta tese assim como, de minha vida pessoal.

À D ra Maria Helena Prado de Mello Jorge, pelo carinho, disponibilidade e ensinamentos preciosos em metodologia para o estudo das causas externas.

Ao Dr Renato Sergio Poggetti, pela disponibilidade e atenção para elucidar dúvidas sobre codificação das lesões dos pacientes de trauma, pelos contatos feitos com pesquisadores norte-americanos para esclarecer dúvidas metodológicas relativas a mensuração da gravidade do trauma e especialmente pelas sugestões por ocasião da leitura do projeto de pesquisa.

Ao Hemerson Martins Nalepa, pela disponibilidade para a construção do banco de dados.

À Profa Dra Heimar de Fátima Marin pelo empenho e colaboração durante a visita ao Beth Israel Deaconess Medical Center junto às Enfermeiras Dianne Danis - Trauma Nurse coordinator e Nancy Richter Responsável pelo Banco de Trauma.

Ao Dr Antonio Carlos Fernandes, pela amizade, incentivo e ajuda na classificação das lesões.

Ao Prof Aristarcho Lobo Netto e Profa Elaine Tonini Pinto, pela inestimável competência, disponibilidade e especial carinho que me dedicaram.

À Dra Karen Brohi do Royal London Hospital, pelas informações metodológicas relacionadas aos índices de trauma.

Aos médicos Dr Carlos Delmonti Fernandes, Dr Elias A. Sallum e Dr Marco Antonio Herculano, pela colaboração na classificação das lesões. 
Aos funcionários da Divisão de Arquivo Médico do Instituto Central do HCFMUSP, pela gentileza e disponibilidade às inúmeras solicitações que se fizeram necessárias durante a coleta de dados.

Às funcionárias do Serviço de Arquivo Médico do Instituto de Ortopedia e Traumatologia do HCFMUSP, Irene e Izilda, pela atenção na recuperação dos prontuários.

Aos funcionários do Instituto Médico Legal, pela ajuda na recuperação dos laudos de necropsia.

Ao Prof Dr Clovis de Araujo Peres, pela assessoria estatística.

A Ivone Borelli, pelas revisões e disponibilidade acima do profissional.

À Profa Renata Philippov, pela versão do resumo para o inglês.

A Nadir Aparecida Lopes, pela revisão quanto a forma de apresentação das referências bibliográficas.

A todos que, apesar de sua importância e ajuda não foram citados. 


\section{SUMÁRIO}

Lista de tabelas

Lista de figuras

Lista de abreviaturas e siglas

Resumo

Abstract

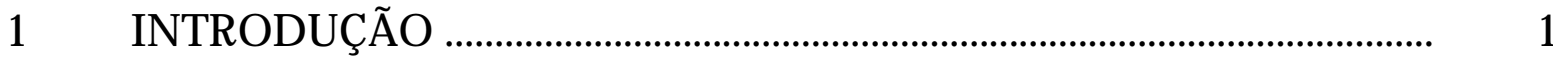

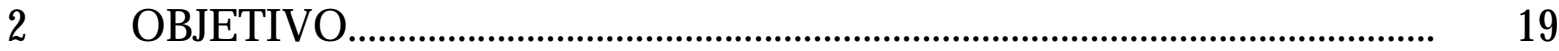

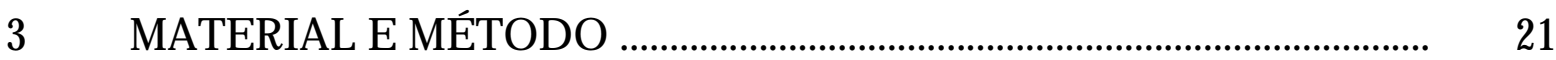

3.1 Procedimentos de coleta de dados.............................................................. 22

3.1.1. Etapa I - Seleção dos pacientes de causas externas e coleta de dados no IC-HCFMUSP

3.1.2. Etapa II - Coleta de dados no Instituto de Ortopedia e Traumatologia (IOT) e Instituto Médico Legal (IML) ......................... 25

3.1.3. Etapa III - Coleta de dados do atendimento pré-hospitalar ................ 27

3.1.4. Etapa IV - Revisão das fichas de coleta de dados .................................. 27

3.2. Procedimentos de categorização ou de codificação dos dados coletados

3.2.1. Critérios especiais utilizados para categorização das variáveis estudadas

3.2.2. Codificação das lesões e conferência dos dados coletados

3.2.3. Digitação no banco de dados

3.3. Cálculo da gravidade do trauma ............................................................... 33

3.3.1. Revised Trauma Score (RTS).................................................................... 33

3.3.2. Injury Severity Score (ISS) ....................................................................... 34

3.3.3. TRauma and Injury Severity Score (TRISS) ............................................ 35

3.4. Tratamento estatístico e análise dos dados ............................................... 37 


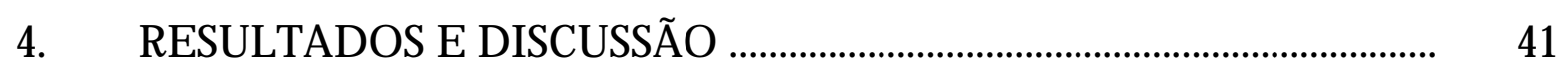

4.1. Caracterização da população estudada ................................................... 41

4.2. G ravidade do trauma analisada pelo sistema AIS/ ISS e RTS .............. 69

4.2.1. G ravidade das lesões AIS ......................................................................

4.2.2. G ravidade do trauma pelo sistema AIS/ ISS ............................................ 85

4.2.3. G ravidade do trauma pelo RTS (fase pré hospitalar) ............................. 92

4.3. Probabilidade de sobrevida (Ps) estimada pelo Trauma and Injury Severity Score (TRISS) ......................................................................... 97

4.3.1. Metodologia Preliminary O utcome - Based Evaluation - PRE.......... 100

4.3.2. Metodologia D efinitive Outcome - Based Evaluation - DEF............ 106

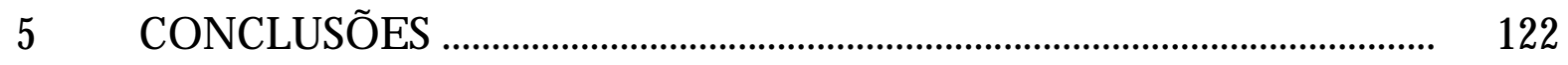

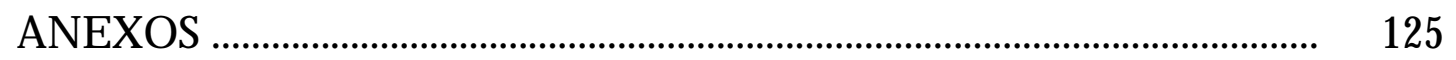

REFERÊNCIAS BIBLIOG RÁFICAS ............................................................ 132 


\section{LISTA DE TABELAS}

Tabela 01 - Pacientes internados, segundo tipo de causas externas, IC- 42 HCFMUSP, 1998.

Tabela 02 - Pacientes internados, segundo tipos de causas externas e 55 procedência, IC-HCFMUSP,1998.

Tabela 03 - Pacientes internados, segundo a procedência e meio de transporte 58 utilizado para chegar ao hospital, IC-HCFMUSP,1998.

Tabela 04 - Pacientes internados, segundo tipos de trauma e causas externas, IC- 70 HCFMUSP, 1998.

Tabela 05 - Distribuição das lesões, segundo regiões corpóreas da AIS e tipo de 76 trauma (N=1542), IC-HCFMUSP, 1998.

Tabela 06 - Distribuição das lesões, segundo região corpórea da AIS e 78 respectivo escore de gravidade (N=1542), IC-HCFMUSP, 1998.

Tabela 07 - Pacientes internados, segundo gravidade do trauma (ISS) e condição de saída hospitalar, IC-HCFMUSP, 1998.

Tabela 08 - Pacientes internados, segundo gravidade (ISS) e tipo de trauma, IC- 88 HCFMUSP,1998.

Tabela 09 - Pacientes internados, segundo os escores RTS-t da fase pré- 93 hospitalar e condição de saída hospitalar (n=228), IC-HCFMUSP 1998.

Tabela 10 - Distribuição dos pacientes da amostra $(n=241)$, segundo a gravidade 99 (ISS) e o tipo de trauma, IC-HCFMUSP, 1998.

Tabela 11 - Distribuição de pacientes da amostra (n=241), segundo a gravidade 100 do trauma (ISS) e a condição de saída, IC-HCFMUSP, 1998.

Tabela 12 - Distribuição de pacientes potenciais para análise do TRISS ( $\mathrm{n}=801), 108$ segundo a gravidade e o tipo de trauma, IC-HCFMUSP, 1998. 


\section{LISTA DE FIGURAS}

Figura 01 - $\quad$ Pacientes internados $(\mathrm{N}=1.781)$, segundo sexo e idade, ICHCFMUSP, 1998.

Figura 02 (A - C) - Pacientes internados, segundo faixas etárias e tipo de causas externas, IC-HCFMUSP, 1998.

Figura 03 -

Pacientes internados $(\mathrm{n}=409)$, segundo intervalo de tempo 60 entre a solicitação do SAMU-SP até a chegada no PS, ICHCFMUSP, 1998.

Figura 04 - $\quad$ Pacientes internados $(\mathrm{N}=1.781)$, segundo a condição de saída do hospital, IC-HCFMUSP, 1998.

Figura 05 (A - C) - Pacientes internados, segundo tempo de permanência no hospital e condição de saída (N=1.553), IC-HCFMUSP, 1998.

Figura 06 - Distribuição das lesões, segundo o tipo de trauma $(\mathrm{N}=1.542)$, IC-HCFMUSP, 1998.

Figura 07 - Distribuição das lesões, segundo as regiões corpóreas AIS 74 (N=1.542), IC-HCFMUSP, 1998.

Figura 08 - Distribuição das lesões, segundo os escores de gravidade (N=1.542), IC-HCFMUSP, 1998.

Figura 09 - Pacientes internados $(\mathrm{N}=1.527)$, segundo a gravidade do 85 trauma (ISS), IC-HCFMUSP,1998.

Figura 10 (A - D) - Pacientes internados, segundo tipo de trauma, condição de 90 saída hospitalar e gravidade do trauma (ISS), IC-HCFMUSP, 1998.

Figura 11 - $\quad$ Pacientes de trauma contuso e penetrante $(n=241)$, segundo 0 ISS e RTS em relação ao limite de $50 \%$ de probabilidade de sobrevida estimada pelo TRISS, IC-HCFMUSP, 1998. 
Figura 12 - $\quad$ Pacientes internados com trauma contuso $(n=180)$, segundo o ISS e RTS em relação ao limite de 50\% de probabilidade de sobrevida estimada pelo TRISS-hc, IC-HCFMUSP, 1998.

Figura 13 - $\quad$ Pacientes internados com trauma penetrante $(n=60)$, segundo o ISS e RTS em relação ao limite de $50 \%$ de probabilidade de sobrevida estimado pelo TRISS-hc, IC-HCFMUSP, 1998. 


\section{LISTA DE ABREVIATURAS E SIGLAS}

AAAM

ACS

AIH

AIS

CID-10

СОВОМ

DEF

ECGl

HCFMUSP Hospital das Clínicas da Faculdade de Medicina da Universidade de São Paulo

IC-

HCFMUSP da Universidade de São Paulo

IOT

ISS

MTOS

NISS

PRE

"Association for the Advancement of Automotive Medicine"

"American College of Surgeons"

Autorização de Internação Hospitalar

"Abbreviated Injury Scale". Sistema de base anatômica apresentado sob a forma de um manual onde centenas de lesões são listadas de acordo com o seu tipo, localização e gravidade.

Classificação Estatística Internacional de Doenças e Problemas Relacionados à Saúde. D écima revisão

Centro de 0 perações dos Bombeiros

"D efinitive outcome - based evaluation"

Escala de Coma de Glasgow. Escala de base fisiológica que classifica o nível de consciência com base em três indicadores (abertura ocular, resposta verbal e resposta motora)

Instituto Central do Hospital das Clínicas da Faculdade de Medicina Instituto de Ortopedia e Traumatologia do HCFMUSP "Injury Severity Score". Escore obtido a partir da soma dos quadrados dos escores AIS mais altos de três regiões diferentes do corpo mais gravemente traumatizadas.

"Major Trauma O utcome Study"

"New Injury Severity Score". Escore obtido a partir da soma dos quadrados dos escores AIS das três lesões mais graves, independente da região corpórea.

"Preliminary outcome-based evaluation". Método para identificar resultados inesperados com base no TRISS. 
Ps

RTS

SAMU

TCE

TRISS

TRISS-hc

UR

USA

Probabilidade de sobrevida

Revised Trauma Score. Índice fisiológico, baseado em três indicadores: pressão arterial sistólica, freqüência respiratória e ECGl Serviço de A tendimento Médico de Urgência Trauma Crânio Encefálico Trauma and Injury Severity Score.

Trauma and Injury Severity Score, com coeficientes derivados da amostra do estudo.

Unidade de Resgate de Suporte Básico de Vida

Unidade de Suporte Avançado 


\section{RESUMO}

WHITAKER, I.Y. Gravidade do trauma e probabilidade de sobrevida em pacientes internados. São Paulo, 2000. 148p. Tese (D outorado)- Escola de Enfermagem, Universidade de São Paulo.

Estudos de morbidade por causas externas são escassos em virtude da dificuldade de obtenção de dados para sua realização. Ainda mais escassos são aqueles que examinam a gravidade do trauma com vistas a determinar sua magnitude e repercussão na assistência aos que sofreram os agravos. $O$ estudo apresenta a análise descritiva retrospectiva sobre a morbi-mortalidade hospitalar por causas externas com o uso de medidas objetivas da gravidade do trauma e probabilidade de sobrevida. Os índices utilizados para mensurar a gravidade do trauma foram o sistema "Abbreviated Injury Scale" (AIS) / "Injury Severity Score" (ISS) e o "Revised Trauma Score"(RTS). Para calcular a probabilidade de sobrevida (Ps), usou-se o "Trauma and Injury Severity Score" (TRISS). A população do estudo foi constituída por 1.781 pacientes de causas externas internados no Instituto Central do Hospital das Clínicas da Faculdade de Medicina da Universidade de São Paulo no ano de 1998. Do total de pacientes, 30,15\% foram internados em decorrência de acidente de transporte, $24,32 \%$ por agressões e $17,24 \%$ por quedas. A população foi constituída, predominantemente, por pacientes do sexo masculino e jovens entre 15 e 39 anos. Entre os pacientes, 43,34\% foram provenientes da cena do evento e 39,08\% transferidos de outros hospitais. $\mathrm{O}$ atendimento pré-hospitalar foi realizado em tempo médio de 49 minutos a maioria daqueles que vieram diretos da cena do evento. A mortalidade hospitalar foi $12,63 \%$, e nas primeiras 24 horas morreram $64,01 \%$. A maioria das causas externas foi classificada em trauma contuso (61,42\%), seguido de penetrante (23,24\%). A gravidade da lesão possível para 1.542 (86,58\%) pacientes de acordo com 0 Manual AIS resultou em 4.918 lesões decorrentes, predominantemente, de trauma contuso $(75,79 \%)$, mais freqüentes na região da cabeça $(28,12 \%)$ seguida da face $(22,00 \%)$. A média de lesões por paciente foi 3,19. Em relação à gravidade, verificou-se que lesões leves (AIS1) foram freqüentes na face $(45,03)$ e as lesões sérias (AIS 3), graves (AIS4) e críticas (AIS5) foram mais freqüentes na região da cabeça, 43,21\%, 75,00\% e $69,82 \%$, respectivamente. A gravidade do trauma (ISS) com base na gravidade das lesões 
(AIS), foi calculada para $1.527(99,02 \%)$ pacientes. A maioria (65,75\%) foi classificada com escores ISS $<16$. No grupo de sobreviventes, predominaram os escores ISS $<16$ $(76,32 \%)$ e, no grupo de óbitos, os escores ISS $\geq 16$ (96,40\%), indicativos de trauma importante. A média do ISS em trauma contuso foi 13,08 e em penetrante, 11,97. A gravidade do trauma na fase pré-hospitalar verificada por meio do RTS-triagem foi possível para 228 (49,14\%) pacientes. Entre os sobreviventes, 94,93\% obtiveram escore 12, indicativo de condição fisiológica inalterada e 93,75\% dos óbitos obtiveram escore zero, ausência de resposta fisiológica. O TRISS calculado para uma amostra de 241 pacientes, revelou dez casos de morte inesperada pela metodologia PRE. Além disso, os valores da estatística " $\mathrm{Z}$ " e " $\mathrm{W}$ " tanto para trauma contuso quanto penetrante, indicaram que os resultados da amostra foram diferentes em relação à população do "Major Trauma Outcome Study". Ajustados os coeficientes do TRISS para a amostra deste estudo, observou-se por meio do método PRE que em trauma contuso, ocorreram cinco mortes inesperadas e uma sobrevida inesperada. Em trauma penetrante, ocorreu uma morte inesperada e não houve casos de sobrevidas inesperadas. Espera-se que este estudo ofereça subsídios para ações preventivas e melhoria da qualidade da assistência aos pacientes hospitalizados em decorrência das causas externas. 


\begin{abstract}
WHITAKER, I. Y. Injury Severity and Survival Probability in Inpatients. São Paulo, 2000. 148p. PhD. dissertation submitted to the Escola de Enfermagem, Universidade de São Paulo.
\end{abstract}

Studies on morbidity resulting from external causes are scarce, due to the difficulty of gathering data for this purpose. Even scarcer are those studies analysing injury severity's magnitude and consequences in relation to the care of trauma patients. This study presents a retrospective descriptive analysis of hospital morbidity and mortality due to external causes by applying objective measurements of injury severity and survival probability. The indexes used to measure injury severity consisted of the "Abbreviated Injury Scale" (AIS), the "Injury Severity Score" (ISS), and the " Revised Trauma Score" (RTS). So as to calculate probability of survival (Ps), the "Trauma and Injury Severity Score" (TRISS) was applied. The target population in this study consisted of 1,781 external-cause inpatients at the Instituto Central do Hospital das Clínicas da Faculdade de Medicina da Universidade de São Paulo in 1998. Out of those patients, 30.15\% were hospitalized as a result of transportation accidents, $24.32 \%$ of aggression and $17.24 \%$ of falls. This population mainly included young male-sex patients aged 15-39. Among these, 43.34\% came from the injury scene and 39.08\% were transfered from other hospitals. Prehospital time took 49 minutes in average for the majority of field patients. Hospital mortality reached $12.63 \%$, out of which cases $64.01 \%$ died within the first 24 hours. Most external-cause types were classified as blunt trauma (61.42\%), followed by penetrating trauma (23.24\%). According to the AIS Manual, injury severity was possible for 1,542 patients; data showed 4,918 injuries of predominant blunt trauma ( $75.79 \%$ ), being it most frequent in the head $(28.12 \%)$, and followed by that on the face (22.00\%). Average injury per patient was of 3.19. In relation to severity it was verified that minor injuries (AIS1) were frequent on the face (45.03) and the serious ones (AIS3), the severe ones (AIS4) and the critical ones (AIS5) were more frequent in the head: $43.21 \%, 75.00 \%$ and $69.82 \%$, respectively. Injury Severity Score was calculated for 1,527 patients. The majority $(65.75 \%)$ was classified with scores ISS $<16$. For the survival group scores ISS $<16$ 
predominated and in the death group scores reached ISS> 16 (96.40\%), indicating major trauma. Average ISS in blunt trauma was 13.08 and 11.97 in penetrating trauma. Injury severity in prehospital care, verified through RTS - in a triage of 228 (49.14\%) patients showed that $94.93 \%$ of survivors obtained score 12, indicating unaltered physiological condition, and that $93.75 \%$ of deaths obtained score zero, lack of physiological response. TRISS, calculated for 241 patients, indicated 10 unforseen deaths through PRE methodology. Furthermore, "Z" and "W" statistics, for both blunt and penetrating trauma, pointed out that sample results differed in relation to the "Major Trauma Outcome Study" 's population. Once TRISS coefficients were adjusted to the sample in this study, it was observed, through the PRE method, that in blunt trauma five unexpected deaths and one unexpected survival occurred. There was one unexpected death in penetrating trauma. It is hoped that this study may offer means for preventive actions and assurance of the quality of care for inpatients due to external causes. 


$$
\text { I Introdução }
$$




\section{INTRODUÇÃO}

Ano após ano, tem-se verificado a elevação gradativa da mortalidade por causas externas em vários países do mundo. Mesmo tendo sido reconhecido como problema de saúde pública e apesar dos esforços para reduzir sua ocorrência, a compreensão e 0 controle dos eventos que resultam em trauma ainda não foram totalmente alcançados, sobretudo, em razão de características multifatoriais. Assim, as causas externas estão atualmente classificadas entre as dez primeiras ou, até mesmo, entre as cinco primeiras causas de morte praticamente em todo o mundo (BAKER, 1987, 1988, 1997; ROSENBERG, 1988; SCHWAB, 1993; ROUX, 1994; MELLO JORGE, 1997b; BARSS et al., 1998).

O Brasil não está excluído desse panorama assustador. Em nosso meio, as causas externas sobressaem-se como a segunda principal causa de morte, desconsideradas as causas mal definidas. Pela evolução percebe-se que nos últimos 15 anos, o aumento das mortes por causas externas foi, proporcionalmente, mais que $50 \%$ em relação às demais causas (MELLO JORGE; LAURENTI 1997; MELLO JORGE; GAWRYSZEWSKI; LATORRE, 1997).

As consequiências dos eventos traumáticos implicam em carga social de proporções importantes. No custo econômico do trauma inclui-se a assistência préhospitalar, médico-hospitalar, a perda da produção e produtividade (segundo estimativa dos anos potenciais de vida perdidos), custos impostos a terceiros (parentes e acompanhantes) além dos custos psicossociais gerados pela incapacidade ou fatalidade (CHAMPION et al., 1994; IUNES, 1997; MEYER, 1998; DESLANDES; SILVA; UGÁ, 1998).

Embora os elevados valores das estatísticas de mortalidade das causas externas provoquem impacto, esses não representam a totalidade desse agravo à população (MELLO JORGE; LAURENTI 1997). Resta ainda acrescentar os dados relativos à natureza das lesões e envenenamentos para determinar a magnitude das causas externas. Porém, a recuperação destes dados constitui-se em verdadeiro desafio, pois referem-se à grande maioria da população acometida. Esta pode ter sido atendida em prontos-socorros 
ou em outros tipos de recursos de assistência médica e dispensada ou, ter sido internada com evolução para alta curada, alta seqüelada ou óbito. BARSS et al. (1998) considera três categorias para estudos de morbidade em trauma: os óbitos, as hospitalizações e outros. E salienta que as duas primeiras são mais facilmente definidas e quantificáveis que a categoria "outros" relacionada àqueles que receberam assistência médica em clínicas, ambulatórios, domicílios e os sem tratamento.

A abordagem utilizada para quantificar a mortalidade é a causa externa da lesão (como se deu o fato), enquanto nos estudos de morbidade, o interesse relaciona-se à conseqüência do evento - à natureza da lesão - (o que aconteceu ao indivíduo). (LEBRÃO , 1993; MELLO JORGE; LAURENTI 1997).

As estatísticas de mortalidade são produzidas com base em um fato inequívoco, 0 óbito. Por se tratar de um dado oficial e de registro contínuo encontra-se facilmente disponível possibilitando uma coleta sistemática (MELLO JORGE; LAURENTI 1997). Entretanto, os estudos sobre a natureza das lesões e envenenamentos dependem da definição atribuída à lesão e da fonte de dados disponíveis para delimitar seu escopo, o que implica em procura de registros de dados que, freqüentemente, são periódicos, mas nem sempre sistemáticos ou padronizados (BARSS, et al., 1998).

No Brasil, a Autorização de Internação Hospitalar (AIH) é um documento de preenchimento obrigatório nos hospitais que recebem do sistema público de saúde os pagamentos referentes à internação dos pacientes. Por meio desse documento que contendo informações relativas às internações como dados demográficos, diagnósticos, procedimentos realizados e custos, é possível conhecer parte do perfil da morbidade hospitalar. 0 sistema AIH é responsável por cerca 80\% da assistência médico-hospitalar prestada à população brasileira (LEBRÃ O MELLO JO RGE; LAURENTI, 1997).

Utilizando-se a AIH como fonte de dados, LEBRÃO; MELLO JORGE; LAURENTI (1997) pela primeira vez no Brasil estudaram a morbidade por lesão e envenenamento, revelando o perfil da parcela mais grave da morbidade resultante dos acidentes e violência, a hospitalar.

Os resultados do estudo revelaram que, no ano de 1994, foram totalizadas 14.698.988 internações no País. As lesões e envenenamentos foram responsáveis por 
5,8\% desse total (sétima colocada), representando em números absolutos 848.560 pacientes internados (LEBRÃO; MELLO JO RGE; LAURENTI, 1997).

No ano de 1998, de acordo com o Sistema de Informações Hospitalares do Sistema Único de Saúde (SIH/ SUS), houve 490.303 internações na rede hospitalar do SUS no município de São Paulo, dentre as quais 39.748 foram por lesão e envenenamento (BRASIL, 1999).

As lesões resultantes de causas externas podem ser únicas ou múltiplas de intensidade e de localizações corpóreas variadas, sua descrição completa deve incluir a topografia (descrição anatômica), o tipo (mecanismo do trauma) e a gravidade (definição objetiva difícil). Geralmente para indicar a gravidade, costuma-se relacionar a lesão às características do tipo, extensão, risco de vida, período e gravidade de incapacidade e proporção de incapacidade permanente, além da necessidade e tempo de internação hospitalar, óbito, complexidade e custo do tratamento (JORGENCEN, 1981; BARSS et al., 1998).

Inicialmente, métodos denominados sistemas ou escalas foram desenvolvidos com base na natureza da lesão para quantificar o grau de dano nos pacientes de trauma (BARSS et al., 1998); expressaram a gravidade por meio de um valor numérico, a fim de torná-la objetiva, possibilitando o uso de uma linguagem uniforme como medida de comparação e controle da assistência no trauma.

Nas décadas de 70 e 80, surgiram vários índices de gravidade para possibilitar a avaliação objetiva da gravidade do trauma, alguns foram fundamentados em critérios fisiológicos, outros em critérios anatômicos ou em ambos (TEASDALE; JENNET, 1974; BAKER et al.. 1974; BAKER; O'NEILL, 1976; CAYTEN; EVANS 1979; CHAMPION et al.., 1980; GIBSO N, 1981; TRUNKEY, 1983a; THOMPSO N; DAINS, 1986; CALES, 1986; SMITH et al., 1990; CHAMPION et al., 1991).

O conhecimento atual dos índices de trauma foi adquirido por meio de pesquisa no "Major Trauma O utcome Study "(MTOS) (CHAMPION et al., 1990b). O estudo foi organizado pelo médico Howard S.Champion e coordenado pelo "Committee on Trauma (COT) of American College of Surgeons"(ACS); iniciou-se em $1982 \mathrm{com}$ a finalidade de aprimorar métodos para mensurar a gravidade do trauma e normatizar um padrão em 
âmbito nacional para avaliar e garantir a assistência prestada ao paciente traumatizado na América do Norte. Além disso, o MTOS é uma iniciativa que atende às recomendações contidas no relatório intitulado "Injury in America: a continuing public health problem", apresentado pela "Academy of Science" em 1985 nos Estados Unidos da América (EUA) sobre a necessidade de dados para programas de prevenção e assistência em trauma (ROSENBERG, 1987).

Até 0 ano de 1989, com a participação voluntária de cerca de 150 hospitais (dos Estados Unidos da América, Canadá, Austrália e Reino Unido) os dados de mais de 170.000 pacientes de trauma foram submetidos ao MTOS para desenvolver metodologia própria para estudar morbi-mortalidade hospitalar e testar normas de probabilidade de sobrevida com base nos índices de gravidade, considerado o estado da arte na época (CHAMPION et al., 1990b; CHAMPION et al., 1991).

Pelo MTOS, os hospitais puderam comparar a mortalidade individualmente por meio de normas baseadas em lesões de gravidade semelhante. Isso significa que é possível identificar matematicamente os pacientes que morreram quando eram prognosticados para sobreviver, os que sobreviveram quando eram prognosticados para morrer, e realizar uma revisão detalhada desses casos. Assim, ao monitorar os resultados da assistência prestada, os hospitais podem avaliar e melhorar 0 atendimento à pessoa que sofreu trauma (CHAMPION et al., 1990b).

BOUILLO N et al. (1997) descreveram precisamente a utilidade dos índices pelas palavras de Baker: "Se você nunca sentiu a necessidade de utilizar qualquer método de mensuração da gravidade do trauma então, provavelmente, nunca teve que explicar como uma taxa de sobrevida de $58 \%$ de um centro de trauma é, realmente, melhor que a taxa de sobrevida de $97 \%$, de algum hospital, onde os pacientes estavam menos gravemente traumatizados".

Pelos índices, torna-se possível documentar as características epidemiológicas do trauma, avaliar a assistência prestada, planejar sistemas de cuidados de emergência e estimar custos do tratamento (CHAMPION et al., 1991). Todas essas possibilidades advindas do uso de índices revestem-se de uma característica fundamental, a utilização de uma linguagem uniforme. 
Os índices de gravidade fazem parte do programa de qualidade da assistência em trauma, de acordo com os padrões mínimos recomendados pelo "COMMITTEE on TRAUMA of AMERICAN COLLEGE of SURGEONS" (ACS, 1986).

Os índices preconizados pelo ACS, (1986) e AMERICAN COLLEGE OF EMERGENCY PHYSICIANS (1992) são o Revised Trauma Score (RTS), o sistema AIS/ ISS formados pelos Abbreviated Injury Scale (AIS) e Injury Severity Score (ISS) e, 0 Trauma and Injury Severity Score (TRISS).

Para descrever o RTS, em primeiro lugar é apresentada a Escala de Coma de Glasgow (ECGl), por ser um dos componentes desse índice.

A ECGl foi desenvolvida por TEASDALE; JENNETT (1974) no início da década de 70 para avaliar a alteração do nível de consciência dos pacientes acometidos por trauma crânio-encefálico. Reconhecida mundialmente, por ter forte correlação com mortalidade e ser de aplicação fácil, a ECGl é amplamente utilizada na triagem de vítimas de trauma e em todo tipo de paciente internado (ALVES, 1998).

A avaliação tanto da função e dano cerebral quanto da evolução do nível de consciência é baseada com base em três respostas comportamentais: abertura ocular, melhor resposta verbal e melhor resposta motora. 
ESCALA DE COMA DE GLASGOW

\begin{tabular}{|c|c|c|}
\hline componentes & resposta & pontos \\
\hline \multirow{4}{*}{$\begin{array}{l}\text { A bertura O cular } \\
\text { (AO) }\end{array}$} & espontânea & 4 \\
\hline & com estímulo verbal & 3 \\
\hline & com estímulo doloroso & 2 \\
\hline & nenhuma resposta & 1 \\
\hline \multirow{5}{*}{$\begin{array}{l}\text { Melhor Resposta Verbal } \\
\text { (MRV) }\end{array}$} & orientado & 5 \\
\hline & confuso & 4 \\
\hline & palavras impróprias & 3 \\
\hline & sons incompreensíveis & 2 \\
\hline & nenhuma resposta & 1 \\
\hline \multirow{7}{*}{$\begin{array}{l}\text { Melhor Resposta } \\
\text { Motora } \\
\text { (MRV) }\end{array}$} & & \\
\hline & Obedece & 6 \\
\hline & localiza e retira estímulos & 5 \\
\hline & localiza o estímulo & 4 \\
\hline & responde em flexão & 3 \\
\hline & responde em extensão & 2 \\
\hline & nenhuma resposta & 1 \\
\hline \multicolumn{3}{|c|}{$\overline{\mathrm{AO}+\mathrm{MRV}+\mathrm{MRM}}$} \\
\hline
\end{tabular}

A pontuação ECGl varia de 3 a 15, e os escores mais elevados indicam menores graus até a ausência de disfunção no nível de consciência. A pontuação $\leq 8$ indica 0 coma, isso significa que pacientes sem abertura ocular (1 ponto), que emitem somente sons incompreensíveis ou não apresentam resposta verbal (2 ou 1 ponto) e não obedecem aos comandos verbais (de 5 a 1 ponto) são considerados em coma. A classificação da intensidade do comprometimento cerebral no trauma crânio-encefálico de acordo com a pontuação da ECGl é leve de 13 a 15, moderada de 9 a 12 e grave de 3 a 8 (WHITAKER, KOIZUMI, 1993; IMAI, 1994).

A ECGl é uma das variáveis do Revised Trauma Score (RTS), índice de base fisiológica, considerado o mais avançado em sua categoria, pois seus escores têm forte correlação com sobrevida e mortalidade (TRUNKEY, 1982; CHAMPION et al., 1983; SMITH et al., 1990; WISNER, 1992). Pode ser utilizada na fase pré-hospitalar para fins de triagem e no hospital para mensurar a gravidade do trauma. 
O desenvolvimento do RTS por CHAMPION et al. (1980) data de 1974. Inicialmente observando-se o poder preditivo de mortalidade de 16 variáveis funcionais, seja pela análise isolada ou inter-relacionada de cada uma delas em uma série de 1.084 pacientes, surgiu o "Triage Index". A seleção dessas variáveis baseou-se em uma investigação clínica das alterações que ocorrem secundariamente às lesões anatômicas e que, freqüentemente, acometem o sistema nervoso central, cardiovascular e respiratório nas mortes precoces após o trauma. 0 "Triage Index" foi então construído com cinco variáveis de maior poder preditivo, eliminando-se redundâncias e medidas de valores marginais. O "Triage Index" era utilizado para calcular a probabilidade de sobrevida (Ps). Para a aplicação na prática clínica derivaram o "Triage Score", cuja finalidade era a triagem de pacientes na fase pré-hospitalar. Essa forma permitia a soma aritmética dos escores absolutos determinados para cada uma das cinco variáveis selecionadas (expansão torácica, enchimento capilar e três elementos da ECGl) (anexo I).

A pontuação variava de zero a 16 e os escores mais elevados eram indicativos de maior gravidade.

Em 1981, o Triage Score/ Index foi modificado. CHAMPION et al. (1981) introduziram 0 "Trauma Score" (TS), com a inclusão das variáveis, pressão arterial sistólica (PAS) e freqüência respiratória (FR), além daquelas já existentes (anexoII).

Com a utilização do TS, os participantes do "Major Trauma Outcome Study" detectaram que 0 índice subestimava a gravidade do dano cerebral de alguns pacientes. Além disso, constataram haver dificuldades na avaliação dos itens enchimento capilar e expansão torácica, especialmente, quando a referida avaliação era feita à noite (CHAMPION et al., 1989a).

Em razão dessas considerações, o TS foi submetido a nova revisão, baseada na inter-relação entre Escala de Coma de Glasgow, pressão arterial sistólica (PAS) e freqüência respiratória (FR). Portanto, o principal objetivo para o desenvolvimento do RTS foi melhorar o desempenho do índice para avaliar o paciente com dano cerebral (CHAMPIO N et al., 1989a).

A análise de regressão logística para derivar coeficientes mais ajustados para pacientes com dano cerebral, resultou em peso de valor substancialmente mais elevado 
para a ECGl em relação a PAS e FR. Entre as várias possibilidades de combinação das condições fisiológicas verificou-se que houve redução de 30\% na probabilidade de sobrevida quando os valores da PAS e FR estão normais, mas o escore da ECGl é três.

Após a revisão do TS adotou-se a nova versão, o RTS, por demonstrar maior precisão para caracterizar o dano cerebral, maior confiabilidade na avaliação da assistência prestada e maior facilidade em sua aplicação (CHAMPION et al., 1989a).

Os dados do quadro a seguir mostram a visão geral dos parâmetros e a respectiva atribuição dos escores no RTS (CHAMPION et al., 1989a).

REVISED TRAUMA SCORE - RTS

\begin{tabular}{|c|c|c|c|}
\hline ECGl & PAS & FR & Escore \\
\hline $13-15$ & $>89$ & $10-29$ & 4 \\
$9-12$ & $76-89$ & $>29$ & 3 \\
$6-8$ & $50-75$ & $6-9$ & 2 \\
$4-5$ & $1-49$ & $1-5$ & 1 \\
3 & 0 & 0 & 0 \\
\hline
\end{tabular}

Pelo RTS, a função circulatória é avaliada pela medida da pressão arterial sistólica (PAS) em mmHg, e os valores são pontuados de zero a quatro de acordo com intervalos predeterminados. Para a função respiratória, avalia-se a freqüência respiratória (FR) por minuto e atribui-se um escore que varia de zero a quatro, de acordo com o intervalo correspondente. A pontuação do RTS para os intervalos dos valores da ECGl varia de zero a quatro (CHAMPION et al., 1989a).

A pontuação total varia de 0 a 12, sendo o escore 12 o de menor gravidade e zero de maior gravidade, possibilitando a quem o está aplicando decidir de imediato as intervenções prioritárias a serem feitas, além de auxiliar na tomada de decisão quanto ao hospital adequado a ser encaminhado (CHAMPION et al., 1989a).

$\mathrm{Na}$ fase pré-hospitalar, onde a finalidade primordial é a triagem, CHAMPION et al. (1989a) recomendaram que o RTS seja obtida somente pela somatória dos valores absolutos dos escores correspondentes aos intervalos de cada parâmetro. 
No algoritmo de triagem, preconizado pelo ACS (1986), o RTS é o primeiro componente da tomada de decisão para encaminhamento ao Centro de Trauma seguido pelos critérios anatômicos, intensidade e mecanismo do trauma, idade e doenças preexistentes. Desse modo, nos serviços de resgate norte-americanos a triagem baseada no RTS fundamenta-se no critério: "vítimas de trauma com escores na ECGl $<13$ ou PAS $<90 \mathrm{mmHg}$ ou, FR $<10$ ou $>29 \mathrm{mr} /$ min devem ser encaminhados para um Centro de Trauma". Assim sendo vítimas de acidente ou violência com escores < 11 devem ser tratadas no Centro de Trauma (CHAMPIO N et al., 1989a).

Q uando o RTS é utilizado para avaliação de resultado hospitalar, atribui-se peso ao escore obtido em cada variável. Os pesos foram derivados da análise de regressão de uma população de 25.000 pacientes de trauma do MTOS. O escore total utilizando os pesos, varia de zero a 7,8408 (CHAMPIO N et al., 1989a).

A probabilidade de sobrevida (Ps), conforme os dados dos valores do RTS:

\begin{tabular}{|c|c|c|c|c|c|c|c|c|c|}
\hline RTS & 8 & 7 & 6 & 5 & 4 & 3 & 2 & 1 & 0 \\
\hline Ps & 0,988 & 0,969 & 0,919 & 0,807 & 0,605 & 0,361 & 0,172 & 0,071 & 0,027 \\
\hline
\end{tabular}

O poder preditivo de índices de base fisiológica é influenciado pela variabilidade temporal. Fatores como droga, álcool, sedativos ou analgésicos influenciam negativamente na avaliação do nível de consciência, propiciando 0 aparecimento de resultados falso positivos. Por outro lado, determinados tipos de lesões torácicas em jovens traumatizados que possuem compensação fisiológica diante de perdas sanguíneas maciças e atendimento pré-hospitalar rápido com tempo resposta mínimo podem resultar em resultados falso negativos (TRUNKEY, 1983a; HILL et al., 1991; JURKOVICH et al., 1992; WHITAKER, 1993). Além disso, determinadas condições do paciente podem impossibilitar a obtenção de resposta em alguma variável mensurada, o que deve impedir a aplicação desse tipo de índice. Nessa situação, os casos precisam ser analisados cuidadosamente para interpretação correta dos resultados.

O Injury Severity Score (ISS) é um índice anatômico que tem sido usado amplamente na determinação da gravidade do trauma e como padrão na avaliação de desempenho dos índices, por se tratar de um instrumento que consegue prognosticar 
sobrevivência e mortalidade de maneira bastante sensível (BAKER et al., 1974; BAKER; O'NEILL, 1976, CHAMPION et al., 1983; AAAM, 1990, 1998), foi preconizado pelo "Committee on Trauma of American College of Surgeons".

Para verificação da gravidade do trauma por meio do ISS é imprescindível que se utilize um sistema de base anatômica denominado Abbreviated Injury Scale (AIS) (AAAM, 1990, 1998) que determina a gravidade da lesão, de acordo com as regiões do corpo.

Os primeiros esforços para categorizar lesões traumáticas e gravidade datam de 1960 pelo aparecimento de grupos multidisciplinares para investigação de colisão de veículo a motor. Sob o patrocínio da "American Medical Association for Automotive Medicine" e da "Society of Automotive Engineers" e com o auxílio de em torno de 35 consultores surgiu a primeira AIS publicada no ano de 1971 (AAAM, 1998).

Nessa época, embora a AIS fosse de alcance limitado, tornou-se o modelo para investigações sobre colisão pelo "D epartment of Transportation" dos Estados Unidos da América (EUA), universidades e indústrias automobilísticas dos EUA, Europa e Austrália. Mas com a evolução de sistemas de assistência ao trauma e bancos de registros de trauma em 1980, houve necessidade de expandir a AIS para também codificar as lesões decorrentes de trauma penetrante (AAAM, 1998).

Nas revisões periódicas da AIS, descrições novas sob linguagem clínica aceitável foram sendo acrescentadas o que estimulou, cada vez mais seu uso para codificação das lesões decorrentes de trauma. A versão mais atual denominada Manual AIS-90 atualização 98, contém em torno de 1.300 descrições de lesões (AAAM, 1998).

A AIS classifica as lesões decorrentes do trauma de acordo com uma escala ordinal de gravidade que oscila de 1 (menor gravidade) a 6 (quase sempre fatal). 


\begin{tabular}{|c|c|}
\hline Código AIS & Gravidade \\
\hline 1 & Leve \\
2 & Moderada \\
3 & Séria \\
4 & Grave \\
5 & Crítica \\
6 & Máxima \\
9 & Desconhecida \\
\hline
\end{tabular}

O Manual AIS está dividido em seções: Cabeça (crânio e cérebro), face, pescoço, tórax, abdome e conteúdo pélvico, coluna, membros superiores, membros inferiores, superfície externa e outros (AAAM, 1998).

A utilização da AIS pressupõe princípios que direcionam sua aplicação. Primeiro, a AIS é baseada em lesão anatômica, por isso um único escore é aplicado para cada lesão da pessoa; segundo, a AIS pontua lesões e não as conseqüências das mesmas; terceiro, a AIS não indica a mortalidade a partir da lesão (AAAM, 1998).

Avaliando a observação da mortalidade, conforme a gravidade das lesões, BAKER et al. (1974) constataram que a elevação da porcentagem de óbitos nos escores AIS mais elevados não ocorria de maneira linear. Observaram ainda que, o porcentual de óbitos se elevava quando outras lesões estavam associadas, principalmente, aquelas de escores AIS elevados. Como a AIS não avalia o efeito cumulativo das múltiplas lesões de um paciente de trauma idealizaram o método denominado ISS que possibilitou mensurar a gravidade do trauma de maneira global (BAKER et al., 1974; BAKER; O'NEILL, 1976).

O ISS é um escore obtido por cálculos matemáticos com base na soma dos quadrados dos escores AIS mais elevados de três diferentes regiões do corpo mais gravemente traumatizadas. É importante mencionar que, para o cálculo do ISS as regiões corpóreas estão agrupadas em cabeça/ pescoço; face; tórax; abdome/ conteúdos pélvicos; extremidades/ cintura pélvica e superfície externa. Os escores ISS variam de 1 a 75, e a gravidade do trauma é proporcional ao incremento da pontuação. As lesões AIS-6 automaticamente resultam no máximo ISS, ou seja, 75 (AAAM, 1998).

D entre os índices de base anatômica o ISS tem sido adotado como padrão para mensurar a gravidade do trauma, por se correlacionar melhor com mortalidade. Um ISS 
de 16 é preditivo de, pelo menos, 10\% de mortalidade e definido como um trauma importante (CHAMPION et al., 1983; CHAMPION et al., 1989a).

D eterminada a gravidade do trauma calcula-se a probabilidade de sobrevida (Ps) dos pacientes. Um dos métodos é o "Trauma and Injury Severity Score" ( TRISS ), que combina o "Revised Trauma Score" (RTS), o "Injury Severity Score" (ISS) e a idade do paciente (CHAMPION et al. 1981; BOYD et al., 1987; CHAMPION et al. 1990b).

Na metodologia TRISS calcula-se a probalidade do paciente para sobreviver ao evento traumático, baseada na equação de regressão que leva em conta a idade do paciente, a gravidade do trauma medida pelo ISS e a alteração fisiológica mensurada pelo RTS (CHAMPION et al., 1991). Os valores da expectativa de sobrevida foram obtidos com base em uma amostra de 24.000 pacientes tratados em 51 centros de trauma no período de 1983 até 1985 nos EUA (ACS, 1986).

Considerado como um dos componentes das normas que avaliam a qualidade da assistência no sistema de trauma norte-americano, o TRISS pode ser utilizado como um instrumento adjunto de duas formas: para identificação de pacientes que evoluíram com um resultado estatisticamente inesperado e para comparar resultados em diferentes grupos de pacientes

Outro método de cálculo da probabilidade de sobrevida é o "A Severity Characterization of Trauma" (ASCOT) (CHAMPION et al., 1990a, 1996), que tenta superar algumas limitações do TRISS. Há também estudos para eliminar defeitos no poder preditivo do ISS (OSLER; BAKER; LONG , 1997).

Contudo, o RTS, o ISS e o TRISS ainda permanecem soberanos visto que o poder preditivo dos novos índices não foi confirmado (HANNAN et al., 1995b OSLER; BAKER; LONG , 1997; BRENNEMAN et al. 1998;).

A preocupação e 0 empenho para 0 aprimoramento dos índices de trauma relaciona-se também ao desenvolvimento e avaliação dos sistemas de assistência ao trauma nos EUA (CHAMPION et al., 1991; WISNER, 1992)

O planejamento efetivo dos sistemas de assistência ao trauma norte-americano iniciou-se no ano de 1966, após a publicação do documento "Morte acidental e incapacidade - A doença negligenciada da Sociedade Moderna", apresentada pela 
"National Academy of Sciences, National Research Council", sobre a morbi-mortalidade resultante do trauma, que custavam bilhões de dólares por ano à nação. Para planejar e desenvolver 0 atendimento precoce aos pacientes de trauma, foram necessários a reorganização da estrutura de assistência à saúde preexistente, a implementação de novas tecnologias e o desenvolvimento de programas educacionais, para que as modalidades de tratamento clínico e cirúrgico, comprovadamente, efetivas no ambiente hospitalar pudessem ser aplicadas e testadas nas fases pré-hospitalar e inter-hospitalar (TRUNKEY, 1982).

Um sistema de trauma é composto de quatro componentes fundamentais ao paciente 0 acesso à assistência, a assistência pré-hospitalar , a assistência hospitalar e a reabilitação. 0 objetivo do sistema de trauma é otimizar o retorno do paciente à sociedade

O acesso ao sistema de trauma envolve componentes tecnológicos como número telefônico de emergência e rádiotransmissores, mas fundamentalmente deve estar disponíveis, ser de fácil acesso e os usuários precisam saber como utilizá-lo.

$\mathrm{Na}$ fase de atendimento pré-hospitalar, as ações fundamentais são a triagem, as medidas de manutenção da vida e o transporte. Um dos princípios que regem 0 atendimento pré hospitalar é "encaminhar o paciente certo ao hospital certo no momento certo". Por sua realização, torna-se possível a adequação de recursos humanos e materiais às reais necessidades da vítima, podendo desta forma exercer influência nas taxas de morbidade e mortalidade (CHAMPION, 1982; MORRIS et al., 1986; WHITAKER, 1993).

$\mathrm{Na}$ fase de atendimento hospitalar, o paciente deverá receber assistência qualificada de acordo com a gravidade do trauma. Para tal, a rede hospitalar deve estar regionalizada e estratificada, levando-se em consideração os recursos disponíveis em cada uma delas, para 0 atendimento do paciente traumatizado (CIVIL, 1986; CIVIL; SCHWAB, 1989).

O processo de reabilitação inicia-se na fase aguda e continua após a alta hospitalar, através de seguimento ambulatorial, domiciliar ou em centro de reabilitação, propiciando 
aos pacientes de trauma maior chance de recuperação da função traumatizado (CIVIL, 1986; CIVIL; SCHWAB, 1989).

Os sistemas de trauma ainda devem incluir outros componentes vitais para a sociedade, programas de prevenção de acidentes, organização da assistência médica em situação de catástrofe, programas educacionais e pesquisa (ACS 1986, 1999).

É importante ressaltar que a existência de sistemas integrados de assistência ao trauma pode influenciar nos resultados de morbi-mortalidade dos pacientes de causas externas, uma vez que esses são organizados de forma a atender as necessidades de uma pessoa com agravo, desde o momento do evento até a alta em um processo contínuo (WHITAKER; GUTIÉRREZ; KOIZUMI, 1993; SAMPALIS ET AL., 1995 MELLO JORGE, 1997; FERREIRA 1999).

A efetividade dos sistemas de trauma existentes nos EUA na redução da mortalidade por trauma tem sido registrada por meio de estudos ao longo de sua implementação e desenvolvimento (MULLINS; MANN, 1999). Além disso, MANN (1999) confirmou haver consenso entre os especialistas a respeito do efeito benéfico de um sistema de trauma organizado sobre o resultado do paciente e da efetividade da estrutura constituída dos sistemas de trauma existentes.

No Brasil, esforços mais efetivos para implementar ou aprimorar os sistemas existentes foram feitos após o Plano Qüinquenal de Saúde 1990/ 95 do Ministério da Saúde que previa a estruturação de sistemas de atendimento às emergências (BRASIL, 1991)

Em relação ao município de São Paulo, até a década de 80 a assistência às urgências estava estruturada em um modelo baseado fundamentalmente na remoção desorganizada de pacientes graves ou de maior complexidade aos hospitais públicos de referência, ocasionando acúmulo de pacientes nesses prontos-socorros.

Em fevereiro de 1990, foi implementado um sistema de atendimento préhospitalar denominado Serviço de Atendimento Médico de Urgência do Município de São Paulo( SAMU-SP ), após a resolução conjunta entre a Secretaria de Estado da Saúde e a Secretaria de Segurança Pública do Estado de São Paulo (SÃO PAULO, s.d.; WHITAKER, 1993; FERREIRA, 1999). 
O SAMU-SP visa prestar assistência às vítimas em situação de emergência em vias ou logradouros públicos nos casos de acidente de trânsito, acidente com lesão corporal traumática, tentativa de suicídio, emergência clínica e obstétrica e outras emergências determinadas pelo médico regulador.( SÃO PAULO, s.d.)

$\mathrm{O}$ atendimento pré-hospitalar pelo SAMU-SP é efetuado por meio de Unidades de Resgate (UR) e Unidades de Suporte Avançado (USA). As UR são veículos de suporte básico de vida que têm como apoio as USA constituídas de veículos terrestres e helicóptero. As USA são acionadas nas situações em que a condição da vítima exige material e pessoal especializado para a realização de procedimentos terapêuticos no local. Todas essas unidades foram projetadas para 0 transporte de equipamentos apropriados para o salvamento e estabilização da vítima no local do evento. As UR são tripuladas por bombeiros treinados em suporte básico de vida e as USA são tripuladas por médicos e enfermeiros( SÃO PAULO, s.d.).

Todas as unidades mantêm contato com a Centro de Operações dos Bombeiros (COBOM) o que possibilita ao médico regulador coordenar e gerenciar as ações dos atendimentos pré-hospitalares( SÃO PAULO, s.d.). D essa forma, os pacientes podem ser encaminhados ao hospital mais apropriado de acordo com suas condições, favorecendo a integração da fase pré-hospitalar com a hospitalar no sistema de atendimento às urgências.

$\mathrm{O}$ encaminhamento de pacientes é feito de acordo com a regionalização e a hierarquização dos hospitais por meio de um Sistema de Regulação Metropolitano da Grande São Paulo formado pelo SAMU-SP, Plantão Controlador Metropolitano e Centra de vagas (SÃO PAULO, 1993). O acesso da população ao SAMU-SP é feito via telefone 193.

Além do SAMU-SP, existe outro serviço de atendimento pré-hospitalar no município de São Paulo. Trata-se do Serviço da Secretaria de Saúde do Município que antecedeu o SAMU-SP, mas estava estruturado para realizar remoções inter-hospitalares. Atualmente, foi remodelado e realiza também atendimento pré-hospitalar na cidade de São Paulo, é acionado via telefone 192. 
O estabelecimento de sistemas de trauma em nosso meio proposto como uma estratégia para melhorar a assistência em trauma é ainda relativamente novo, mas a necessidade de avaliar os efeitos dessa medida começam a surgir.

Um primeiro estudo de vítimas de trauma $(\mathrm{n}=1.414)$ atendidas pelo SAMU-SP, foi realizado em 1993 com ocorrências do no ano de 1991 (WHITAKER, 1993). Constou-se que os atendimentos foram principalmente a vítimas de acidente de transporte $(64,50 \%)$, predominantemente do sexo masculino $(76,73 \%)$, na faixa etária entre15 e 44 anos $(77,90 \%)$ cujo atendimento ocorreu, na maioria das vezes (81,31\%), no intervalo de um a quarenta minutos. Sobre a gravidade do trauma, observou-se que entre as vítimas fatais $(n=130)$ a maioria $(73,55 \%)$ era decorrente de acidente de transporte e $61,16 \%$ obtiveram ISS $\geq 16$ e 38,84\% tiveram ISS $\geq 25$. Para 63,63\% das vítimas fatais, a morte ocorreu nas primeiras 24 horas pós-evento.

Com o desenvolvimento de sistemas integrados de atendimento ao trauma em várias cidades do Brasil, espera-se que com avaliação dos resultados as experiências possam ser comparadas e compartilhadas entre os sistemas.

Reconhecendo que as elevadas taxas de mortalidade por causas externas representam somente parte da população acometida pelos seus eventos, urge desvelar a outra grande parcela que em razão de seus agravos necessitou de assistência médicohospitalar.

Estudos têm sido feitos e gradativamente o perfil da morbidade por causas externas está se revelando em nosso meio. (LEBRÃO; MELLO JORGE; LAURENTI, 1997; MESQUITA FILHO, 1998; ANDRADE, 1998; KOIZUMI, 2000)

0 uso dos índices de trauma possibilita medir a gravidade daqueles que necessitaram de internação hospitalar. Permite observar, de certa forma, mais acuradamente, quais pacientes permaneceram internados para tratamento de seus agravos. Além disso, por meio dos índices de trauma e conhecendo-se a probabilidade de sobrevida de maneira objetiva pode-se verificar quais são os pacientes prognosticados matematicamente para viver, mas que morreram e os prognosticados para morrer que sobreviveram e comparar esses resultados com os de outros serviços que utilizaram a mesma metodologia. 
Mesmo com um instrumento que permita mensurar a gravidade, ainda a variabilidade e quantidade das lesões associadas à dificuldade de recuperação dos dados de maneira sistematizada e abrangente dificultam os estudos sobre morbidade em trauma.

Tendo em vista a importância das causas externas e suas conseqüências à população e a inexistência de estudos sobre morbi-mortalidade hospitalar com o uso de medidas objetivas de gravidade e probabilidade de sobrevida no Brasil, pretende-se estudar os pacientes internados em um hospital de referência para trauma do município de São Paulo que conta com a existência de um sistema de atendimento préhospitalar há dez anos, adotando as referidas medidas de gravidade e probabilidade de sobrevida.

Espera-se, com esse estudo, a obtenção de subsídios para prevenção, pesquisa e melhoria da qualidade da assistência em trauma. 


$$
2 \text { Objetivos }
$$




\section{OBJETIVOS}

Este estudo sobre pacientes internados, em razão de causas externas, em um hospital terciário, referência para trauma no município de São Paulo, teve os seguintes objetivos:

Caracterizar os pacientes segundo tipo de causa externa e de trauma, sexo, idade, procedência, tipo de transporte, tempo de atendimento pré-hospitalar, tempo de permanência e condição de saída;

Caracterizar a gravidade do trauma sob as óticas, anatômica com o sistema AIS/ ISS e fisiológica com o RTS

Estimar a probabilidade de sobrevida por meio do TRISS. 


\section{Material e Métodos}




\section{MATERIAL E MÉTODOS}

Este estudo refere-se à análise retrospectiva de pacientes de trauma que foram atendidos, no período de 1 de janeiro a 31 de dezembro de 1998, no Pronto-Socorro (PS) do Instituto Central (IC) do Hospital das Clínicas da Faculdade de Medicina da Universidade de São Paulo (HCFMUSP) e permaneceram internados nessa Instituição.

O HCFMUSP é um complexo hospitalar composto por seis Institutos (Instituto Central, Instituto de Ortopedia e Traumatologia, Instituto de Psiquiatria, Instituto da Criança, Instituto do Coração e Instituto de Radiologia) e três Unidades auxiliares (Hospital Auxiliar de Suzano, Hospital Auxiliar de Cotoxó e Divisão de Medicina e Reabilitação). É um hospital público de ensino, de nível terciário e referência universitária, localizado no município de São Paulo. No sistema de atendimento hierarquizado e regionalizado ao trauma do município, o IC-HCFMUSP é referência para a zona oeste e municípios vizinhos dessa região. Em 1998, o IC estava com 875 leitos ativos.

As fontes pesquisadas para obtenção dos dados foram o prontuário do paciente, ficha de atendimento pré-hospitalar preenchida por médicos e enfermeiros das unidades de suporte avançado, terrestre e aéreo do Serviço de A tendimento Médico de Urgência do Município de São Paulo (SAMU-SP), banco de dados do atendimento pré-hospitalar da Centro de O perações dos Bombeiros (CO BO M) e o laudo de necropsia dos pacientes que evoluíram com óbito.

\subsection{PROCEDIMENTOS DE COLETA DE DADOS}

A coleta de dados iniciou-se após a obtenção do parecer favorável da Comissão de Ética para Análise de Projetos de Pesquisa - CAPPesq da Diretoria Clínica do HCFMUSP, da autorização do Diretor da Divisão de Arquivo Médico (DAM) do ICHCFMUSP, do Diretor Executivo do Instituto de Ortopedia e Traumatologia (IOT) do HCFMUSP, do Coordenador do SAMU-SP da Secretaria de Saúde do Estado, do COBO M e do Diretor do Instituto Médico Legal (IML) do Estado de São Paulo. 
O período de coleta de dados correspondeu de abril de 1998 a julho de 1999 e foi realizado pela própria pesquisadora desta tese e outra pós-graduanda da Escola de Enfermagem da USP que estudou parte da população desta pesquisa.

Para a verificação da mortalidade da população estudada, considerou-se na coleta de dados o prazo de 180 dias a partir da data da ocorrência do evento, tendo em vista que, praticamente, a totalidade dos óbitos por causas externas ocorre nesse intervalo de tempo (MELLO JORGE, 1979; KOIZUMI, 1984)

3.1.1. Etapa I - Seleção dos pacientes de causas externas e coleta de dados no ICHCFMUSP

Com base na relação mensal referente à saída de pacientes de causas externas internados no IC-HCFMUSP, processada pela PRODESP - Companhia de Processamento de Dados do Estado de São Paulo e fornecida pela DAM, foi selecionada a população do estudo.

Consideraram-se pacientes de causas externas aqueles acometidos por eventos denominados no capítulo XX - Causas Externas de Mortalidade e de Morbidade sob as rubricas de V01 a Y 34 da Classificação Estatística Internacional de D oenças e Problemas Relacionados à Saúde - 10a revisão (CID 10) (O MS, 1998a, b).

Todos os prontuários dos pacientes internados no IC-HCFMUSP relacionados na lista fornecida pela PRODESP foram solicitados e verificados quanto à existência de anotações registradas sobre 0 atendimento no PS. Os prontuários dos pacientes com a ficha de atendimento do PS foram selecionados, conforme as informações indicadoras de ocorrência de um evento relativo às causas externas que determinaram a internação do paciente. Portanto, foram elegíveis os pacientes de causas externas provenientes do local do evento que receberam o atendimento inicial no PS do IC-HCFMUSP, assim como os encaminhados pelos serviços de resgate que realizaram 0 atendimento pré-hospitalar. Além disso, considerou-se os pacientes que receberam atendimento inicial em outras instituições de saúde que foram transferidos ao IC-HCFMUSP para tratamento definitivo , tendo em vista tratar-se de um hospital de referência para trauma. 
Os pacientes de causas externas listados pela PROD ESP, foram excluídos quando:

- 0 atendimento no PS do IC-HCFMUSP foi realizado fora do período considerado neste estudo (01/ 01 a 31/ 12 de 1998);

- o prontuário não continha a ficha de atendimento do PS;

- 0 motivo da procura pelo PS foi em razão de manifestação de complicações decorrentes de lesão(ões) traumática(s), para realização da complementação do tratamento ou tratamento de seqüelas;

- 0 diagnóstico definitivo referiu-se a uma condição clínica, sem relação às causas externas;

- os pacientes de trauma transferidos ao IC-HCFMUSP, admitidos via PS, eram doadores de órgãos;

- a necropsia não confirmou a lesão decorrente da causa externa como causa da morte;

- o prontuário do paciente não pôde ser recuperado para consulta.

Conforme os pacientes iam sendo selecionados, seus dados eram coletados utilizando-se uma ficha específica para esse fim (anexo III). Os dados transcritos do prontuário dos pacientes foram:

- identificação do paciente (nome, número de registro HC, sexo e idade);

- causa externa e código da CID;

- data e horário de entrada no Pronto-Socorro, data e horário da alta, transferência ou óbito;

- origem do paciente, meio de transporte utilizado, local do evento, tempo decorrido até a chegada ao PS;

- história na admissão do PS e atendimento inicial;

- escores parciais e total da ECGl, valores absolutos da PAS e FR obtidos na admissão no Pronto Socorro e registros sobre a presença de edema palpebral, tubo endotraqueal e uso de sedativos, anestésicos ou miorrelaxantes; 
- presença de álcool ou droga e doenças preexistentes;

- descrições das lesões anatômicas;

- descrições do nível de consciência registrada pelos médicos ou pela enfermagem durante o período de internação.

3.1.2. Etapa II - Coleta de dados no Instituto de Ortopedia e Traumatologia (IOT) e Instituto Médico Legal (IML)

Considerando que a mensuração da gravidade do trauma do ponto de vista anatômico depende da obtenção completa tanto do número quanto da descrição das lesões, buscaram-se outras fontes de dados que, também, possuíam informações relativas às lesões (HARVIEL et al., 1989; STREAT;CIVIL, 1990; GENNARI et al., 1997). 0 objetivo foi coletar o máximo de informações possíveis que pudessem auxiliar a descrever com exatidão a extensão da lesão traumática. Esse cuidado foi possível aos pacientes que foram transferidos ou encaminhados ao IOT, para realizarem algum procedimento ortopédico cirúrgico e àqueles que morreram e foram encaminhados ao IML. Os demais pacientes que foram transferidos para outras instituições não tiveram seus dados complementados, em razão da dificuldade de percorrer os inúmeros serviços do município para onde os pacientes foram encaminhados. Portanto, as fontes adicionais de coleta de dados foram o IOT e o IML.

\section{Obtenção de dados no IOT}

Entre os pacientes houve aqueles que receberam alta do IC-HCFMUSP e foram encaminhados ao IOT para concluírem o tratamento ortopédico e, também, os que durante o período em que estavam internados no IC-HCFMUSP foram encaminhados ao aquele Instituto para realizarem procedimento ortopédico cirúrgico. 0 prontuário desses pacientes foi solicitado ao Serviço de Arquivo Médico do IOT e analisado para, caso necessário, fosse complementada a descrição das lesões ortopédicas. 
Os prontuários verificados no IOT relacionaram-se aos pacientes que permaneceram internados e àqueles que realizaram algum procedimento cirúrgico nesse Instituto. Q uando a identificação de registro não correspondia à existência de prontuário de internação, foram verificados os nomes na listagem de atendimento do PS do IOT. Isso se deve ao fato de que os pacientes quando são encaminhados do IC-HCFMUSP, são atendidos inicialmente no PS do IOT para daí, conforme a necessidade, serem internados, transferidos ou encaminhados para tratamento ambulatorial. Quando foram identificados na lista de atendimento do PS-IOT, localizou-se a respectiva ficha de atendimento e seus dados foram verificados e comparados com os já coletados no ICHCFMUSP.

Obtenção de dados no IML

Considerando-se que as mortes por causas não naturais exigem, por força da lei, 0 exame necroscópico para fornecimento do atestado de óbito, os pacientes deste estudo que morreram tiveram seus dados relativos às descrições das lesões complementadas pelo laudo da necropsia.

Os números dos laudos foram localizados com base na listagem do movimento diário de cadáveres no IML e também do banco de dados informatizado tendo como referência a data e a procedência. Para aqueles sem identificação do registro civil (desconhecido) e os com nome discrepante, realizou-se um processo de procura no IML utilizando-se as características pessoais e o número do boletim de ocorrência, registrado pelo plantão policial do IC-HCFMUSP, que possibilitou concluir a localização do laudo de necropsia correspondente ao paciente.

Os dados de laudo da necropsia necessários ao estudo foram transcritos para outra ficha de coleta de dados - IML (anexo IV). Essas informações consistiram em descrições de lesões anatômicas verificadas no exame necroscópico, para complementar aquelas obtidas no IC-HCFMUSP pelo prontuário do paciente, acrescido dos dados de identificação do paciente (nome, idade, sexo, número do registro $\mathrm{HC}$ ), causa externa, número do Boletim de $\mathrm{O}$ corrência e do laudo de necropsia, data do óbito e da necropsia e a "causa mortis". 


\subsubsection{Etapa III - Coleta de dados do atendimento pré-hospitalar}

Tendo em vista a existência de dois serviços de atendimento pré-hospitalar no município de São Paulo (SAMU-SP e serviço 192), descritos anteriormente que encaminharam pacientes ao PS do IC, optou-se por coletar dados do atendimento préhospitalar do serviço com o maior número de casos.

Todos os pacientes que foram registrados como tendo sido atendidos pelo SAMUSP na fase pré-hospitalar foram rastreados no banco de dados informatizado do COBO M. 0 rastreamento foi efetuado utilizando-se como referência a data, a hora e 0 local do evento. Quando necessário utilizou-se como referência a unidade de transporte que encaminhou o paciente até o hospital e seu respectivo número.

D os pacientes transportados pelas unidades de suporte avançado terrestre e aéreo, denominados respectivamente, USA e Águia coletaram-se também, os dados da ficha de atendimento pré-hospitalar preenchida pelos médicos e enfermeiros que prestaram assistência ao paciente, disponíveis na Secretaria de Saúde do Estado - Projeto Resgate.

Cumpre mencionar que os dados registrados no COBOM estão limitados ao município de São Paulo. Assim, pacientes vindos de municípios vizinhos para o PS do IC-HCFMUSP não constam desse banco de dados e, portanto, seus registros da fase préhospitalar não puderam ser recuperados.

Os dados referentes à fase pré-hospitalar coletados foram tempo de demora do atendimento pré-hospitalar (desde a chamada do serviço até a chegada ao hospital), dados fisiológicos (ECGl, PAS e FR) e a unidade que transportou (UR, USA ou Águia).

\subsubsection{Etapa IV - Revisão das fichas de coleta de dados}

Uma vez encerrada a fase de coleta de dados, cada ficha foi novamente analisada com atenção aos critérios de inclusão no estudo. 
No ano de 1998, 2.021 pacientes de causas externas foram internados no ICHCFMUSP totalizando 2.132 internações, segundo a relação fornecida pela PRODESP. Convém ressaltar que houve pacientes com mais de uma internação.

Do total de 2.021 pacientes de causas externas que foram internados no ICHCFMUSP, 240 foram excluídos conforme relacionado a seguir.

\begin{tabular}{|l|c|c|}
\hline \multirow{2}{*}{ MO TIVO DA EXCLUSÃo } & \multicolumn{2}{c|}{ Paciente } \\
\cline { 2 - 3 } & sobrevivente & óbito \\
$\mathrm{N}$ & $\mathrm{N}$ \\
\hline A admissão não foi via PS & 44 & 2 \\
\hline $\begin{array}{l}\text { Internação por complicação ou para complementação do } \\
\text { tratamento das lesões traumáticas }\end{array}$ & 94 & 1 \\
\hline O motivo da internação não se relacionou à causa externa & 41 & 14 \\
\hline O prontuário não pôde ser recuperado & 29 & 4 \\
\hline Admitido como doador de órgãos & - & 11 \\
\hline Total & 208 & 32 \\
\hline
\end{tabular}

No decorrer do processo de seleção de pacientes para o estudo, constatou-se que somente oito além de atenderem aos critérios de inclusão do estudo possuíam mais de uma internação. Trataram-se de uma criança, uma idosa e três adultos (com história de convulsão) que foram internados mais de uma vez no IC, no intervalo de dois a cinco meses por terem sofrido queda. Além destes, havia um paciente que sofreu atropelamento e, quatro meses após esse evento, foi agredido fisicamente. Por fim, dois pacientes com episódios repetidos de intoxicação exógena. De acordo com o registro na ficha do PS, tratava-se de evento distinto daquele que havia determinado a internação anterior. Em virtude dessa característica e por serem numericamente mínimos, foram incluídos na população do presente estudo e considerados como pacientes distintos.

Cabe ressaltar que os prontuários não recuperados foram solicitados pelo menos três vezes com diferença de um mês entre as solicitações.

D esta forma, a população de estudo ficou constituída do total de 1.781 pacientes. 


\subsection{PROCEDIMENTOS DE CATEGORIZAÇÃO OU DE CODIFICAÇÃO DOS DAD OS COLETADOS}

3.2.1. Critérios especiais utilizados para categorização das variáveis estudadas.

Causas externas

Os 1.781 pacientes selecionados para este estudo tiveram suas causas externas codificadas, segundo o capítulo XX - causas externas de morbidade e de mortalidade da CID -10. A codificação das causas externas processadas na D AM foi respeitada e agrupada neste estudo em:

Acidente de Transporte (V01 a V99)

- Atropelamento de V01 a V09;

- Acidente automobilístico de V40 a V79;

- Acidente de motocicleta de V20 a V29;

- O utros acidentes de transporte incluem V10 a V19, V80 a V89.

Agressões (X 85 - Y 09)

- Arma de Fogo (X93 a X95)

- O bjeto cortante ou penetrante (X99)

- O utros tipos de agressão (X 85 a X 92, X 96 a X 98, Y 00 a Y 09)

Q uedas (W00 a W19)

- Q ueda de altura (W06 a W15 e W17)

- Queda da própria altura (W00 e W18)

- O utras quedas (W02 a W05, W16 e W19)

Exposição a forças mecânicas

\footnotetext{
${ }^{1}$ Não houve casos nos códigos V30-V39 (envolvendo ocupantes de triciclo motorizado), V90-V94 (referentes a acidentes de transporte por água) e V98-V99 (outros acidentes de transporte e os não especificados)
} 
- Inanimadas (W20 a W49)

- Animadas (W50 a W64)

Eventos de intenção indeterminada (Y10 a Y34)

Exposição acidental a fatores e aos não-especificados (X58 e X59)

Envenenamento / intoxicação acidental (X 40 a X 49)

Exposição à corrente elétrica (W85 e W99)

Afogamento e submersão acidentais (W65 a W74)

Exposição ao fogo e chamas ou fonte de calor e substâncias quentes (X 00 a X 19)

Lesões autoprovocadas voluntariamente (X60 X 84)

Tipo de trauma

Considerou-se pacientes de trauma contuso aqueles acometidos por acidente de transporte, queda, agressão com objetos contundentes, explosão e, pacientes de trauma penetrante os que foram acometidos por arma de fogo, objetos cortantes ou pontiagudos ACS, 1999b; NAEMT, 1999).

Idade

A idade foi agrupada em faixas etárias subdivididas de cinco em cinco anos e os extremos com os pacientes de idade $<1$ ano e mais de 75 anos. Esse agrupamento foi adotado para verificar a freqüência dos diversos eventos deste estudo em relação a essa variável.

Tempo de atendimento pré-hospitalar

O tempo de atendimento na fase pré-hospitalar foi considerado desde a solicitação do serviço de resgate até a chegada ao PS do IC-HCFMUSP. Considerou-se 0 horário da solicitação do atendimento pré-hospitalar aquele registrado no banco de dados do COBOM. No sentido de uniformizar o horário de chegada ao hospital, adotou-se 
aquele registrado na ficha do PS no momento da entrada do paciente. Os intervalos de tempo foram definidos de 15 em 15 minutos até o tempo máximo verificado.

Período de permanência no hospital

Considerou-se o período de permanência ou tempo de internação no hospital, desde 0 momento da entrada do paciente no PS (data e hora) até a saída do hospital (data e hora). 0 agrupamento dos pacientes foi dividido em tempo de permanência $<24$ horas (subdivididos de uma em uma hora), de um a sete dias (subdivididos de um em um dia) e por semanas (subdivididos de uma em uma semana até mais que 63 dias). 0 agrupamento foi feito por causa da concentração de pacientes nesses intervalos de tempo.

Tipo de saída

Os tipos de saída foram definidos em alta, óbito, transferência e outros. Em alta, consideraram-se os pacientes que obtiveram alta hospitalar. No grupo de óbitos, foram incluídos todos os óbitos ocorridos no PS ou demais unidades do IC. Considerou-se transferência, os pacientes que saíram do IC transferidos para outros hospitais. Em outros, foram incluídos os pacientes que tiveram alta a pedido ou evadiram-se do hospital.

\subsubsection{Codificação das lesões e conferência dos dados coletados.}

A codificação de cada lesão dos pacientes foi efetuada de acordo com o Manual AIS/ 90-atualização 98 (AAAM, 1988). Essa codificação foi feita manualmente pela própria autora do estudo e por uma pesquisadora que estudou parte desta população e foram revisadas, em conjunto, periodicamente.

Todas as lesões registradas no prontuário do paciente e confirmadas quanto à sua existência por meio de exame físico, raios $\mathrm{X}$, tomografia computadorizada, ultrasonografia, ressonância nuclear magnética, cirurgia, necropsia foram codificadas.

Cada lesão, por sua vez, foi codificada utilizando-se uma seqüência numérica de seis dígitos acrescida de mais um número à direita do ponto decimal que representa 0 
escore de gravidade da lesão AIS. A seguir está esquematizado o significado de cada dígito, utilizando-se o código da fratura do colo de fêmur, como exemplo:

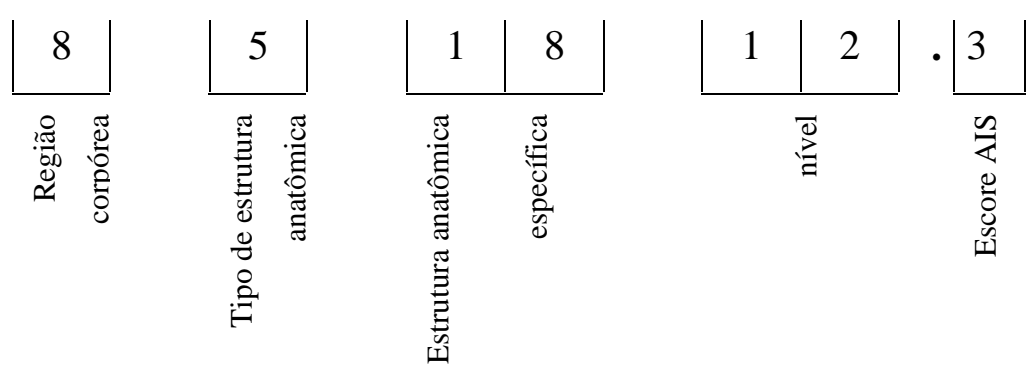

Como durante a codificação das lesões dos pacientes, verificou-se que algumas descrições de lesões do prontuário estavam diferentes daquelas descritas no Manual AIS foram feitas consultas a médicos especialistas (em neurocirurgia, cirurgia do trauma, ortopedia e em medicina legal) para confrontar e elucidar a equivalência das descrições contidas no prontuário do paciente e, também, no relatório de necropsia com aquelas do Manual AIS.

3.2.3. Digitação no banco de dados

Os dados foram armazenados em banco informatizado construído com 0 programa Access 97 da Microsoft.

Nesse banco constituído por cerca de cem campos, o registro do paciente só podia ser inserido uma única vez, evitando dessa forma a inclusão repetida do mesmo paciente.

Os dados foram digitados duplamente por diferentes pessoas por causa da técnica utilizada para 0 processo de verificação da consistência da digitação dos dados. 0 programa de verificação da consistência apontou 2.087 digitações não coincidentes. A correção foi realizada conferindo-se cada dado inconsistente com a fonte (ficha de coleta de dados) e submetida a nova consistência da digitação.

Após essa etapa, os dados puderam ser processados para calcular a gravidade do trauma de acordo com os índices adotados neste estudo. 


\subsection{CÁLCULO DA GRAVIDADE DO TRAUMA}

Os dados para cálculo da gravidade do trauma determinados pelos índices (RTS, ISS e TRISS) utilizados no estudo foram processados eletronicamente, obedecendo-se às regras preconizadas para sua aplicação.

\subsubsection{Revised Trauma Score (RTS)}

O escore RTS foi calculado conforme metodologia preconizada por CHAMPION et al. (1989a) a todos pacientes que possuíam os dados necessários independente da idade. Convém ressaltar que o RTS é utilizado de duas formas: para triagem (RTS-t) e para avaliação de resultados (RTS), conforme descrito a seguir.

No cálculo do RTS-t, para fins de triagem, são utilizados os valores da ECGl, PAS e FR obtidos no banco de dados do $\mathrm{COBOM}$, os registrados na ficha de atendimento pré-hospitalar do SAMU-SP ou aqueles que foram informados no momento da admissão no hospital e registrados na ficha do PS. Para a triagem de pacientes na fase préhospitalar, o escore RTS-t é obtido somando-se os pontos de zero a 4 atribuídos ao valor absoluto de cada parâmetro, portanto, nessa etapa, a pontuação varia de zero a 12.

Os dados fisiológicos empregados para o cálculo do RTS, quando para fins de avaliação de resultados, foram os aferidos durante 0 atendimento inicial na Sala de Emergência (SE) do PS. O valor absoluto de cada parâmetro é convertido em valores de zero a 4 , conforme o intervalo correspondente e multiplicado pelos respectivos coeficientes determinados pela regressão logística dos dados do Major Trauma O utcome Study (CHAMPION et al., 1989a).

\begin{tabular}{|cc|}
\hline RTS - peso de cada parâmetro \\
\hline ECGl & 0,9368 \\
PAS & $-0,7326$ \\
FR & $-0,2908$ \\
\hline
\end{tabular}


Assim, o cálculo do RTS foi efetuado da seguinte forma:

$\mathrm{RTS}=0,9368(\mathrm{ECGl})+0,7326(\mathrm{PAS})+0,2908(\mathrm{FR})$

Sendo possível valores RTS entre zero a 7,8408

De acordo com o registro, os dados dos pacientes que estavam sob efeito de sedativos, anestésicos, álcool, apresentavam edema palpebral ou estavam com tubo endotraqueal não foram considerados, pois a alteração ou inexistência de algum dado estaria relacionada à interferência desses fatores e não refletiria o estado real do paciente (OFFNER, 1992; MARION, 1994). Essas condições não foram consideradas aos pacientes que foram admitidos em parada cardiorrespiratória no PS.

Quando não havia registro do valor absoluto da FR e da ECGl, mas foram constatados os termos eupneico, respiração normal na avaliação da respiração do paciente e consciente sem "déficit" na avaliação do nível de consciência, optou-se por considerar no RTS a pontuação máxima (4) nesses parâmetros. A conduta foi adotada por entender que nessas condições 0 estado do paciente corresponderia àquelas de escore 4 nos intervalos determinados para ECGl e FR.

\subsubsection{Injury Severity Score (ISS)}

O ISS está fundamentado na AIS, uma vez que todas as lesões registradas no prontuário do paciente e no laudo da necropsia previstas no Manual AIS estavam codificadas, pode-se proceder ao cálculo do ISS para cada paciente conforme a metodologia preconizada por BAKER; O’NEILL (1976).

Cada lesão com um escore AIS, variando de 1 a 6, foi classificada de acordo com as seis regiões corpóreas determinadas para o cálculo do ISS (cabeça/ pescoço, face, tórax, abdome/ conteúdo pélvico, extremidade/ cintura pélvica e externa). 0 valor do ISS foi obtido efetuando-se a somatória do quadrado dos 3 escores mais elevados de três diferentes regiões corpóreas.

$$
\text { ISS }=(*) 2+(*) 2+(*) 2
$$

onde* se refere aos escores mais elevados de três diferentes regiões corpóreas. 
O exemplo (AAAM, 1998) apresentado, a seguir, mostra como calcular o ISS de uma vítima com múltiplos traumas, tendo-se como base o sistema AIS/ ISS.

\begin{tabular}{|c|c|c|c|c|}
\hline $\begin{array}{c}\text { REGIÃO } \\
\text { CORPÓREA }\end{array}$ & LESÃO & $\begin{array}{c}\text { ESCORE } \\
\text { AIS }\end{array}$ & $\begin{array}{l}\text { ESCORE AIS } \\
\text { MAIS ALTO }\end{array}$ & $\overline{\mathrm{AIS}^{2}}$ \\
\hline Cabeça/ Pescoço & $\begin{array}{l}\text { - Contusão cerebral } \\
\text { - Transeção completa da carótida } \\
\text { interna }\end{array}$ & $\begin{array}{l}3 \\
4\end{array}$ & 4 & 16 \\
\hline Face & - Laceração de pavilhão auricular & 1 & 1 & \\
\hline Tórax & - Fratura das $3^{\mathrm{a}}$ e $4^{\mathrm{a}}$ costelas à $\mathrm{E}$ & 2 & 2 & \\
\hline $\begin{array}{l}\text { Abdome/conteúdo } \\
\text { pélvico }\end{array}$ & - Hematoma retroperitoneal & 3 & 3 & 9 \\
\hline Extremidades & - Fratura de fêmur & 3 & 3 & 9 \\
\hline Externa & - Escoriações generalizadas & 1 & 1 & \\
\hline
\end{tabular}

A classificação dos pacientes conforme os valores do ISS foi feita observando-se a recomendação de COPES et al. (1988b) e utilizada no MTOS, tendo em vista que se correlaciona melhor com os picos de mortalidade baseados na gravidade do trauma, abrandando os efeitos da heterogeneidade entre os valores ISS. Os intervalos ISS adotados foram 1 a 8, 9 a 15, 16 a 24, 25 a 40, 41 a 49, 50 a 74 e 75.

O valor do ISS dos pacientes com alta ou transferidos foi obtido partindo das lesões descritas no prontuário do IC e do IOT e aos pacientes que morreram acrescentouse, também, as lesões descritas no laudo da necropsia.

Os pacientes que foram internados em decorrência de afogamento e submersão acidental, envenenamento / intoxicação acidental e penetração de corpo estranho no e através do olho ou orifício natural foram excluídos do cálculo do ISS, porque as lesões decorrentes desses eventos não são previstas no Manual AIS.

\subsubsection{TRauma and Injury Severity Score (TRISS)}

Para estimar a probabilidade de sobrevida (Ps), utilizando-se a metodologia TRISS, a população do estudo foi classificada, conforme o tipo de trauma: contuso e penetrante. 
0 TRISS tem como base o RTS, ISS, a idade do paciente e 0 tipo de trauma e é estimado pelo modelo logístico: (CHAMPION et al., 1981, BOYD et al., 1987)

$$
\begin{aligned}
& P s=\frac{1}{1+e^{-b}} \\
& \text { Onde } 0 \text { "e" é 2,7183 (base do logarítimo neperiano) } \\
& \mathrm{e} \\
& \mathrm{b}=\mathrm{b} 0+\mathrm{b} 1 \text { ( RTS ) + b2 ( ISS ) + b3 ( idade ) }
\end{aligned}
$$

Os coeficientes aplicados aos componentes do TRISS (RTS, ISS, idade, acrescidos da constante (b0) de acordo com o tipo de trauma) são os ajustados à codificação da lesão anatômica do Manual AIS - 90, conforme a tabela abaixo (CHAMPION; SACCO; COPES, 1995).

\begin{tabular}{lcccc}
\hline $\begin{array}{c}\text { Mecanismo } \\
\text { do trauma }\end{array}$ & $\begin{array}{c}\text { Constante } \\
\left(\mathrm{b}_{0}\right)\end{array}$ & $\begin{array}{c}\text { RTS } \\
\left(\mathrm{b}_{1}\right)\end{array}$ & $\begin{array}{c}\text { ISS } \\
\left(\mathrm{b}_{2}\right)\end{array}$ & $\begin{array}{c}\text { Idade } \\
\left(\mathrm{b}_{3}\right)\end{array}$ \\
\hline fechado & $-0,4499$ & 0,8085 & $-0,0835$ & $-1,7430$ \\
penetrante & $-2,5355$ & 0,9934 & $-0,0651$ & $-1,1360$ \\
\hline
\end{tabular}

Para pacientes com idade abaixo de 55 anos, o coeficiente b3 multiplicará 0 valor zero para idade. Para aqueles com idade igual ou superior a 55 anos, o b3 multiplicará 0 valor um para idade .

Os critérios matemáticos que indicam um resultado inesperado com o uso do TRISS são:

paciente com Ps > 50\% e morreu (morte inesperada);

paciente com Ps $<50 \%$ e sobreviveu (sobrevida inesperada).

Considerando-se que os dados do RTS utilizados para o cálculo do TRISS devem ser os obtidos na SE do PS, os pacientes que vieram transferidos de outras instituições de saúde não puderam ter a Ps calculada, pois os dados do atendimento inicial do paciente nesses locais não foram enviados com 0 encaminhamento. 
No cálculo do TRISS, os tipos de trauma considerados são contuso e penetrante, portanto, o grupo de pacientes com queimadura e outros tipos de trauma foram excluídos da análise.

\subsection{TRATAMENTO ESTATÍSTICO E ANÁLISE DOS DADOS}

Os dados foram organizados em tabelas e figuras apresentados em forma de números absolutos e porcentuais.

Os dados da caracterização da população estudada foram verificados e comparados quanto a freqüência absoluta e relativa e medidas de tendência central.

A relação entre a gravidade do trauma e Ps calculada usando-se o TRISS foi analisada empregando-se os métodos PRE e DEF, termos originados da abreviação dos nomes em inglês "PREliminary outcome-based evaluation" e "DEFinitive outcome-based evaluation" (ACS, 1986, 1999; CHAMPION et al., 1991)

O PRE é um instrumento que apresenta graficamente a Ps de cada paciente estudado, comparando-o com um padrão predeterminado. 0 gráfico é construído tendo no eixo vertical os valores RTS e no eixo horizontal os valores ISS. Partindo dos pontos que indicam a Ps $=0,50$, traça-se uma reta entre as duas coordenadas. $O$ cálculo das Ps 0,50 que determinam a reta é efetuado considerando-se $b=0$ no modelo logístico. Essa linha indicativa de Ps 0,50 considera o paciente com Ps $>0,50$, quando o RTS e ISS posicionam-se abaixo e à esquerda da linha e, com Ps $<0,50$ quando estiverem posicionados acima e à direita da linha. Portanto de acordo com a localização do ponto determinado pelo RTS e o ISS no gráfico, pode-se comparar o resultado evolutivo de cada paciente com base nos dados do MTOS. A linha indicativa de Ps 0,50 é distinta para cada tipo de trauma, pois é derivada partindo-se de coeficientes dependentes do trauma contuso e penetrante. Sendo assim, a apresentação do PRE foi preparada de acordo com as categorias idade e tipo de trauma.

Uma vez estudado o resultado de cada paciente em relação a um padrão predeterminado, a análise prossegue verificando-se o resultado da população em estudo. 
O método DEF foi empregado para comparar o resultado evolutivo (sobrevida e mortalidade) da população estudada com um padrão predeterminado. A análise DEF é feita usando-se a metodologia denominada "Z-statistic" (estatística "Z") ( FLORA, 1978) que testa a hipótese nula de que a mortalidade ou a sobrevida estimada (MTOS) e a observada (grupo de estudo) são iguais ( TAYLOR; SACCO; CHAMPION, 1986).A estatística "Z" foi calculada pela da fórmula:

para comparar mortalidade

$$
Z=\frac{D-\sum Q i}{\sum P i Q i}
$$

onde:

D - número de óbitos no grupo estudado

Qi - (1-Pi) probabilidade estimada de óbito do paciente i

$\Sigma Q i$ - número de óbitos estimado pelo TRISS

$\mathrm{Pi}$ - Ps estimada para o paciente $\mathrm{i}$

para comparar sobrevida

$$
Z=\frac{S-\sum Q i}{\sum P i Q i}
$$

onde:

S- número de sobreviventes no grupo estudado

$\mathrm{Pi}$ - Ps estimada do paciente i

$\Sigma$ Pi - número de sobreviventes estimado pelo TRISS

Embora 0 cálculo seja diferente (óbitos e sobreviventes) e o sinal de "Z" variar entre + e - , 0 valor em módulo de "Z" não se modifica.

Os valores em módulo de "Z" correspondem em nível de significância, ou seja, quando o valor de "Z" é maior que 1,96 (ou mais que dois desvios-padrão da média) indica que a diferença entre os dois grupos é estatisticamente significante em nível de 0,05. Os valores de "Z" que indicam o grau de significância são (BOYD , 1987): 


\begin{tabular}{|c|c|}
\hline nível de significância & valor de "Z" \\
\hline 0,001 & 3,29 \\
\hline 0,005 & 2,81 \\
\hline 0,010 & 2,58 \\
\hline 0,025 & 2,24 \\
\hline 0,050 & 1,96 \\
\hline 0,100 & 1,65 \\
\hline
\end{tabular}

Quando os valores de "Z" estiverem entre +1.96 e -1.96 , a diferença da Ps calculada por meio do TRISS entre o grupo em estudo e o grupo controle (MTOS) não é estatisticamente significante

A comparação do resultado evolutivo (sobrevida e mortalidade) de uma população estudada com um padrão predeterminado não deve ser feita aplicando-se somente a estatística "Z". Para completar a análise utiliza-se uma medida de significado clínico relacionada à evolução (sobrevida ou óbito) entre o grupo em estudo e o grupo controle denominado "W statistic" (estatística "W"). 0 resultado indica a diferença entre 0 número de sobreviventes ou óbitos e o número estimado pelo MTOS por 100 pacientes tratados(HOLLIS; FOSTER, 1995;Y OUNGE et al., 1997; CO IMBRA et al., 1997)

A estatística "W" é calculada com a seguinte fórmula:

para sobreviventes

$W=\frac{100\left(S-\sum P i\right)}{N}$

Onde

S- número de sobreviventes no grupo estudado

$\mathrm{Pi}$ - Ps estimada do paciente $\mathrm{i}$

$\Sigma \mathrm{Pi}$ - número de sobreviventes estimado pelo TRISS

$\mathrm{N}$ - número de pacientes no grupo estudado

para óbitos

$W=\frac{100\left(D-\sum Q i\right)}{N}$

onde:

D - número de óbitos no grupo estudado

Q i - (1-Pi) probabilidade estimada de óbito do paciente i

$\Sigma$ Qi - número de óbitos estimado pelo TRISS

$\mathrm{N}$ - número de pacientes no grupo estudado 
Os valores positivos (ou negativos) de " $\mathrm{W}$ " representam o número de pacientes sobreviventes (óbitos) acima ( abaixo) daquele estimado pelo MTOS em 100 pacientes tratados. Q uando os valores de "Z" estão entre +1.96 e -1.96, o valor de "W" é zero.

Considerando a existência de diferenças entre o resultado obtido neste estudo com o padrão do MTOS, novos coeficientes ajustados à amostra estudada foram calculados.

A representatividade da amostra em relação ao grupo de pacientes deste estudo

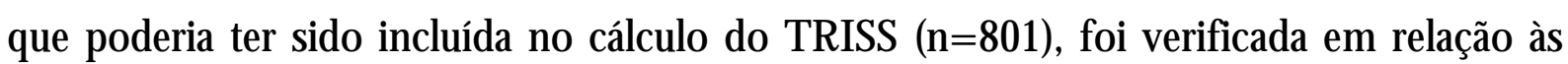
variáveis idade, sexo, condição de saída (sobrevivente ou óbito), tipo de trauma (contuso e penetrante) por meio da análise descritiva, teste " $t$ " de Student (BUSSAB; MORETTIN, 1987). Para a gravidade do trauma (ISS) utilizou-se o teste Kolmogorov-Smirnov (CONOVER, 1999).

Tendo em vista a representatividade da amostra que possui todos os dados necessários para o cálculo do TRISS, procedeu-se a análise descritiva quanto às variáveis sexo, idade mecanismo do trauma, RTS, ISS e procedência dos pacientes do grupo em relação ao tipo de saída (sobrevivente e óbito). Os testes estatísticos aplicados foram 0 Q ui-quadrado (AGRESTI, 1990) e " $\mathrm{t}$ ” de Student (BUSSAB; MORETTIN, 1987).

A análise inferencial foi feita pela de regressão logística (HOSMER; LEMESHOW, 1989) para estimar os novos coeficientes das variáveis idade, RTS e ISS com vistas à estimação da probabilidade de sobrevida dos pacientes tendo como base a amostra obtida deste estudo. 


\section{Resultados e Discussão}




\section{RESULTADOS E DISCUSSÃO}

\subsection{CARACTERIZAÇÃO DA POPULAÇÃO ESTUDADA}

No ano de 1998, foram atendidos no PS do IC-HCFMUSP 7.893 pacientes cujo motivo da procura pelo serviço relacionou-se aos eventos de causas externas. Do total de pacientes foram internados $2.021(25,60 \%)$ e de acordo com os critérios de inclusão predeterminados, 1.781 foram selecionados para este estudo.

Tabela 01 - Pacientes internados, segundo tipo de causas externas, IC-HCFMUSP, 1998.

\begin{tabular}{|c|c|c|c|}
\hline \multicolumn{2}{|l|}{ CAUSAS EXTERNAS } & $\begin{array}{l}\mathrm{N} \\
233\end{array}$ & $\%$ \\
\hline Acidente de Transporte & $\begin{array}{l}\text { Atropelamento } \\
\text { Acidente Automobilístico } \\
\text { Acidente de Motocicleta } \\
\text { Outros acidentes de transporte }\end{array}$ & $\begin{array}{l}233 \\
195 \\
84 \\
25\end{array}$ & $\begin{array}{c}13,08 \\
10,95 \\
4,72 \\
1,40\end{array}$ \\
\hline \multicolumn{2}{|l|}{ Subtotal } & 537 & 30,15 \\
\hline Agressões & $\begin{array}{l}\text { Arma de fogo } \\
\text { Objeto cortante ou penetrante } \\
\text { Outras agressões }\end{array}$ & $\begin{array}{c}252 \\
72 \\
109 \\
\end{array}$ & $\begin{array}{c}14,16 \\
4,04 \\
6,12 \\
\end{array}$ \\
\hline \multicolumn{2}{|l|}{ Subtotal } & 433 & 24,32 \\
\hline Quedas & $\begin{array}{l}\text { Queda de altura } \\
\text { Queda da própria altura } \\
\text { Outras quedas }\end{array}$ & $\begin{array}{c}159 \\
96 \\
52 \\
\end{array}$ & $\begin{array}{l}8,93 \\
5,39 \\
2,92 \\
\end{array}$ \\
\hline \multicolumn{2}{|l|}{ Subtotal } & 307 & 17,24 \\
\hline Exposição a Forças mecânicas & $\begin{array}{l}\text { Inanimadas } \\
\text { Animadas }\end{array}$ & $\begin{array}{c}202 \\
16 \\
\end{array}$ & $\begin{array}{c}11,34 \\
0,90\end{array}$ \\
\hline \multicolumn{2}{|l|}{ Subtotal } & 218 & 12,24 \\
\hline \multicolumn{2}{|c|}{ Eventos de intenção indeterminada } & 74 & 4,15 \\
\hline \multicolumn{2}{|c|}{ Exposição acidental a outros fatores e aos não especificados } & 67 & 3,76 \\
\hline \multirow{2}{*}{\multicolumn{2}{|c|}{$\begin{array}{l}\text { Exposição ao fogo e chamas ou fonte de calor e substâncias quentes } \\
\text { Envenenamento/ Intoxicacão acidental }\end{array}$}} & 62 & 3,48 \\
\hline & & 34 & 1,91 \\
\hline \multicolumn{2}{|c|}{ Lesões autoprovocadas voluntariamente } & 27 & 1,52 \\
\hline \multicolumn{2}{|l|}{ Exposição à corrente elétrica } & 20 & 1,12 \\
\hline \multicolumn{2}{|c|}{ Afogamento e submersão acidentais } & 2 & 0,11 \\
\hline \multicolumn{2}{|l|}{ Total } & 1781 & 100,00 \\
\hline
\end{tabular}


Os dados da Tabela 01 mostram que dos 1.781 pacientes de causas externas selecionados para este estudo, 537 (30,15\%) foram internados no IC-HCFMUSP em decorrência de acidentes de transporte, 433 (24,32\%) por agressões e 307 (17,24\%) por quedas. O s três eventos foram as principais causas de internação dos pacientes de trauma deste estudo (71,71\%).

Entre os 537 pacientes de acidentes de transporte, observou-se um porcentual maior entre os de atropelamento (13,08\%), seguido de acidente automobilístico (10,95\%). No grupo de pacientes internados por agressões, mais de 50\% dos casos foram em virtude do uso de arma de fogo. Entre os pacientes internados por motivo de quedas, verificou-se que o evento queda de altura resultou em um maior número de internações, 159 (51,79\%) pacientes do total de 307.

Dos restantes 504 (28,29\%) pacientes internados, 218 (12,24\%) tinham sofrido exposição a forças mecânicas, notadamente, pelas denominadas "inanimadas", 202 (11,34\%). Nesse grupo verificou-se uma elevada freqüência, 119 pacientes, em razão de "penetração de corpo estranho no ou através de olho ou orifício natural", evento de código W44 na CID-10. Além do grupo de exposição a forças mecânicas, os demais pacientes foram internados em decorrência de causas externas assim agrupados: 74 pacientes $(4,15 \%)$ por eventos de intenção indeterminada, 67 (3,76\%) por exposição acidental a outros fatores e aos não especificados, 62 (3,48\%) por exposição ao fogo e às chamas ou contato com fonte de calor ou substâncias quentes, 34 (1,91\%) por envenenamento/ intoxicação acidental por exposição a substâncias nocivas, 27 (1,52\%) por lesões autoprovocadas voluntariamente, $20(1,12 \%)$ por exposição a corrente elétrica e $2(0,11 \%)$ por afogamento e submersão acidentais.

Nos dados das tabelas subseqüentes, os eventos de intenção indeterminada (Y10Y 34), exposição acidental a outros fatores e aos não especificados (X 58-X 59), exposição ao fogo e às chamas ou contato com fonte de calor ou substâncias quentes (X00-X19), envenenamento/ intoxicação acidental por exposição a substâncias nocivas (X 40-X49), lesões autoprovocadas voluntariamente (X60-X 84), exposição à corrente elétrica (W85W87), afogamento e submersão acidentais (W66-W74) foram agrupados e denominados de "outras causas". 
Os eventos que ocasionaram a internação dos pacientes estudados por CHAMPION et al. (1990) obtidos de 139 hospitais norte-americanos, foram os acidentes com veículo a motor, acidentes de motocicleta e atropelamento que somados alcançaram $49,1 \%$, seguidos daqueles que envolveram uso de arma de fogo e branca (19,5\%) e quedas (16,5\%). No estudo de YATES; WOODFORD; HOLLIS (1992) que analisaram 33 hospitais do Reino Unido, os principais eventos que produziram lesões e resultaram em internação de pacientes foram as quedas $(56,63 \%)$ seguidas de acidentes rodoviários $(27,29 \%)$.

De maneira geral, os eventos mais freqüentes verificados neste estudo são os mesmos observados na população norte-americana estudada por CHAMPIOM et al. (1990). Contudo, é importante ressaltar que tanto o estudo de CHAMPIOM et al. (1990) como o de YATES; WO O DFORD; HOLLIS (1992) excluem os eventos cujas lesões não constam do Manual AIS. O fato deve ser considerado quando se comparam os tipos de eventos observados no presente estudo com os citados anteriormente, tendo em vista que aqui todos e quaisquer tipos de causas externas que resultaram em internação foram incluídos e não somente aqueles que resultaram em lesões descritas no manual AIS.

Observando-se a parcela daqueles que sobreviveram ao evento e necessitaram de hospitalização, verificou-se que o tipo de causa externa com maior porcentual de pacientes internados, neste estudo, foi 0 acidente de transporte. 0 resultado difere da principal causa de óbito observada nas estatísticas de mortalidade das causas externas do Brasil. 0 tipo de causa com maior porcentual de óbitos, a partir da década de 90, é 0 homicídio (MELLO JORGE; LAURENT, 1997). 0 fato de os acidentes de transporte resultarem em maior porcentual de pacientes internados pode estar relacionado ao tipo e à gravidade das lesões que possibilitam à pessoa acometida sobreviver ao evento, diferente das causas que resultam em homicídio, que têm como pressuposto a intenção de provocar uma lesão fatal.

Observando-se o fenômeno "causas externas" sob óticas distintas, verifica-se que a distribuição de óbitos por tipos de causas externas nas estatísticas de mortalidade definiu um perfil diferente daquele que se observa nos internados em hospitais para 0 tratamento das conseqüências (as lesões e envenenamento) resultantes das causas 
externas. A mortalidade é o retrato de um fato consumado, as medidas necessárias para interromper essa cadeia de eventos devem estar voltadas, fundamentalmente, às ações preventivas, ou seja, prevenir para reduzir a ocorrência das causas básicas de mortalidade. Para a outra parcela, os sobreviventes que procuraram ou foram encaminhados aos hospitais, interromper a cadeia de acontecimentos patológicos significa instituir a cura (MELLO JORGE; LAURENT, 1997). Para tal medida, torna-se necessário conhecer a causa básica, a lesão propriamente dita e associá-la aos fatores circundantes como o tipo de causa externa e de trauma resultante, as condições e evolução do paciente, o momento da ocorrência do evento, a gravidade e a terapêutica.

A morbidade hospitalar por lesão e envenenamento decorrente de acidentes e violências no Brasil foi estudada, pela primeira vez, por LEBRÃO; MELLO JORGE; LAURENTI (1997) tendo como fonte de dados a Autorização de Internação Hospitalar (AIH). Os resultados desse estudo revelaram que, no ano de 1994, do total de 14.698 .988 internações no País, as decorrentes de lesões e envenenamentos foram responsáveis por 848.560 (5,8\%) internações (sétima colocada). Entretanto, pelas AIH não foi possível verificar os eventos que determinaram a internação da população estudada em razão da ausência desses dados. D esse modo, os autores apresentaram os resultados da assistência hospitalar prestada aos pacientes internados em decorrência de lesões e/ ou envenenamento, mas não puderam verificar sua causa, a base para implementar medidas preventivas e reduzir as ocorrências dos eventos e, conseqüentemente, reduzir o número de internações.

Desde 0 ano de 1998 no Brasil, as AIH referentes às internações decorrentes de causas externas devem indicar além do diagnóstico principal, ou seja, a natureza da lesão, a causa externa no diagnóstico secundário. Assim, o banco de dados do Sistema de Informações Hospitalares - Sistema Único de Saúde , tem permitido estudar a natureza da lesão e a causa externa que a determinou.

Existem eventos que ocorrem com maior freqüência em certos subgrupos da população. A identificação do padrão de ocorrência de um evento em grupos de alto risco ligados à pessoa ou a outros fatores facilita a instituição de medidas apropriadas. 
Para definir o perfil da população deste estudo, os fatores de risco da pessoa, idade e sexo foram relacionados aos eventos de causas externas que resultaram em internação hospitalar.

A distribuição dos pacientes internados por causas externas, conforme sexo e idade, pode ser vista na Figura 01. A média de idade foi 29,31 anos e variou de 1 mês a 89 anos com desvio-padrão de 17,86 anos, sendo para homens 29,49 anos e variou de 1 mês a 87 anos com desvio-padrão de 16,68 anos e para mulheres 29,31 anos que variou de 4 meses a 89 anos com desvio-padrão de 21,31 anos.

Figura 01 - Pacientes internados ( $\mathrm{N}=1.781)$, segundo sexo e idade, IC-HCFMUSP, 1998.

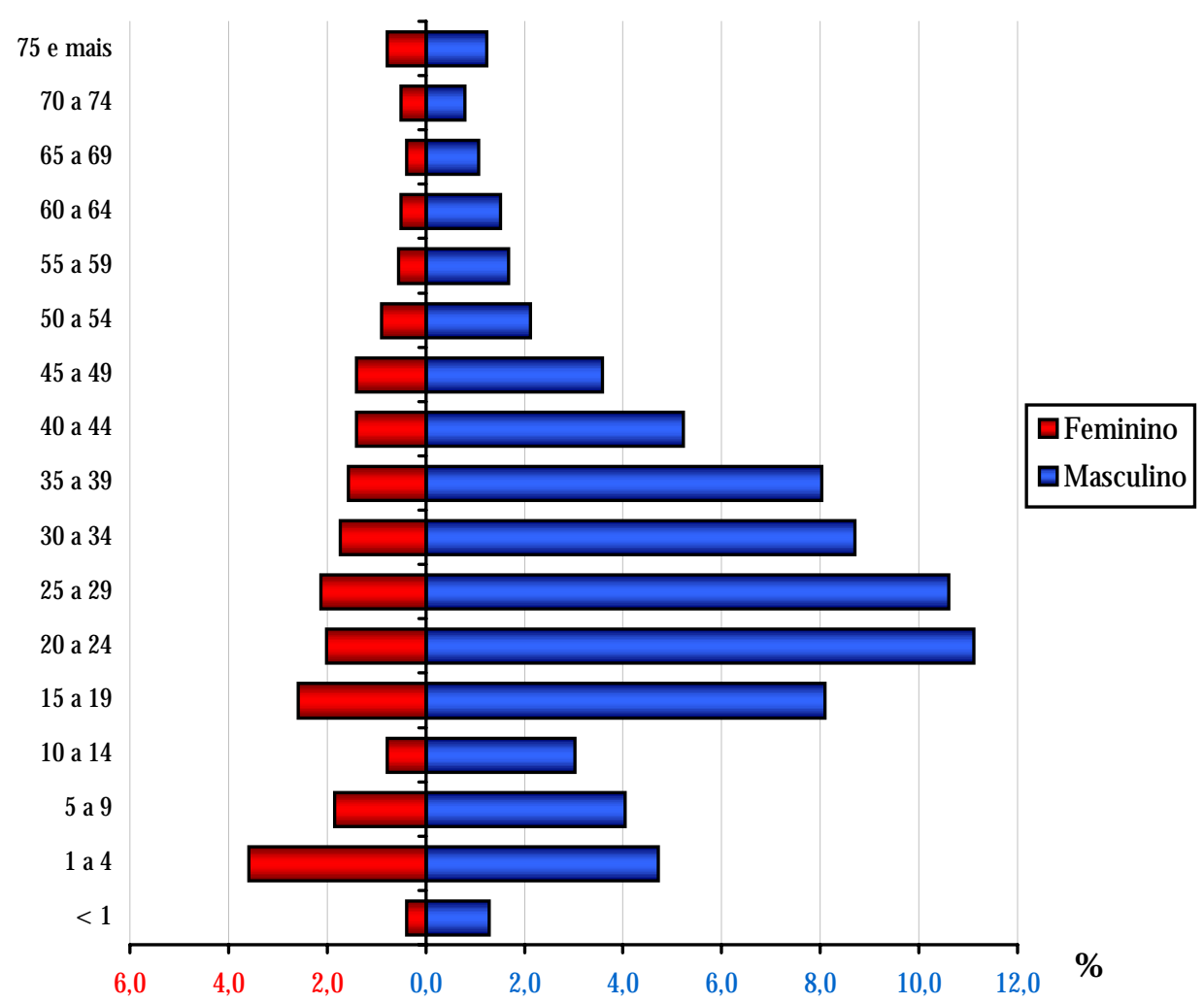

D o total de pacientes internados 1.369 (76,87\%) eram do sexo masculino, número três vezes maior que o verificado no sexo feminino, 412 (23,13\%). A maior concentração de pacientes (56,60\%) foi observada nas faixas etárias compreendidas entre 15 e 39 anos. 
A distribuição entre os pacientes do sexo masculino e feminino nas faixas etárias deu-se de forma diferente. Entre os pacientes do sexo masculino, os maiores percentuais foram observados entre 15 e 39 anos, destacando-se os da faixa etária entre 20 e 29 anos. Entre as mulheres o porcentual mais elevado foi verificado na faixa etária de um a quatro anos seguida da faixa etária entre 15 e 19 anos. Além disso, a proporção entre homens e mulheres nas faixas etárias entre 20 e 39 anos variou entre 4,9 a 5,5 :1. Nas faixas etárias dos extremos, entre um e nove e acima de 65 anos, a diferença da proporção entre homens e mulheres foi menor variando entre 1,3 a 2,7 :1.

Considerando-se o sexo e a idade dos pacientes de causas externas internados, observou-se que a maioria tratava-se de adolescentes e adultos jovens, sobretudo, do sexo masculino observando-se também a freqüência nas crianças de um a quatro anos de ambos sexos. Além disso, a partir de 70 anos notou-se elevação dos percentuais que declinaram progressivamente desde a faixa etária entre 25 e 29 anos em ambos os sexos.

Para observar a freqüência de pacientes conforme a idade em cada tipo de causa externa relacionada à internação hospitalar, consideraram-se os eventos com percentuais mais elevados verificados na Tabela 01, quais sejam os acidentes de transporte, as agressões e as quedas como se observa na Figura 02 (A-C). 
Figura $02(\mathrm{~A}-\mathrm{C})$ - Pacientes internados, segundo faixas etárias e tipo de causas externas, IC-HCFMUSP, 1998.

A - Acidentes de transporte $(\mathrm{n}=537)$

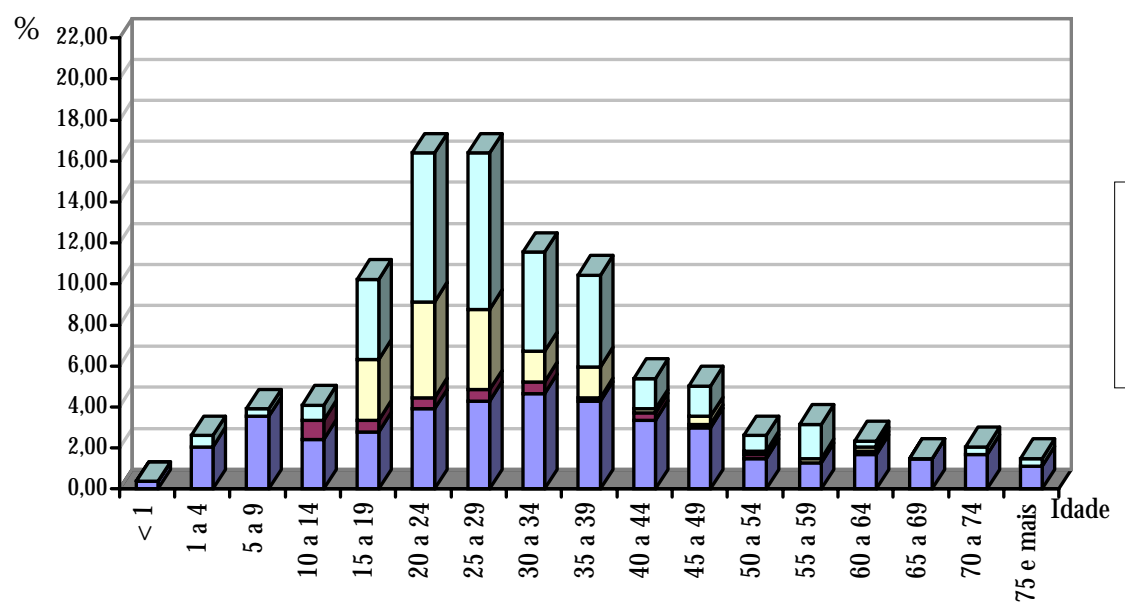

口Ac. Veículo a motor

口Ac. Moto

-Outros Ac. Transp.

口Atropelamento

B - Agressões $(n=433)$

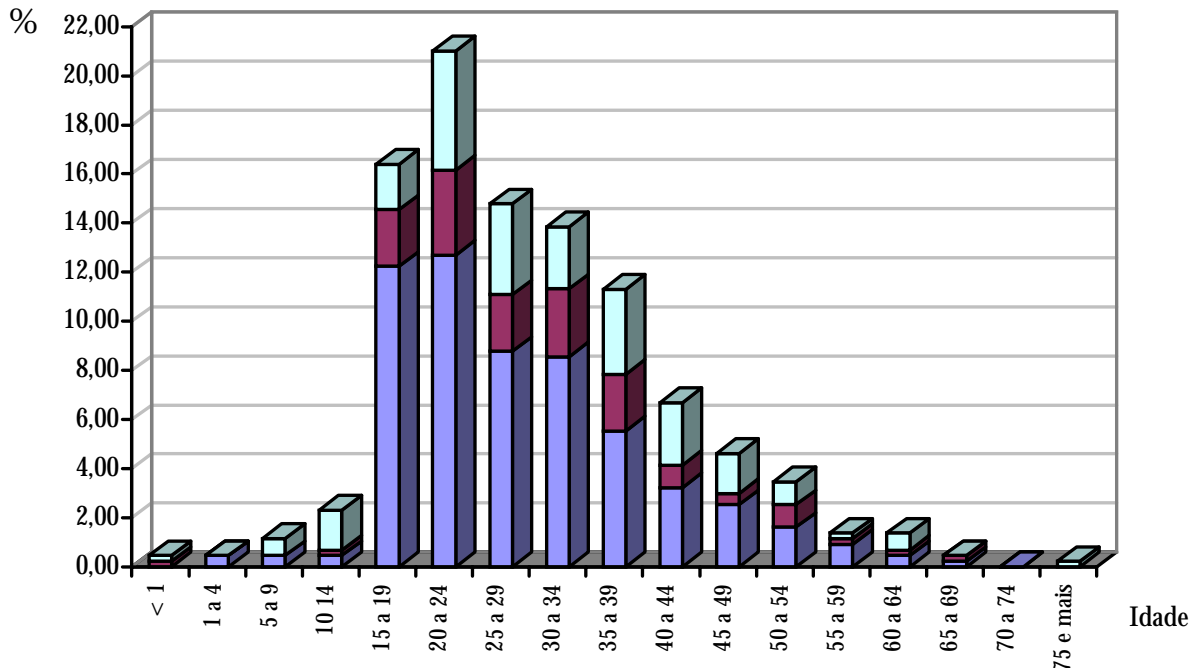

C - Quedas ( $\mathrm{n}=307)$

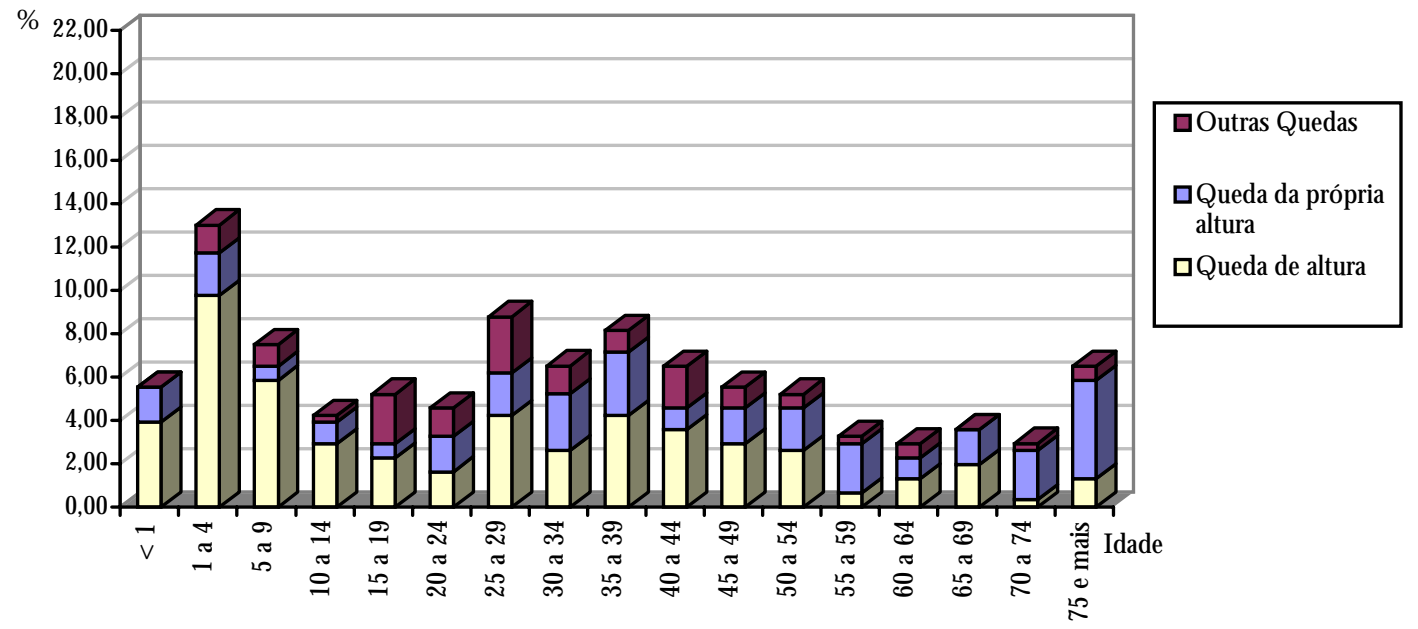

$\square \mathrm{FAB}$

$\square \mathrm{FAF}$ 
A distribuição de pacientes internados conforme tipo de causa externa e a idade foi diferente em cada evento.

No grupo de acidentes de transporte, (Figura 02-A) 0 atropelamento foi 0 evento que manteve freqüência de pacientes em todas as faixas etárias, destacando-se 0 porcentual mais elevado entre 30 e 34 anos. É importante ressaltar que nas idades abaixo de 14 e acima de 60 anos 0 atropelamento foi o evento mais freqüente.

No grupo de pacientes internados por acidente automobilístico, destacou-se a elevada concentração de pacientes, nas faixas etárias entre 15 e 39 anos, em relação aos demais eventos considerados no grupo de acidentes de transporte.

Os pacientes internados por acidente de motocicleta tinham entre 15 e 64 anos, com predomínio entre 20 e 29 anos.

Na Figura 02-B, observa-se uma abrupta elevação no número de pacientes internados por agressão, com destaque àqueles acometidos por arma de fogo, partindo da faixa etária de 15 a 19 anos até a faixa subseqüente, declinando progressivamente até a faixa etária entre 60 e 64 anos. Apesar do reduzido número, chama a atenção a existência de bebês e crianças internadas por agressão por meio de objeto cortante ou penetrante, por outros meios e também por arma de fogo.

Pelos dados da Figura 02-C, observou-se que o evento quedas foi responsável pelas internações de pacientes em todas as faixas etárias, com predomínio das quedas de altura na maioria das vezes. Entre os pacientes internados por motivo de queda de altura, destacam-se as crianças, de um a quatro anos e, em queda da própria altura, os pacientes acima de 75 anos.

Ao observar a freqüência de pacientes de acordo com as faixas etárias nos demais eventos, constatou-se que no grupo de exposição a forças mecânicas inanimadas a maior concentração ocorreu na faixa etária entre um e quatro anos. Tratava-se de eventos de código W44, referentes à penetração de corpo estranho no ou através de olho ou orifício natural, que foram freqüentes em crianças dessa idade, necessitando a realização de procedimentos como broncoscopia para retirada dos corpos estranhos. O utro evento que 
mostrou a concentração mais acentuada de pacientes na faixa etária entre 1 e 4 anos foi a exposição a fogo e chamas ou contato com fonte de calor ou substâncias quentes.

No estudo de morbidade hospitalar em causas externas no Brasil, LEBRÃO; MELLO JORGE; LAURENTI (1997) observaram que os pacientes eram, particularmente, adultos jovens do sexo masculino destacando-se aqueles da faixa etária entre 15 e 29 anos, pois a primeira causa de internação nesse grupo foi por lesões e envenenamentos.

As características demográficas da população do MTOS, também, reafirmaram 0 trauma como um agravo primariamente do sexo masculino, na relação de três homens para uma mulher, de maior incidência em jovens e adultos jovens (média da idade 32,4 anos), decorrentes de acidentes com veículo a motor, acidentes de motocicleta e atropelamento, eventos que envolvem o uso de arma de fogo e branca e quedas (CHAMPION et al., 1990).

A descrição da casuística de atendimento prestado a acidentados de trânsito no Hospital Municipal de Porto Alegre em 1988, apresentada por OTT et al. (1993), mostrou que entre os pacientes internados (1.470), os maiores percentuais foram observados nas idades entre 20 e 39 anos (43,3\%) com predominância do sexo masculino (73,4\%). Os acidentes por atropelamento apresentaram maior magnitude (57\%) entre os pacientes internados alcançando os maiores percentuais em todas as faixas etárias, especialmente, as abaixo de 19 anos e acima de 50 anos.

Pessoas que sofreram acidentes de trânsito de veículo a motor e foram internadas no IC (mesmo hospital deste estudo) e no IOT do HCFMUSP, nos meses de janeiro e fevereiro de 1995, foram analisadas por CALIL (1995). A autora também verificou 0 elevado porcentual de pacientes internados que sofreram acidente de trânsito, com predomínio do sexo masculino (85\%), na qualidade de pedestre $(50,46 \%)$, seguida de ocupante de auto $(37,73 \%)$ e ocupante de moto (11,81\%). A faixa etária com o maior porcentual de pacientes foi 20 a 29 anos (31,82\%), chamando atenção às idades abaixo de dez anos e acima de 60 anos em razão da ocorrência mais freqüente de acidente de trânsito na condição de pedestre. 
AND RADE (1998) ao analisar 3.643 vítimas de acidentes de transporte terrestre ocorridos em Londrina (PR) no ano de 1996, verificou que se tratavam de vítimas jovens, sobretudo, do sexo masculino $(74,5 \%)$ nas faixas etárias entre 15 e 24 anos. Porém, observou diferenças importantes no perfil das vítimas quanto ao sexo e idade, quando observadas de acordo com a sua qualidade no acidente. Na qualidade de pedestre, verificaram-se proporções maiores entre 1 e 14 anos e entre 30 e 49 anos com distribuição mais equilibradas quanto ao sexo. Nos ocupantes de carro, camionete e motociclista os percentuais mais elevados foram encontrados entre 15 e 39 anos, entretanto a distribuição entre os sexos foi equilibrada para ocupantes de carro, camionete, mas diferente nos motociclistas observando-se preponderância masculina.

No estudo de KOIZUMI (1985 a,b) sobre acidentes de motocicleta no município de São Paulo que analisou 4.480 vítimas, foi verificado o predomínio de vítimas do sexo masculino(79,99\%) e a ocorrência freqüente (52,77\%) em jovens (15 a 24 anos), como observou ANDRADE (1998).

Vários estudos realizados no Brasil e no exterior levam à constatação de um perfil de padrão mundial das vítimas de acidentes de transporte que foi também observado neste estudo (HARRUFF; AVERY; ALTER-PANDYA, 1998; SCALASSARA; SOUZA; SOARES, 1998; AND RADE, 1998; VASCONCELLOS, 1999).

Os pacientes internados em razão de agravos resultantes de agressões, especialmente, por meio de arma de fogo na faixa etária entre 15 e 24 anos, constituem-se partes do que se observa nas taxas de mortalidade por causas externas nessas faixas etárias. Dados sobre morbidade hospitalar decorrentes de agressão são escassos, dificultando a comparação desses resultados.

CHAVES et al. (1987) estudaram 812 vítimas de agressões físicas internadas no PS do IC-HCFMUSP no ano de 1984. Verificaram que houve predomínio do sexo masculino (92,3\%), com maior freqüência de vítimas entre 16 e 45 anos (59,8\%). A agressão por meio da arma de fogo foi a forma mais freqüente $(64,5 \%)$ seguida da arma branca $(58,6 \%)$.

Dentre as 1.192 vítimas atendidas em prontos-socorros da Região Sul do município de São Paulo em razão de colisão de veículos, atropelamento, ferimento por 
arma de fogo e arma branca, nos meses de dezembro/ 1990 e janeiro/ 1991, houve predomínio do sexo masculino (75\%). A relação entre homens e mulheres foi 8,25:1 no grupo de ferimento por arma de fogo (WHITAKER; VIANNA, 1991).

A evolução crescente do homicídio no Brasil e em outros países da América nos últimos anos de forma alarmante em jovens adultos fez dessa causa a primeira, entre todas as demais causas externas, responsável pelas mortes de pessoas entre 20 e 29 anos do sexo masculino(YUNES; RAJ 1994; SOUZA 1994; MELLO JORGE; GAWRYSZEWSK I; LATORRE, 1997; OPAS/ OMS, 1998).

As quedas são causas freqüentes de lesões que resultam em hospitalização, podem ocasionar incapacidade física permanente e também produzir lesões de intensidade leve, em muitos países, tratam-se da principal causa de lesão em domicílio. Além disso, idade e sexo são fatores de risco pessoal significantes. Entre os idosos de ambos os sexos, queda é uma causa importante de morbidade, incapacidade e óbito, provavelmente pela influência de certos fatores de risco que desenvolvem com a idade como redução da visão e audição, mobilidade, reflexos e maior fragilidade da estrutura óssea (BARSS et al., 1998).

Em razão do crescente número de pessoas idosas e sua vulnerabilidade aos eventos traumáticos, é importante observar os tipos de causas externas que determinaram a internação de pacientes com idade acima de 65 anos. Neste estudo, a queda da própria altura (26 casos) foi o evento mais freqüente seguido de atropelamento (23 casos), entre os 85 pacientes internados com idade acima de 65 anos, observando-se que a proporção entre homens e mulheres foi mais baixa em relação à observada na média (Figura 01).

Do total de 1.906 pacientes com idade acima de 55 anos, internados em decorrência de quedas e estudados por HANNAN et al. (1995a), 70\% eram mulheres e tendendo para mais idade, pois em idades acima de 85 anos a frequêencia de mulheres foi $36 \%$, enquanto a de homens foi $19 \%$. Verificaram ainda que a sobrevida em homens foi mais baixa, salientando que as condições preexistentes ao evento traumático e sexo estão relacionadas à mortalidade decorrente de quedas em pessoas acima de 55 anos. Além disso observaram que as insuficiências cardiopulmonares foram as doenças de maior influência na mortalidade do grupo estudado. 
HELLING et al. (1999) estudaram 176 pacientes internados em razão de quedas de altura abaixo de seis metros. Verificaram que esse evento foi mais freqüente em jovens, $63 \%<60$ anos, mas entre os pacientes que evoluíram com óbito $(8 \%)$ metade tinha idade acima de 60 anos, ressaltando que a co-morbidade influenciou na mortalidade desses pacientes.

CHAMPION et al. (1989b) estudaram 3.833 pacientes com idade acima de 65 anos e verificaram que a causa mais freqüente foi a queda, seguida de acidente com veículo a motor e agressão com arma de fogo. Observaram também que, embora a queda tivesse sido a causa mais freqüente de trauma em pessoas acima de 65 anos, independente do sexo, a mortalidade desse evento foi inferior se comparada aos acidentes de veículo a motor e atropelamentos.

A morbidade decorrente de queda foi estudada por MOSENTHAL et al. (1995) em 356 pacientes internados em centro de trauma. A população de estudo constituiu-se de pacientes de todas as faixas etárias, observando-se percentuais elevados em idades inferiores a quatro anos e entre 25 e 39 anos. As quedas em adultos do sexo masculino estavam relacionadas a atividades ocupacionais (acidentes em construções) e não ocupacionais (desempregados), com níveis elevados de álcool e toxicológico positivo para cocaína, narcóticos, benzodiazepínicos e maconha. As quedas em idosos não alcançaram percentuais tão elevados como em adultos jovens e crianças, mas relacionaram-se a quedas ocorridas no domicílio, de pequena altura, durante as atividades de vida diária e foram responsáveis por 50\% dos óbitos da população estudada. Nas crianças, o evento esteve associado aos fatores de risco ambientais como janelas ou escadas (50\%) e resultou em baixa mortalidade (2\%).

No município de São Paulo em 1998, período considerado neste estudo, conforme os dados Programa de Aprimoramento das Informações de Mortalidade no Município de São Paulo (PROAIM) as causas externas ocuparam a terceira posição $(13,7 \%)$ na classificação geral dos grupos das causas de mortalidade, superadas pelas doenças do aparelho circulatório (33,5\%) e neoplasias (16,4\%). Entre os principais tipos de causas externas, chama a atenção a violência como principal causa de morte nesse grupo que alcançou o porcentual assustador de $60 \%$ atingindo todas as faixas etárias com 
predomínio entre adolescentes e adultos jovens. Nas idades abaixo de dez anos e acima de 50 anos, prevaleceram as mortes acidentais, sendo para os menores de cinco anos a sufocação, entre cinco e nove anos e entre 60 e 69 anos os acidentes de trânsito e as quedas em idades acima de 70 anos. Nesse ano, dentre os eventos considerados em acidentes de trânsito, os atropelamentos alcançaram o maior porcentual de mortos (59,8\%) (SÃO PAULO, 1999).

Nos resultados apresentados por GAWRYSZEWSKI (1995) sobre a mortalidade por causas externas no município de São Paulo em 1991 verificou-se que a mortalidade foi 15,\% do total de óbitos de residentes, ocupando o segundo lugar dentre todas as causas. Os homicídios concentraram o maior porcentual de mortos (48,3\%) e os acidentes de trânsito foram responsáveis por 22,9\%. A faixa etária com o maior número de mortes foi a de 15 a 39 anos e a razão entre os coeficientes masculino/ feminino foi 6,4 , variando conforme a idade e tipo de violência.

A elevada ocorrência de eventos que, potencialmente, produzem lesões que demandam atenção médica, contribui na sobrecarga dos prontos-socorros dos hospitais públicos na cidade de São Paulo.

O IC-HCFMUSP por ser um hospital público, de ensino, de nível terciário e de referência para trauma faz com que a procura por seus recursos especializados seja intensa, tanto por outros serviços de saúde quanto pela população de maneira geral.

Pelos dados da Tabela 02, pode-se ver de onde os pacientes vieram. Eles foram agrupados de acordo com sua procedência em direto da cena, quando o paciente veio diretamente do local do evento ao IC; outro hospital, quando o paciente veio transferido de outro hospital para o IC; residência, quando veio da residência; e sem registro, quando não havia registro sobre sua procedência no prontuário do paciente. 
Tabela 02 - Pacientes internados, segundo tipos de causas externas e procedência, IC-HCFMUSP,1998.

\begin{tabular}{lccccccccccc}
\hline & \multicolumn{10}{c}{ PROCED ÊNCIA } \\
\cline { 2 - 12 } & \multicolumn{1}{c}{ Direto da cena } & Outro hospital & \multicolumn{2}{c}{ Residência } & \multicolumn{2}{c}{ Sem registro } & \multicolumn{2}{c}{ Total } \\
CAUSA & $\mathrm{N}$ & $\%$ & $\mathrm{~N}$ & $\%$ & $\mathrm{~N}$ & $\%$ & $\mathrm{~N}$ & $\%$ & $\mathrm{~N}$ & $\%$ \\
EXTERNA & & & & & & & & & & \\
\hline $\begin{array}{l}\text { Acidente de } \\
\text { transporte }\end{array}$ & 348 & 19,54 & 142 & 7,97 & 29 & 1,63 & 18 & 1,01 & 537 & 30,15 \\
Agressões & 209 & 11,74 & 181 & 10,16 & 21 & 1,18 & 22 & 1,24 & 433 & 24,32 \\
Quedas & 103 & 5,78 & 123 & 6,91 & 56 & 3,14 & 25 & 1,40 & 307 & 17,24 \\
$\begin{array}{l}\text { Exposição a forças } \\
\text { mecânicas animada/ } \\
\text { inanimada }\end{array}$ & 25 & 1,40 & 135 & 7,58 & 44 & 2,47 & 14 & 0,79 & 218 & 12,24 \\
Outras causas & 87 & 4,88 & 115 & 6,46 & 60 & 3,37 & 24 & 1,34 & 286 & 16,05 \\
\hline Total & 772 & 43,34 & 696 & 39,08 & 210 & 11,79 & 103 & 5,79 & 1781 & 100,00 \\
\hline
\end{tabular}

Entre os pacientes internados no ICHCFMUSP em decorrência de trauma, 772 (43,34\%) eram provenientes do local de ocorrência do evento, 696 (39,08\%) foram transferidos de outros hospitais, 210 (11,79\%) provenientes da residência e 103 (5,79\%) não possuíam registro quanto à procedência do paciente. Tratando-se de um hospital terciário e de referência para trauma, espera-se que os percentuais de pacientes vindos diretamente do local do evento e dos transferidos fossem elevados.

D os $772(43,34 \%)$ pacientes provenientes do local do evento, 557 (31,28\%) eram de acidentes de transporte e agressões.

Entre os pacientes transferidos ou provenientes de outros hospitais, houve diversificação, mas os percentuais mais elevados também foram aqueles de acidentes de transporte $(7,97 \%)$ e agressões $(10,16 \%)$, seguidos daqueles por exposição a forças mecânicas animadas e inanimadas (7,58\%) e quedas (6,91\%).

Os maiores percentuais entre os pacientes internados provenientes da residência foram do grupo de outras causas (3,37\%) e de quedas (3,14\%). No grupo outras causas, composto por vários tipos de eventos, a razão da relação entre a causa e a origem do 
paciente foi dificultada, mas deve-se lembrar que esse grupo inclui a causa exposição ao fogo e chamas, evento cuja maior freqüência foi verificada entre as crianças e que, provavelmente, ocorreu em suas casas. Quanto às quedas, é importante salientar que se trata de um evento de ocorrência freqüente em domicílio envolvendo crianças e pessoas idosas.

COPES et al. (1995) verificaram que entre os 21.175 pacientes admitidos em Centros de Trauma na Pensilvania, 74,0\% eram provenientes do local do evento, 24,3\% eram transferidos e 1,6\% eram de origem desconhecida.

BAZZOLI et al. (1995) analisaram as respostas dos administradores e diretores de 37 sistemas de trauma estaduais e regionais dos Estados Unidos da América, obtidas por meio de questionários, com a finalidade de examinar as condições de desenvolvimento e funcionamento desses sistemas, segundo suas características estruturais e operacionais. Um dos componentes chaves dos sistemas de trauma analisados pelos autores foi a transferência inter-hospitalar. Consideraram que mesmo nos locais com um sistema de trauma bem estabelecido o processo ocorrerá. Os hospitais que não são centros de trauma podem receber pacientes traumatizados graves em razão de erros de aplicação do protocolo de triagem ou deterioração das condições do paciente que impedem um transporte mais prolongado. Assim, cada sistema de trauma deve estabelecer os critérios para realização das transferências de pacientes entre hospitais e centros de trauma, alertando que a demora na implementação desses critérios pode reduzir os benefícios que um paciente gravemente traumatizado pode usufruir dos recursos disponíveis em um sistema de trauma.

Os resultados de 4.364 pacientes graves que foram encaminhados diretamente do local do evento para um centro de trauma (63\%) e comparados, por SAMPALIS et al. (1997),com aqueles que receberam atendimento inicial em um hospital não especializado (37\%), antes de serem transferidos para um centro de trauma. A mortalidade do grupo transportado direto para o centro de trauma foi inferior $(4,8 \%)$ ao verificado no grupo dos transferidos (8,9\%). A média do tempo de permanência no hospital foi maior entre os transferidos (16 dias ) em relação aos que foram diretos a um centro de trauma (13 dias). Os autores concluíram que o transporte de pacientes graves do local do evento ao centro 
de trauma está associado à redução da morbi-mortalidade em trauma. Além disso, apontaram dois possíveis fatores que influenciam o resultado dos pacientes transferidos, a demora para à instituição da assistência definitiva e os efeitos adversos da transferência.

CAMERON et al. (1995), quando apresentaram o porcentual de pacientes transferidos para Centros de Trauma em Vitória na Austrália (24,5\% do total de 2.944) chamaram a atenção para a existência de 19 pacientes que foram transferidos, mais de uma vez antes de chegarem ao hospital definitivo.

O estudo de SANTOS (1989) sobre lesão traumática de medula espinhal em 428 pacientes que foram internados no IOT-HCFMUSP entre 1982 e 1987 revelou que $63,2 \%$ dos pacientes chegaram ao hospital dentro das primeiras 24 horas após o evento traumático, entretanto 83,2\% tinham sido atendidos em pelo menos um hospital antes de chegarem ao IOT. Tratando-se de tipos de pacientes que necessitam de assistência especializada, a locomoção de um hospital a outro até conseguir a assistência definitiva pode prejudicar o paciente. $\mathrm{Na}$ época da internação desses pacientes não existiam serviços de atendimento pré-hospitalar na cidade de São Paulo e a regionalização e a hierarquização dos hospitais não eram bem sistematizadas. Dessa forma as transferências de pacientes eram práticas muito freqüentes e, possivelmente, descoordenadas.

Atualmente, os serviços de atendimento pré-hospitalar na cidade de São Paulo são um meio de encaminhar pacientes para assistência definitiva respeitando a regionalização e a hierarquização dos hospitais em casos de ocorrência de eventos traumáticos, mas para uma grande parcela de pessoas que se dirigem ou são encaminhadas aleatoriamente aos serviços de emergência, as transferências para hospitais de referência ou especializados ainda permanecem freqüentes.

0 meio de transporte utilizado para encaminhar o paciente ao IC-HCFMUSP relacionou-se, sobretudo, com a procedência do paciente (Tabela 03 ). 
Tabela 03 - Pacientes internados, segundo a procedência e meio de transporte utilizado para chegar ao hospital, IC-HCFMUSP,1998.

\begin{tabular}{lcccccc}
\hline & \multicolumn{5}{c}{ PROCED ENNCIA } \\
\cline { 2 - 7 } & \multicolumn{2}{c}{ Direto da cena } & \multicolumn{2}{c}{ Outros } & \multicolumn{2}{c}{ Total } \\
MEIO DE & $\mathrm{N}$ & $\%$ & $\mathrm{~N}$ & $\%$ & $\mathrm{~N}$ & $\%$ \\
TRANSPO RTE & & & & & & \\
\hline Ambulância do local de & - & - & 676 & 67,00 & 676 & 37,96 \\
origem & & & & & & \\
Sem registro & 90 & 11,66 & 298 & 29,53 & 388 & 21,79 \\
UR & 359 & 46,49 & 1 & 0,10 & 360 & 20,20 \\
Polícia Militar & 176 & 22,80 & 7 & 0,69 & 183 & 10,28 \\
Águia & 72 & 9,33 & 8 & 0,79 & 80 & 4,49 \\
Veículo particular & 31 & 4,02 & 14 & 1,39 & 45 & 2,53 \\
USA & 33 & 4,27 & 1 & 0,10 & 34 & 1,91 \\
Resgate municipal & 5 & 0,65 & - & - & 5 & 0,28 \\
Outros & 6 & 0,78 & 4 & 0,40 & 10 & 0,56 \\
\hline Total & 772 & 100,00 & 1009 & 100,00 & 1781 & 100,00 \\
\hline
\end{tabular}

Os dados da Tabela 03, em relação à procedência dos pacientes, considerou-se 0 grupo direto da cena quando o paciente veio diretamente do local do evento, em outros foram incluídos os pacientes que vieram transferidos de outro hospital, de sua residência e os sem registro.

D o total de pacientes, 772 (43,34\%) vieram diretos da cena do evento. Entretanto, certamente esse porcentual está subestimado, considerando que alguns eventos ocorreram em domicílios e os pacientes foram trazidos por familiares, amigos, vizinhos ou outras pessoas e registrados no prontuário como procedentes da residência.

Os dados da Tabela 03 demonstram que do total de pacientes provenientes diretos da cena do evento, 60,09\% foram encaminhados pelas unidades do SAMU-SP. Tendo em vista a importância do atendimento adequado e precoce instituído desde o local do evento e observando-se a existência de dois serviços de resgate no município de São Paulo (descritos anteriormente), pode-se considerar que $60,74 \%$ destes pacientes receberam 
assistência na fase pré-hospitalar e foram transportados em veículos próprios para esse fim, especialmente, pela Unidade básica de Resgate (UR) (46,49\%) .

O segundo recurso mais utilizado para transportar os pacientes do local do evento foi o veículo da polícia militar. Nesse recurso, 176 (22,80\%) pacientes foram transferidos em veículos utilizados para outros fins que não o resgate de vítimas e por profissionais que não são treinados para tal.

Considerando-se os meios de transportes, verificou-se o predomínio de pacientes que foram transportados com a ambulância do hospital onde foi feito 0 atendimento inicial, ou seja, vieram transferidos de outro hospitais, totalizando 676 (37,96\%). Ainda, observou-se que $388(21,79 \%)$ pacientes não possuíam registro sobre o meio de transporte que foi utilizado para chegar ao hospital. A maioria também não era proveniente do local do evento.

No estudo de CAMERON et al. (1995) que analisa 2.944 pacientes atendidos em 25 hospitais de uma região da Austrália, o meio de transporte mais freqüente de pacientes do local do evento até o hospital foram as ambulâncias de suporte básico de vida (56\%), seguido de veículo particular (19\%), ambulância de suporte avançado (15\%) e helicóptero (9\%). A unidade de suporte básico de vida também foi o meio de transporte mais utilizado (63,61\%) aos transportes inter-hospitalares, seguido do helicóptero (16,39\%).

Neste estudo, o principal meio empregado para transporte inter-hospitalar foi a ambulância dos hospital de origem. As UR, USA e Águia transportaram 10 pacientes com esse fim, tendo em vista que a finalidade primordial dessas unidades é 0 atendimento préhospitalar em nosso meio.

Com base nas fichas de atendimento pré-hospitalar das USA do SAMU-SP no ano de 1995 verificou-se que, 1286 vítimas foram atendidas. A maioria delas (60,9\%) necessitaram de atendimento em razão de acidente de trânsito (WHITAKER et al., 1997)

Para verificar o tempo gasto desde 0 momento da ocorrência do evento até a chegada ao PS, calculou-se o intervalo de tempo dos pacientes que foram trazidos diretos do local do evento pelo SAMU-SP (Figura 03). 
Figura 03 - Pacientes internados $(\mathrm{n}=409)$, segundo intervalo de tempo entre a solicitação do SAMU-SP até a chegada no PS, IC-HCFMUSP, 1998.

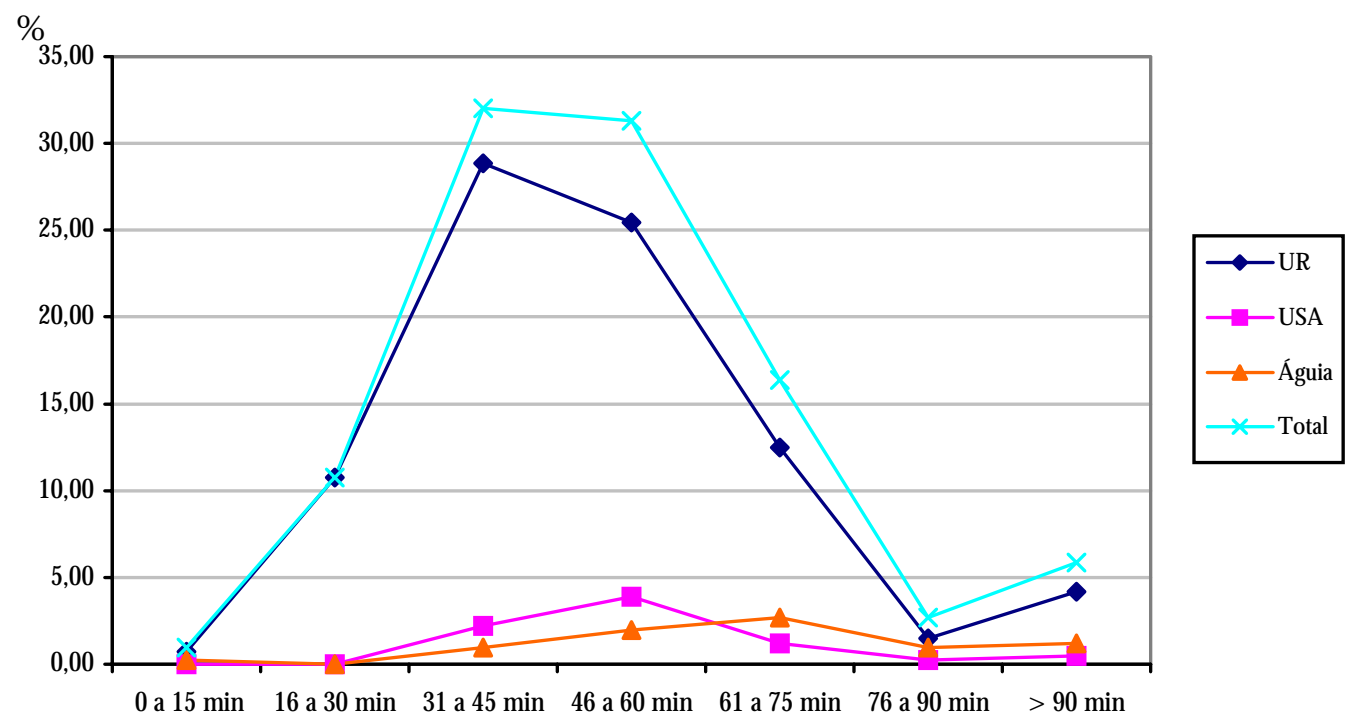

0 intervalo de tempo medido refere-se ao tempo total, desde o momento da chamada do serviço 193 até a entrada do paciente no PS. É importante ressaltar que a primeira unidade designada para deslocar-se até o evento é a UR, cabendo ao médico decidir a necessidade de acionar a USA terrestre ou aérea (Águia) (FERREIRA, 1999; SÃO PAULO, s.d.). Portanto, para analisar os resultados apresentados deve-se considerar que o tempo medido não se relaciona ao tempo isolado de cada tipo de unidade móvel no local, mas o tempo utilizado como um todo na fase pré-hospitalar para encaminhar 0 paciente ao IC-HCFMUSP.

Do total de 464 pacientes, que foram atendidos na fase pré-hospitalar pelo Sistema 193, foi possível recuperar o tempo total do atendimento pré-hospitalar de 409 (88,15\%) pacientes.

Os percentuais mais elevados foram verificados nos intervalos de 31 a $45 \mathrm{~min}$ (32,03\%) e 46 a 60 min (31,30\%) referentes a UR e USA, respectivamente (Figura 03).

A média geral do tempo, entre a solicitação do serviço 193 até a entrada do paciente no PS foi $49 \mathrm{~min}$, variando entre 12min a 2h43. Levando-se em consideração a unidade móvel que transportou o paciente, verificaram-se médias diferentes de tempo, 
sendo a da UR 48 min, variando entre 13min a 2h43, da USA 53 min, variando entre $31 \mathrm{~min}$ a $1 \mathrm{~h} 30$ e do Águia 1h02, variando entre 12min a $1 \mathrm{~h} 34$.

O tempo do atendimento pré-hospitalar das UR do SAMU-SP no ano de 1991, verificado por WHITAKER (1993) foi inferior ao observado neste estudo. Naquele ano, a maioria (81,31\%) das vítimas foi atendida em um intervalo de tempo entre 1 e 40 minutos e o tempo médio de atendimento das UR foi 30 minutos, tempo ideal e 0 recomendado pelo "Committee on Trauma of American College of Surgeons" em áreas urbanas (ACS, 1986).

Comparando-se o tempo de atendimento pré-hospitalar do SAMU-SP, após sete anos de funcionamento no município de São Paulo, verificou-se que, somente, 11,74\% dos pacientes foram atendidos dentro do intervalo de 30 minutos.

Segundo FERREIRA (1999), em seu estudo sobre a implantação e o desenvolvimento do Sistema Resgate de assistência pré-hospitalar às emergências no Município de São Paulo, o número de ocorrências de resgate atendidas pelo sistema no ano de 1998, ano referência deste estudo foi 42.398 observando-se um aumento constante de mais de $20 \%$ ao ano, nos últimos cinco anos. Esse crescimento vertiginoso dos atendimentos de resgate por esse sistema é um sinal nítido do quantitativo de ocorrências de emergências no Município de São Paulo e da credibilidade da população nesse serviço, uma vez que o sistema é acionado por ela.

Embora da mensuração do tempo de atendimento tenha sido em pacientes de um único hospital, a diferença observada neste estudo pode ser o reflexo da demanda, do intenso tráfego de veículos por toda a cidade de São Paulo e do protocolo de atendimento do paciente no local do evento.

Com o objetivo de identificar os focos prioritários de atenção para melhoria do sistema de atendimento ao trauma de uma cidade mexicana, ARREOLA-RISA et al. (1995) compararam os resultados desse sistema com os de uma cidade norte-americana, em 545 e 533 pacientes, respectivamente. Verificaram que a mortalidade foi mais elevada no sistema mexicano com preponderância da ocorrência de óbito na fase préhospitalar (40\%) e na sala de emergência (11\%) em relação ao norte-americano, 21\% e $6 \%$, respectivamente. 0 tempo de atendimento pré-hospitalar também foi diferente entre 
os sistemas. No mexicano $47 \%$ dos pacientes foram encaminhados ao hospital em tempo inferior a 30 minutos, enquanto no norte-americano o porcentual foi 75\% . Em relação a alguns procedimentos realizados no atendimento pré-hospitalar, observaram que no sistema norte-americano a execução de entubação endotraqueal e reposição volêmica em pacientes hipotensos foi mais freqüente. Os autores concluíram que os fatores tempo de atendimento pré-hospitalar e medidas de reanimação na fase pré-hospitalar e na sala de emergência determinaram as diferenças observadas entre os dois sistemas, ressaltando que os pontos prioritários de atenção para melhoria dos resultados no sistema mexicano devem ser dirigidos ao componente pré-hospitalar e sala de emergência.

McDERMOTT et al. (1996) verificaram o tempo de atendimento pré-hospitalar em 137 casos fatais de acidente rodoviário na Austrália e observaram que 25\% chegaram em até 30 minutos, $48 \%$ entre 30 e 60 minutos, 15\% entre 1 e 2 horas e os demais depois de 2 horas do evento.

A recomendação do "Committee on Trauma of American College of Surgeons" (ACS, 1999) para o atendimento pré-hospitalar consiste na avaliação do paciente, extricação, medidas iniciais de reanimação e transporte rápido ao hospital mais adequado e próximo. Sobre as medidas iniciais de reanimação, esclarece que estão limitadas ao estabelecimento de via aérea pérvia e ventilação, controle da hemorragia, imobilização da coluna e das fraturas. 0 tempo de atendimento no local do evento não deve ser prolongado em decorrência da realização de um acesso venoso, tendo em vista que 0 objetivo do atendimento pré-hospitalar é reduzir as conseqüências do trauma por meio de um transporte rápido e seguro do paciente que deve ser levado, diretamente, a um hospital equipado mais apropriadamente para seu caso, obedecendo à regionalização e à hierarquização das instituições de saúde. Os encaminhamentos devem estar claramente definidos e precisam ser determinados pelas guias de orientação, protocolos de triagem e/ ou direção médica.

Vários fatores podem interferir no prognóstico dos pacientes que foram encaminhados ou que recorreram ao hospital para tratamento dos agravos decorrentes dos eventos de causas externas. No que se refere ao sistema de trauma, é importante garantir o pronto acesso ao paciente que resulte em rápida definição diagnóstica e a 
realização da assistência definitiva dentro do prazo considerado ideal, 60 minutos (ACS, 1986).

Figura 04 - Pacientes internados ( $N=1.781)$, segundo a condição de saída do hospital, IC-HCFMUSP, 1998.
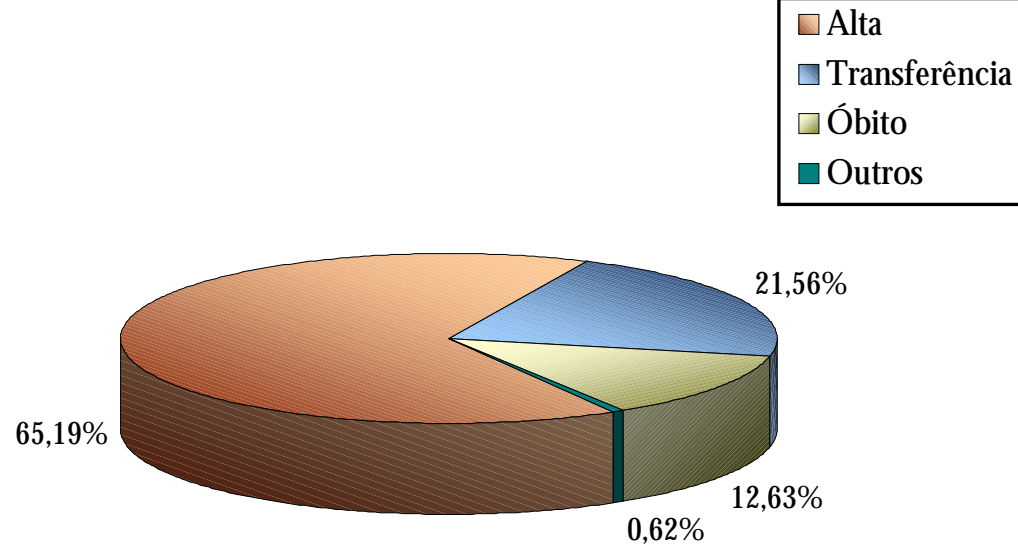

D o total de pacientes internados, 65,19\% tiveram alta hospitalar, 21,56\% foram transferidos e 12,63\% morreram (Figura 04). Como já mencionado, a categoria outros tipos de saída referiram-se a alta a pedido e evasão do hospital.

A taxa de mortalidade hospitalar por lesões e envenenamentos verificada por LEBRÃO; MELLO JORGE; LAURENTI (1997) que analisaram AIH no Brasil, foram 2,2\% óbitos por 100 internações, colocando-se em décimo posto, quando comparadas a outras causas, cujas maiores taxas corresponderam às afecções originadas no período perinatal $(6,6 \%)$ e doenças do aparelho circulatório (6,2\%). Os autores consideraram ainda, com alguma cautela, que a taxa de mortalidade hospitalar verificada para as causas externas não foi excessiva.

D ALOSSI (1993) ao analisar 100 pacientes internados por acidentes de trânsito, quedas, tentativa de homicídio e suicídio em um Hospital de referência para trauma do município de São Paulo, verificou que a mortalidade foi $12 \%$. 
Os dados de CALIL (1997) referentes a 220 pacientes internados no ICHCFMUSP em decorrência de acidente de trânsito mostraram um porcentual de mortalidade de $20,45 \%$.

Os percentuais de óbitos apresentados em vários estudos, cuja população ou amostra foi constituída de pacientes internados por causas externas ou um tipo específico de evento, variam conforme os seus critérios de inclusão, o que dificultou a comparação do resultado deste estudo com outros (CHAMPION et al., 1990b; YATES; WOODFORD; HOLLIS, 1992)

Para analisar o tempo de permanência no hospital, os pacientes foram agrupados em óbitos e sobreviventes englobando aqueles que receberam alta, transferência ou outros. Foi possível calcular o tempo de permanência para 1.553 pacientes que possuíam os dados completos quanto à data de admissão e saída e respectivos horários. D o total de pacientes deste estudo, 228 sobreviventes não possuíam os dados completos para processar esse cálculo.

A média geral do tempo de permanência no hospital, neste estudo, foi seis dias variando entre zero e 157 dias com desvio-padrão de 13 dias. A média dos sobreviventes foi seis dias variando entre 1 hora e 157 dias com desvio-padrão de 13 dias e dos óbitos foi quatro dias variando entre zero e 61 dias com desvio-padrão de dez dias. A média geral do tempo de permanência verificada neste estudo é próxima a obtida por Lebrão et al. (1997) que estudaram a morbidade por causas externas em nosso meio.

As médias de permanência verificadas por LEBRÃO; MELLO JORGE; LAURENTI (1997) pelas AIH referentes às lesões e envenenamentos em 1994 no Brasil, foram cinco dias. Consideradas pelos autores bastante próximas da média geral do tempo de permanência verificada, incluindo-se todas causas de internação (seis dias).

CHAMPION et al. (1990b) verificaram que as médias do tempo de permanência da população do MTOS foram 9,7 dias para sobreviventes e 4,6 dias para óbitos. A média do tempo de permanência para os sobreviventes foi superior a observada neste estudo. Entretanto, esta diferença pode estar relacionada às diversidades metodológicas, em particular, as relacionadas aos critérios de inclusão adotados para o MTOS que considera, fundamentalmente, as causas externas que produzem lesões previstas no Manual AIS. 
Figura 05 (A - C) - Pacientes internados, segundo tempo de permanência no hospital e condição de saída (N=1.553), IC-HCFMUSP, 1998.
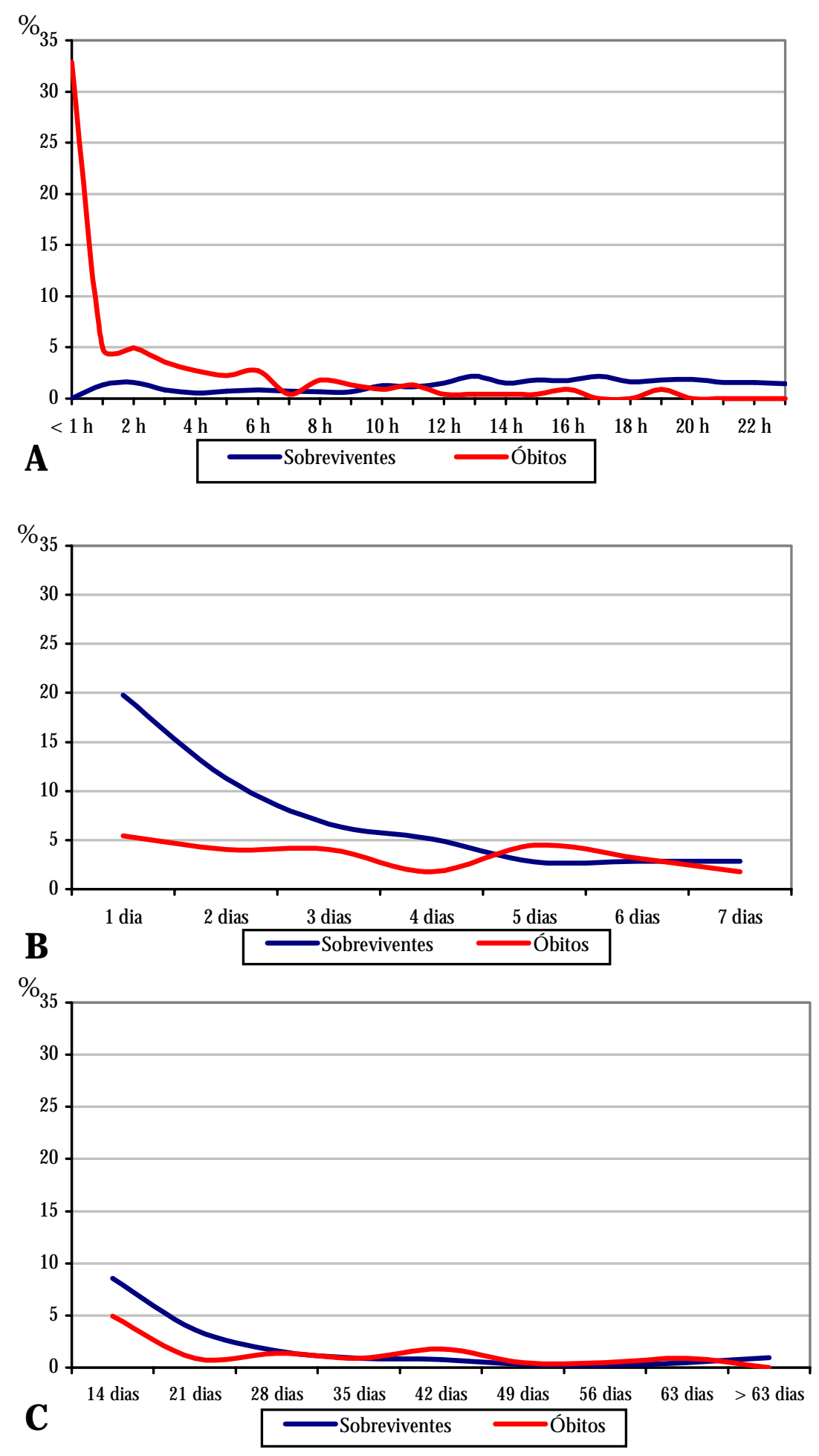
0 tempo de permanência no hospital representado na Figura 05 (A-C) foi separado em três períodos considerando-se as primeiras 24 horas em unidades de horas, a primeira semana em dias e o período restante em semanas, agrupando-se progressivamente de sete em sete dias.

D o total de pacientes, $1.553(87,20 \%)$ possuíam o registro completo, data e hora de entrada e saída, para o cálculo do tempo de permanência no hospital.

Na Figura 05-A, destaca-se o porcentual de óbitos, 33,78\% em tempo de permanência no hospital menor que 1 hora. Ainda, considerando-se os óbitos, embora 0 porcentual pareça reduzido após as primeiras horas, observou-se que antes de completar as primeiras 24 horas, $64,01 \%$ dos óbitos já tinham ocorrido.

Entre os sobreviventes, o porcentual de pacientes que permaneceu no hospital até 24 horas foi baixo (Figura 05-A).

No tempo de permanência entre um e sete dias (Figura 05-B), observou-se uma inversão entre sobreviventes e óbitos em relação às primeiras 24 horas. Enquanto, na Figura 05-A o porcentual entre óbitos foi mais que o dobro daquela observada entre os sobreviventes, na Figura 05-B o porcentual entre sobreviventes (51,36\%) é pelo menos $50 \%$ maior que o verificado no grupo de óbitos (24,44\%). Observando-se um maior quantitativo de saída de sobreviventes com um dia de permanência $(19,80 \%)$, seguido de dois dias (11,30\%).

Pela Figura 05-C pode-se verificar que poucos pacientes permaneceram no hospital por um tempo prolongado (acima de duas semana). Dos restantes 17,38\% sobreviventes que permaneceram internados mais de sete dias, 13,77\% saíram do hospital até 28 dias. No grupo dos óbitos, após 28 dias restaram somente 4,5\% , ou seja, no período de um mês 95,5\% dos óbitos já havia acontecido.

Uma das características da mortalidade dos eventos traumáticos é a distribuição temporal das mortes. Esta foi observada por TRUNKEY (1983b) e constatada por outros pesquisadores em trauma, ocorre em três momentos distintos ou classicamente denominada de trimodal. 0 primeiro pico é constituído pelas mortes imediatas (em torno de 45\%) resultantes de lesões do sistema nervoso central e vascular importantes. 0 segundo pico de maior freqüência de mortes (cerca de 34\%) está relacionado àquelas que 
ocorrem algumas horas após o trauma, portanto, inclui as mortes precoces intrahospitalares em razão de lesões no sistema nervoso central e hemorragia. 0 terceiro pico é constituído pelas mortes tardias (em torno de 20\%), que ocorrem por causa de sepsis e falência de múltiplos órgãos.

ACOSTA et al. (1998) verificaram uma mortalidade de 70\%, nas primeiras 24 horas, em 900 pacientes de trauma de San Diego (EUA) que morreram entre 1985 a 1995. Constataram que as lesões torácicas e do sistema nervoso central foram as causas de morte mais freqüentes na primeira após a admissão do paciente no hospital

SAUAIA et al. (1995) observaram uma variação na distribuição temporal da mortalidade por trauma em Denver (EUA), ao analisarem 289 óbitos decorrentes de trauma no ano de 1992. Seus resultados foram 34\% de óbitos na fase pré-hospitalar e $66 \%$ no hospital. Destes, $81 \%$ morreram nas primeiras 48 horas, $6 \%$ no período de três a sete dias e os restantes $14 \%$ após sete dias. Os autores atribuíram a variação da distribuição temporal de mortes por trauma nesse local ao sistema de atendimento préhospitalar eficiente que, possivelmente, prolongou a sobrevida de alguns pacientes não recuperáveis.

De acordo com MEISLIN et al. (1997), embora a causa de morte decorrente de trauma na primeira hora tenha permanecido constante desde a publicação de TRUNKEY (1983), o segundo pico de morte e as causas de óbito dos pacientes modificaram-se ao longo dos anos. 0 desenvolvimento de sistemas de atendimento ao trauma reduziu a probabilidade de morte para os pacientes com hemorragia e prolongou a sobrevida ao paciente com disfunção neurológica importante. Os avanços que ocorreram no atendimento pré-hospitalar e no tratamento dos pacientes modificaram o padrão de distribuição temporal das mortes em trauma, tornando-o praticamente bimodal. Ressalta ainda que diferenças na distribuição das mortes de acordo com o tempo são variáveis, pois dependem de vários fatores tais como idade, mecanismo do trauma, das características regionais e do sistema de atendimento ao traumatizado.

Os dados do município de São Paulo referentes aos anos de 1960 a 1975 sobre acidentes de trânsito apresentados por MELLO JORGE (1979), mostraram que as mortes ocorridas antes de qualquer assistência médica, ou seja, no local ou a caminho do hospital 
foram $40 \%$ em 1960, reduzindo-se até $30 \%$ em 1975. É importante salientar que 0 período estudado pela autora é anterior à implementação do serviço de atendimento préhospitalar no Município (SAMU-SP 1990). As mortes que ocorreram nas primeiras 24 horas totalizaram $77,27 \%$ em 1960, decrescendo para 56,24\% em 1975. A partir do período de um a sete dias em diante houve incremento dos percentuais no decorrer dos anos estudados (no período de um a sete dias de 15,61\% para 26,08\%; no período de oito a 29 dias de $4,55 \%$ para $12,12 \%$; de um a seis meses de $2,27 \%$ para $5,22 \%$; de seis meses a um ano de nenhum caso a 0,34\%). 0 fato foi observado pela autora como aumento do tempo de sobrevivência dos acidentados de trânsito que poderia estar relacionado, entre outros fatores, a melhor assistência médica de urgência, à prestação de socorro mais rápido no momento do acidente.

Analisando-se 1.414 vítimas que foram atendidas na fase pré-hospitalar pelo SAMU-SP no município de São Paulo, no ano de 1991, WHITAKER, (1993) constatou que $70 \%$ das vítimas fatais (130) morreram nas primeiras 24 horas, 18,46\% entre um a sete dias, 6,92\% entre oito e 30 dias e 4,62\% com mais de um mês. Observando-se as devidas proporções e as diferenças metodológicas entre os estudos de WHITAKER (1993) e MELLO JORGE (1979), verifica-se que o porcentual de óbitos nas primeiras 24 horas foi superior no grupo que recebeu atendimento pré-hospitalar. Vários fatores podem ter influenciado esse aumento, maior intensidade da gravidade dos pacientes, 0 próprio atendimento pré-hospitalar ou até falha na assistência hospitalar. Considerando a existência do atendimento pré-hospitalar é possível que mais pacientes graves tenham conseguido chegar até o hospital, mas em razão da gravidade do morreram dentro das primeiras 24 horas, elevando o porcentual observado por WHITAKER (1993). Contudo, para avaliar a mudança epidemiológica dessa ocorrência novos estudos seriam necessários objetivando analisar as diferenças.

Neste estudo, até as primeiras quatro horas, praticamente, metade $(49,8 \%)$ dos óbitos já havia acontecido até 24 horas 64,01\% e até 48 horas somaram 73,32\% .

O porcentual de óbitos hospitalares com menos de 48 horas, verificado por LEBRÃO; MELLO JORGE; LAURENTI (1997) referente a pacientes de causas 
externas internados em hospitais brasileiros no mês de novembro de 1994 segundo as AIH foi 34,9\% , um valor muito inferior ao verificado neste estudo.

Nos 312 casos de óbito ocorridos no local do evento, estudados por MEISLIN et al. (1999), 60\% foram instantâneas em razão de trauma grave. Os autores ressaltaram a importância da prevenção do evento para redução deste tipo de morte.

$\mathrm{Na}$ caracterização da população estudada, destaca-se que dos 1.781 pacientes aqui incluídos, 30,15\% foram internados em decorrência de acidente de transporte, 24,32\% por agressões e 17,24\% por quedas. Os eventos com o maior porcentual em cada grupo citado foram, respectivamente, atropelamento, agressão por arma de fogo e queda de altura. A população foi constituída, predominantemente, por pacientes do sexo masculino (76,87\%) e jovens entre 15 e 39 anos (56,60\%). Os pacientes foram provenientes diretamente da cena do evento $(43,34 \%)$ e transferidos de outros hospitais $(39,08 \%)$. Entre os que vieram diretos da cena do evento ao PS do IC, a maioria recebeu atendimento pré-hospitalar $(60,74 \%)$ e foi transportada pela UR (46,49\%). 0 tempo de atendimento pré-hospitalar das unidades do SAMU-SP foi 32,03\% entre 31 e 45 minutos e $31,30 \%$ entre 46 e 60 minutos. A mortalidade hospitalar observada foi 12,63\% e 0 porcentual de óbitos com menos de uma hora de permanência foi 33,78\% e a maioria $(64,01 \%)$ ocorreu nas primeiras 24 horas.

Vários fatores influenciam a sobrevida do paciente internado, entre eles, o tipo de trauma e sua gravidade que foram analisados e são apresentados a seguir.

\subsection{GRAVIDADE DO TRAUMA ANALISADA PELO SISTEMA AIS/ ISS E RTS}

A biomecânica do evento traumático determina padrões de lesões resultantes da transferência de energia aos tecidos. Assim, diferentes causas externas, mas com mecanismos de trauma semelhantes, podem resultar em lesões características daquele tipo de trauma.

As lesões mais comuns e freqüentes estão relacionadas ao trauma contuso e são produzidas pelas causas externas do tipo acidentes de transporte, agressões com objeto contundente, quedas e, também, as explosões. Outros padrões de lesões resultam do tipo 
de trauma penetrante e relacionam-se às causas externas como agressões, lesões autoprovocadas voluntariamente, envolvendo o uso intencional ou acidental de arma de fogo, objeto cortante ou penetrante que produzem um tipo peculiar de lesão (NAEMT, 1999; ACS, 1999).

Neste estudo, de acordo com a causa externa e as características do evento traumático descritas na história do paciente, classificou-se os dados sobre os tipos de trauma em contuso, penetrante, queimadura e outros como podem ser verificado na Tabela 04.

Tabela 04 - Pacientes internados, segundo tipos de trauma e causas externas, ICHCFMUSP, 1998.

\begin{tabular}{|c|c|c|c|c|c|c|c|c|c|c|c|}
\hline & & & & & & TRA & MA & & & & \\
\hline & & Con & zuso & Pene & trante & Quei & adura & & tros & & tal \\
\hline CAUSA EX & ERNA & $\mathrm{N}$ & $\%$ & $\mathrm{~N}$ & $\%$ & $\mathrm{~N}$ & $\%$ & $\mathrm{~N}$ & $\%$ & $\mathrm{~N}$ & $\%$ \\
\hline Acidente d & ransporte & 537 & 30,15 & - & - & - & - & - & - & 537 & 30,15 \\
\hline Agressões & $\mathrm{AF} / \mathrm{AB}^{*}$ & - & - & 324 & 18,19 & - & - & - & - & 324 & 18,19 \\
\hline & $\begin{array}{l}\text { Outras } \\
\text { agressões }\end{array}$ & 100 & 5,61 & 8 & 0,45 & - & - & 1 & 0,06 & 109 & 6,12 \\
\hline Quedas & & 307 & 17,24 & - & - & - & - & - & - & 307 & 17,24 \\
\hline Exposição & Forças mecânicas & 77 & 4,32 & 38 & 2,13 & 1 & 0,05 & 102 & 5,73 & 218 & 12,24 \\
\hline Outras cau & s externas & 73 & 4,10 & 44 & 2,47 & 61 & 3,44 & 108 & 6,06 & 286 & 16,06 \\
\hline Total & & 1094 & 61,42 & 414 & 23,24 & 62 & 3,49 & 211 & 11,85 & 1781 & 100,00 \\
\hline
\end{tabular}

* AF/ AB - arma de fogo/ arma branca

Entre os pacientes de causas externas, a maioria (61,42\%) que sofreu o tipo de trauma contuso incluiu, além do acidente de transporte (30,15\%) e quedas $(17,24 \%)$, pacientes do grupo de outras agressões (5,61\%), de exposição a forças mecânicas inanimadas e animadas (4,32\%) e as de outras causas externas (4,10\%).

Tendo em vista a variedade de tipos de causas externas classificadas no grupo de trauma contuso, alguns exemplos são apresentados para esclarecer e ilustrar as classes que abrangem diferentes tipos de eventos. Em exposição a forças mecânicas, observou-se 0 trauma contuso em razão, por exemplo, de impacto causado por objeto lançado, 
projetado ou em queda (W20) (casos de "síndrome do tanque"), impacto acidental originado por equipamento esportivo (W21) ("bolada”), colisão entre duas pessoas (W51), golpe provocado por outros mamíferos (W55). Em outras causas são exemplos de trauma contuso em intenção indeterminada, o contato com objeto contundente (Y29) ("ferimento com pedaço de madeira, trauma com carro, trauma com ferro"), em exposição acidental a outros fatores e aos não especificados, os eventos codificados com X59 ("trauma com cabo de vassoura no olho, braço preso em ferragem”). Além disso, em exposição ao fogo e chamas, classificaram-se três pacientes em trauma contuso, pois 0 evento principal relacionou-se com explosão de bombas. Em lesões autoprovocadas voluntariamente os eventos que definiram o trauma contuso foram a precipitação de um lugar elevado (X80) e precipitação ou permanência diante de um objeto em movimento (X81).

Os pacientes de causas externas que se relacionaram ao tipo de trauma penetrante totalizaram $414(23,24 \%)$ casos constituídos, sobretudo, por 324 (18,19\%) de agressão por arma de fogo e objeto cortante ou penetrante e, em menores percentuais, por outras agressões ( $0,45 \%)$, exposição a forças mecânicas inanimadas ou animadas (2,13\%), outras causas externas $(2,47 \%)$. Exemplos de eventos que foram classificados como trauma penetrante em exposição a forças mecânicas foram contato com vidro cortante (W25), contato com aparelhos domésticos com motor (W29). Em outras causas externas, os exemplos referiram-se ao grupo de eventos de intenção indeterminada do tipo contato com objeto cortante (trauma com vidro, ferimento com faca classificados em Y28).

Em virtude das conseqüências peculiares das queimaduras, optou-se por classificar separadamente esse tipo de trauma. Entre os 62 (3,49\%) pacientes classificados como tipo de trauma queimadura, o maior número coube aos 59 (3,31\%) que sofreram exposição ao fogo e às chamas ou por contato com fonte de calor ou substâncias quentes. Além desses, um paciente de exposição à força mecânica inanimada (referente à queima de fogos e artifícios - W39), 1 paciente de outras causas (em razão à exposição a substâncias químicas nocivas e às não especificadas - X 49, que determinou queimadura química) e um paciente de lesão autoprovocada voluntariamente (por fumaça, fogo e chamas - X 76). 
Os demais pacientes de causas externas cujos eventos não se relacionaram ao trauma contuso, penetrante ou queimadura, foram classificados em outro tipo de trauma. Nesse grupo, foram incluídos $102(5,73 \%)$ pacientes que sofreram exposição a forças mecânicas inanimadas, em especial, as relacionadas à penetração de corpo estranho no ou através de olho ou orifício natural (W44), 108 (6,06\%) pacientes do grupo de outras causas constituído por envenenamento/intoxicação acidental, exposição à corrente elétrica e lesão autoprovocada (auto-intoxicação), e 1 (0,06\%) paciente de agressão cujo evento e tipo de trauma não puderam ser definidos.

A relação entre trauma contuso e penetrante apresenta variações. Nos dados obtidos por YATES; WO ODFORD; HOLLIS (1992) sobre 14.648 pacientes de trauma de 33 hospitais do Reino Unido, referentes aos anos de 1990 e 1991, a relação entre pacientes de trauma contuso (14.051) e penetrante (597) foi 23,54:1.

Na população do MTOS constituída por 80.544 pacientes de trauma de 139 instituições americanas e canadenses relativo ao período de 1982 a 1987, a proporção entre pacientes de trauma contuso (63.555) e penetrante (16.989) foi 3,74:1 (CHAMPION et al., 1990b) e portanto, mais próxima a este estudo que foi 2,64:1.

As lesões podem ser variadas, bem como o escore de gravidade individual das mesmas e podem guardar relação com o tipo de trauma. Estes aspectos serão analisados a seguir.

\subsubsection{GRAVIDADE DAS LESÕES (AIS)}

A análise das lesões da população deste estudo quanto à gravidade, classificação e localização corpórea foi feita com base na AIS. O Manual AIS contém descrições de lesões decorrentes de trauma contuso, penetrante, queimadura (incluindo a ocorrência de inalação) e eletrocussão. Os diferentes tipos de trauma produziram lesões características em uma ou mais regiões do corpo.

Entre os 1.781 pacientes de trauma internados, 1.542 (86,58\%) sofreram lesões cujas descrições estavam previstas no Manual AIS - atualização 98, totalizando 4.918 lesões. A média do número de lesões por paciente foi 3,19. 
Os pacientes excluídos para a análise da gravidade das lesões com base na AIS, 239 (13,42\%), são aqueles cujo tipo de evento em causas externas não resulta em lesões previstas no sistema de classificação de gravidade adotado neste estudo, como por exemplo, envenenamento/ intoxicação e afogamento.

A distribuição das lesões conforme o tipo de trauma foi decorrente, sobretudo, de trauma contuso $(75,79 \%)$, seguida de trauma penetrante $(21,63 \%)$, como ilustrada na Figura 06.

Figura 06 - Distribuição das lesões, segundo o tipo de trauma (N=1.542), ICHCFMUSP, 1998.

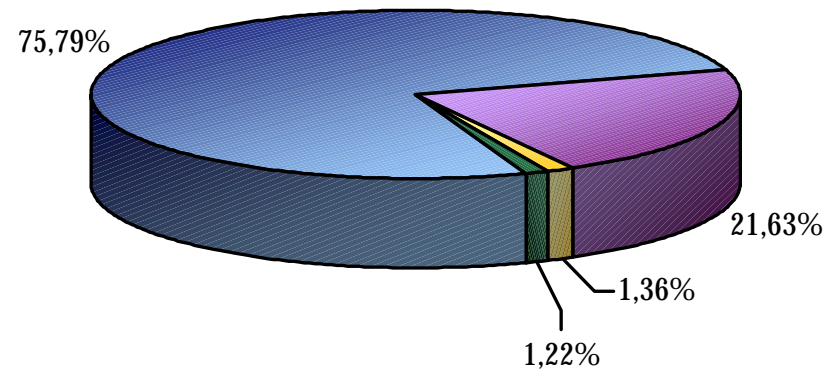

Tendo em vista que a maioria dos eventos $(61,42 \%)$ resultou no tipo de trauma contuso (Tabela 04), era de se esperar um porcentual elevado de lesões nesse tipo de trauma. A localização corpórea dessas lesões está apresentada a seguir. 
Figura 07 - Distribuição das lesões, segundo as regiões corpóreas AIS (N=1.542). IC-HCFMUSP, 1998.

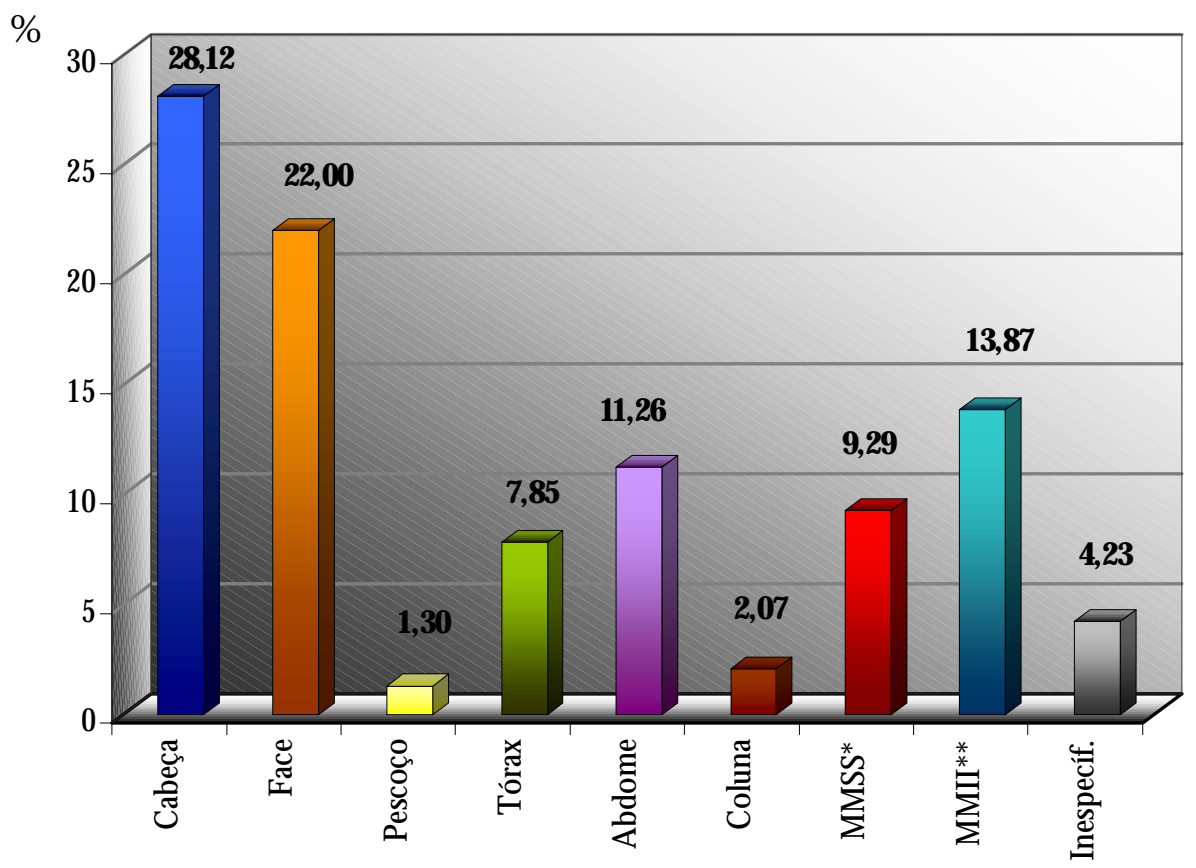

*MMSS - membros superiores

**MMII - membros inferiores

Conforme a Figura 07, as regiões corpóreas mais acometidas ou com o maior número de lesões, genericamente, foram a cabeça $(28,12 \%)$ e face $(22,00 \%)$, seguidas de MMII (13,87\%) e abdome (11,26\%).

Considerando os escores AIS de cada lesão, observou-se a distribuição conforme a classificação da gravidade da lesão (Figura 08). 
Figura 08 - Distribuição das lesões de acordo, com os escores de gravidade (N=1.542). IC-HCFMUSP, 1998.

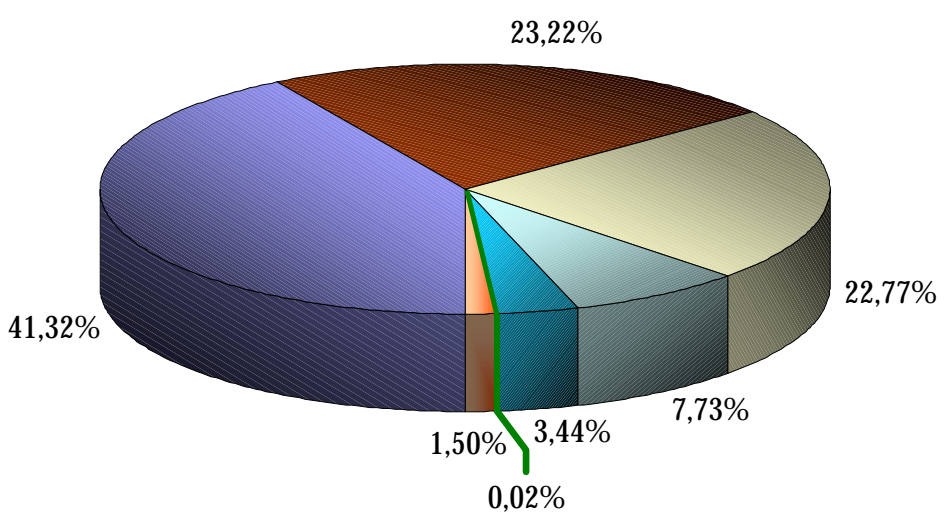

\section{Escores AIS}

$\square 1$ - leve

口 2 - moderada

$\square 3$ - séria

$\square 4$ - grave

$\square 5$ - crítica

घ 6 - máxima

$\square 9$ - não especificada

A maioria (87,31\%) das lesões classificaram-se nas pontuações AIS 1 , 2 e 3. D o total de lesões, o maior porcentual (41,32\%) foi para gravidade leve (AIS 1); 23,22\%, para gravidade moderada (AIS 2) e 22,77\% para as sérias(AIS 3). Nas demais lesões, 7,73\% eram AIS 4 e 3,44\% eram AIS 5, denominadas, graves e críticas, respectivamente. Verificou-se, somente, uma (0,02\%) lesão AIS 6, ou seja, de gravidade máxima ou quase sempre fatal. As lesões com gravidade desconhecida ou AIS 9, referentes às descrições genéricas que impossibilitaram classificar quanto à gravidade da lesão, totalizaram 1,5\%.

Tendo em vista que o acometimento das regiões corpóreas difere conforme o tipo de trauma verificou-se a gravidade das lesões de acordo com sua localização. 
Tabela 05 - Distribuição das lesões, segundo regiões corpóreas da AIS e tipo de trauma (N=1.542), IC-HCFMUSP, 1998.

\begin{tabular}{|c|c|c|c|c|c|c|c|c|c|c|}
\hline \multirow[b]{3}{*}{$\begin{array}{l}\text { REGIÃO } \\
\text { CORPÓ REA AIS }\end{array}$} & \multicolumn{10}{|c|}{ TIPO DE TRAUMA } \\
\hline & \multicolumn{2}{|c|}{ Contuso } & \multicolumn{2}{|c|}{ Penetrante } & \multicolumn{2}{|c|}{ Queimadura } & \multicolumn{2}{|c|}{ Outros } & \multicolumn{2}{|c|}{ Total } \\
\hline & $\mathrm{N}$ & $\%$ & $\mathrm{~N}$ & $\%$ & $\mathrm{~N}$ & $\%$ & $\mathrm{~N}$ & $\%$ & $\mathrm{~N}$ & $\%$ \\
\hline Cabeça & 1261 & 33,83 & 120 & 11,28 & - & - & 2 & 3,33 & 1383 & 28,12 \\
\hline Face & 870 & 23,34 & 191 & 17,95 & 2 & $2,99 \%$ & 19 & 31,67 & 1082 & 22,00 \\
\hline Pescoço & 28 & 0,75 & 36 & 3,39 & - & - & - & - & 64 & 1,31 \\
\hline Tórax & 235 & 6,31 & 150 & 14,10 & - & - & 1 & 1,67 & 386 & 7,85 \\
\hline Abdome & 275 & 7,38 & 277 & 26,03 & - & - & 2 & 3,33 & 554 & 11,26 \\
\hline Coluna & 75 & 2,01 & 26 & 2,44 & - & - & 1 & 1,67 & 102 & 2,07 \\
\hline MMSS* & 306 & 8,21 & 149 & 14,00 & 1 & 1,49 & 1 & 1,67 & 457 & 9,29 \\
\hline MMII** & 572 & 15,35 & 105 & 9,87 & - & - & 5 & 8,33 & 682 & 13,87 \\
\hline Inespecífica & 105 & 2,82 & 10 & 0,94 & 64 & 95,52 & 29 & 48,33 & 208 & 4,23 \\
\hline Total & 3727 & 100,00 & 1064 & 100,00 & 67 & 100,00 & 60 & 100,00 & 4918 & 100,00 \\
\hline
\end{tabular}

No global, as regiões mais acometidas foram cabeça, face e membros inferiores (Tabela 05), mas foram observadas diferenças nessa distribuição de acordo com o tipo de trauma.

A região da cabeça (33,83\%) foi a mais acometida no trauma contuso, seguida da face $(23,34 \%)$ e membros inferiores (15,35\%). Salienta-se que, se somados os porcentuais de lesões em membros inferiores e superiores, estas regiões atingem $23,56 \%$ e passam para a segunda região mais acometida no trauma contuso. Considerando que esse tipo de trauma relaciona-se com acidentes de transporte e quedas, pode-se concluir que essas regiões são as mais vulneráveis no trauma contuso.

Observa-se ainda que a distribuição das lesões no trauma contuso foi semelhante àquela do total de pacientes. 0 mesmo não ocorreu no trauma penetrante

No trauma penetrante, a região mais acometida foi o abdome (26,03\%) seguida da face $(17,95 \%)$, tórax $(14,10 \%)$ e membros superiores (14,00\%). Convém lembrar que 0 
trauma penetrante na face relacionou-se, sobretudo, às lesões em olhos, cujo evento não se referia a agressões, a causa de maior freqüência no grupo de trauma penetrante.

A constatação de que pacientes internados por trauma penetrante apresentaram lesões em regiões corpóreas diferentes (abdome, face e tórax) daquelas verificadas em trauma contuso (cabeça, face e MMII) pode estar relacionada com trauma penetrante na região da cabeça e morte no próprio local do evento.

Em queimaduras, como era de se esperar, a região mais comprometida foi a denominada inespecífica (95,52\%) e que abrange a superfície corpórea.

No grupo outros tipos de trauma, totalizando 60 lesões, a localização mais freqüente recaiu na região inespecífica (48,33\%) e face (31,67\%). Isso se deve às causas de maior freqüência classificadas no grupo outros tipos de trauma, que foram exposição à corrente elétrica e exposição à forças mecânicas inanimadas. No Manual AIS, as lesões decorrentes de exposição à corrente elétrica estão descritas na seção outros traumas sob o código numérico referente à região inespecífica. As lesões na região da face estavam relacionadas, em especial, à penetração de corpo estranho no ou através do olho (W44) classificada em exposição a forças mecânicas inanimadas, o que determinou esse elevado número de lesões em face.

Associando as informações sobre a gravidade da lesão determinada pelo escore AIS e sua localização, foram estudadas as características das lesões traumáticas mais detalhadamente (Tabela 06). 
Tabela 06 - Distribuição das lesões segundo região corpórea da AIS e respectivo escore de gravidade (N=1.542), IC-HCFMUSP, 1998.

\begin{tabular}{|c|c|c|c|c|c|c|c|c|c|c|c|c|c|c|c|c|}
\hline \multirow[b]{3}{*}{$\begin{array}{l}\text { REGIÃO } \\
\text { CORPÓREA } \\
\text { AIS }\end{array}$} & \multicolumn{16}{|c|}{ ESCORES AIS } \\
\hline & \multicolumn{2}{|c|}{1} & \multicolumn{2}{|r|}{2} & \multicolumn{2}{|r|}{3} & \multicolumn{2}{|r|}{4} & \multicolumn{2}{|r|}{5} & \multicolumn{2}{|r|}{6} & \multicolumn{2}{|r|}{9} & \multicolumn{2}{|c|}{ Total } \\
\hline & $\mathrm{N}$ & $\%$ & $\mathrm{~N}$ & $\%$ & $\mathrm{~N}$ & $\%$ & $\mathrm{~N}$ & $\%$ & $\mathrm{~N}$ & $\%$ & $\mathrm{~N}$ & $\%$ & $\mathrm{~N}$ & $\%$ & $\mathrm{~N}$ & $\%$ \\
\hline Cabeça & 289 & 14,22 & 146 & 12,78 & 484 & 43,21 & 285 & 75,00 & 118 & 69,82 & - & - & 61 & 82,43 & 1383 & 28,12 \\
\hline Face & 915 & 45,03 & 156 & 13,66 & 10 & 0,89 & - & 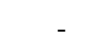 & - & - & 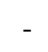 & 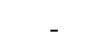 & $r$ & 1,35 & 1082 & 22,00 \\
\hline Pesco & 47 & 2,32 & 10 & 0,88 & 5 & 0,45 & 2 & 0,53 & - & - & - & 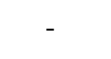 & - & 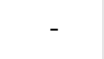 & 64 & 1,31 \\
\hline Tórax & 101 & 4,97 & 29 & 2,54 & 211 & 18,84 & 26 & 6,84 & 15 & 8,88 & 1 & 100,00 & 3 & 4,05 & 386 & 7,85 \\
\hline Abdome & 112 & 5,51 & 229 & 20,05 & 145 & 12,95 & 52 & 13,68 & 12 & 7,10 & - & - & 4 & 5,41 & 554 & 11,26 \\
\hline Coluna & - & - & 84 & 7,36 & 5 & 0,45 & - & - & 8 & 4,73 & - & - & 5 & 6,76 & 102 & 2,07 \\
\hline MMSS & 226 & 11,12 & 188 & 16,46 & 43 & 3,84 & - & - & - & - & - & - & - & - & 457 & 9,29 \\
\hline MMII & 207 & 10,19 & 273 & 23,91 & 197 & 17,59 & 3 & 0,79 & 2 & 1,18 & - & 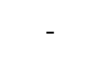 & - & - & 682 & 13,87 \\
\hline Inespecífica & 135 & 6,64 & 27 & 2,36 & 20 & 1,78 & 12 & 3,16 & 14 & 8,29 & - & - & - & - & 208 & 4,23 \\
\hline Total & 2032 & 100,00 & 1142 & 100,00 & 1120 & 100,00 & 380 & 100,00 & 169 & 100,00 & 1 & 100,00 & 74 & 100,00 & 4918 & 100,00 \\
\hline
\end{tabular}

As lesões leves (AIS1), as mais freqüentes neste estudo (Figura 08), localizaram-se, sobretudo, na face $(45,03 \%)$ e, em menor porcentual, na cabeça $(14,22 \%)$. Como pode ser verificado na Figura 07 e Tabela 05, a face foi a segunda região mais acometida tanto no trauma contuso quanto no penetrante. As lesões leves na face, segundo o Manual AIS e presentes neste estudo podem ser exemplificadas com lesões oculares, fratura de nariz, fratura fechada ou deslocamento da mandíbula.

Lesões de escore AIS2, de intensidade moderada foram mais freqüentes em MMII $(23,91 \%)$ e em abdome (20,05\%). No entanto, considerando-se os MMII e MMSS em conjunto verificou-se que 43,96\% das lesões moderadas localizaram-se em extremidades. Os membros, tanto inferiores quanto superiores, foram estruturas lesadas com maior freqüência pelo trauma contuso (Tabela 05). Exemplos de lesões moderadas em MMII, relacionadas ao trauma contuso e, presentes neste estudo, são fraturas fechadas de tíbia, fíbula, patela ou ossos da pélvis, luxação de articulações, lacerações de músculos, tendões ou ligamentos, lacerações ou transecção incompleta de artérias e veias como femoral ou poplítea. Alguns exemplos de lesões em MMSS são lesões não especificadas ou laceração 
em artéria axilar ou braquial, laceração de cápsula articular, luxação glenoumeral, fratura de clavícula, fratura fechada de úmero ou rádio ou ulna.

A segunda região mais freqüentemente acometida com lesão de gravidade moderada (AIS2) foi o abdome. As lesões em abdome foram decorrentes tanto de trauma contuso quanto penetrante (Tabela 05). As lesões do tipo laceração do mesentério, fígado, baço, rim, jejuno ou íleo, ou cólon exemplos de lesões verificadas no estudo são consideradas moderadas segundo o Manual AIS.

Os escores AIS 3 (séria), AIS 4 (grave) e AIS 5 (crítica), chamam a atenção quanto aos percentuais elevados na região da cabeça. Esses dados indicam que a cabeça sofreu lesões mais graves com maior frequiência. Entre as lesões na cabeça, verificadas neste estudo, previstas no Manual AIS e classificadas como sérias (AIS3), estão a contusão cerebral, "brain swelling", hemorragia meníngea traumática, pneumocrânio, fratura cominutiva de crânio . Exemplos de lesões na cabeça classificadas como grave (AIS4) são os hematomas extradural ou subdural, fratura exposta de crânio, os exemplos de lesões críticas (AIS5) são lesão axonal difusa e as formas mais graves ou extensas das lesões cranianas citadas como exemplos de AIS 3 e 4.

Ainda em relação às lesões sérias (AIS3), verificou-se que a segunda região mais freqüentemente acometida foi o tórax. Exemplos de lesões torácicas AIS 3 ou sérias, segundo a AIS, encontradas na população deste estudo são lesões em cavidade torácica sem especificação com hemo / pneumotórax ou pneumomediastino, contusão pulmonar unilateral, laceração do diafragma, fraturas de arcos costais com hemo / pneumotórax, tórax instável ou respiração paradoxal unilateral, laceração sem especificação da artéria ou veia pulmonar ou subclávia.

Somente uma lesão AIS 6 foi verificada, sendo importante observar que se localizava no tórax, região onde se encontram estruturas vitais.

As lesões AIS 9 não são indicativas de intensidade da gravidade, mas são resultados que merecem comentário. D o total de lesões, 1,5\% (Figura 08) foram descritas com os termos genéricos TCE (trauma crânio- encefálico), TAF (trauma abdominal fechado), trauma torácico fechado que impediram mensurar a intensidade da gravidade pelo sistema utilizado e, por isso, receberam escore AIS 9, ou seja, de gravidade 
desconhecida. 0 tipo de descrição foi utilizado, sobretudo, (82,43\%) para lesões na região da cabeça.

Pela análise das lesões sob vários aspectos, constatou-se que aquelas da região da cabeça chamaram a atenção, praticamente, em todos os pontos abordados, seja pela freqüência ou pela gravidade das lesões. A vulnerabilidade da cabeça nos eventos traumáticos resulta em lesões nessa região, sendo uma causa importante de elevada morbi-mortalidade.

A relação entre região corpórea e tipo de trauma verificada por D ALOSSI (1993) em 100 pacientes internados em Hospital de referência para trauma em São Paulo foi semelhante a deste estudo, observando-se maior porcentual de lesões na região da cabeça/ pescoço (33,2\%) em trauma contuso e no trauma penetrante, maior porcentual na região do abdome e conteúdo pélvico (32\%). As lesões percebidas em ambos os tipos de trauma foram, predominantemente, de escores AIS 3 e 4.

CALIL (1997) notou em 220 pacientes internados por acidentes de trânsito no ICHCFMUSP que a cabeça foi a segunda região corpórea com o maior número de lesões $(27,61 \%)$, antecedida por membros e cintura pélvica $(34,66 \%)$, e as lesões de maior gravidade ou o escore AIS mais elevado de cada paciente foi realmente encontrado na região da cabeça $(40,09 \%)$.

A influência do tipo e da gravidade sobre o prognóstico de 225 pacientes com TCE decorrente de atropelamento por veículo a motor, atendidos em hospital de San Francisco (EUA) foram estudadas por CIRICILLO et al. (1992). Seus resultados mostraram que $45 \%$ dos pacientes sofreram hematomas subdural, $8 \%$ hematomas extradural, 10\% hematoma intraparenquimatoso, 9\% contusão cerebral e 28\% lesão axonal difusa. Os percentuais de óbitos foram diferentes em cada tipo de lesão, porém todos foram elevados: no hematoma subdural $59 \%$ dos pacientes faleceram, no extradural $28 \%$, no intraparenquimatoso $45 \%$, na contusão $40 \%$ e na lesão axonal difusa $51 \%$. Após seis meses, $51 \%$ tinham morrido, $13 \%$ estavam em estado neurovegetativo ou gravemente incapacitados, 16\% moderadamente incapacitados e 20\% tiveram recuperação satisfatória.

A mortalidade de acordo com o tipo de lesão observada por MARTINS; BRUGGEMANN; COUTINHO (1997) em 200 casos consecutivos de TCE grave 
(ECGl $\leq 8)$, admitidos na Unidade Terapia Intensiva de um hospital em Florianópolis, também, foi elevada no hematoma subdural $(61,9 \%)$ e menor em hematoma extradural $(26 \%)$.

SOSIN; SACK S; SMITH (1989) verificaram que, na mortalidade geral, o TCE foi responsável por $2 \%$ das mortes e quando relacionado ao trauma foi $26 \%$ nos EUA, no período de 1979 a 1986, segundo os dados do "National Center for Health Statistics", e a taxa de mortalidade por TCE verificada no período foi 16.9 / 100.000 hab.

A morbi-mortalidade por TCE no município de São Paulo com base no ano de 1997 foi verificada por KOIZUMI et al. (2000) com base nas AIH e dados de mortes por causas externas do PROAIM. Constataram que entre 29.717 pacientes internados por lesões e envenenamentos, $12 \%$ possuíam TCE . No estudo, a taxa de mortalidade foi estimada em 26,2 no mínimo e 39,3 no máximo por 100.000 hab.

Analisando-se 49.143 pacientes selecionados da população do MTOS, internados em 95 centros de trauma, GENNARELLI et al. (1989) observaram que lesões crânioencefálicas foram freqüentes em ocupantes de veículo a motor (46\%), ciclistas (46\%), pedestres (48\%), eventos como quedas (34\%) e agressões (32\%), mas a freqüência foi mais baixa que 0 esperado em ferimentos por arma de fogo $(13,1 \%)$ e arma branca $(1,2 \%)$. Constatação semelhante foi observada no presente estudo que mostrou uma quantidade maior de lesões na cabeça no trauma do tipo contuso. Os autores compararam a mortalidade entre pacientes com (34\%) e sem TCE(66\%), verificaram que o porcentual de óbitos dos pacientes com TCE foi desproporcionalmente mais elevado, 1,5 vezes maior que os sem TCE $(60,4 \%$ e $39,6 \%)$.

GENNARELLI et al. (1994) apresentaram cinco anos mais tarde a análise completa sobre a incidência, mortalidade, morbidade e gravidade do TCE na população do MTOS, desta vez constituída por 174.160 pacientes internados em 165 centros de trauma e constataram que o TCE permaneceu como a causa mais importante de morte e incapacidade no trauma.

A elevada incidência de TCE, em especial, nos eventos causadores de trauma contuso, produzindo lesões de gravidade variadas que se relacionam com elevada mortalidade e morbidade têm sido constatadas mundialmente e não se mostram 
diferentes no Brasil. (BAKER et al., 1980; CIVIL, 1986; FIUZA, 1988; CHAMPION et al., 1990b; FREITAS et al., 1990; KOIZUMI, 1990, 1992; TIRET et al., 1991; COHADON et al., 1991; MASINI, 1991; VILALTA et al., 1992; ANDERSEN et al., 1992; SHACKFORD et al., 1993; OTT et al., 1993; GENNARELLI et al., 1994; BARROS et al., 1994; SOUSA; KOIZUMI, 1996; COLLI et al., 1997; MESQUITA FILHO , 1998; ANDRADE, 1998; SEMPLE et al., 1998).

O efeito sinérgico do TCE e lesões de outras regiões corpóreas sobre o paciente foram também constatados por GENNARELLI et al. (1989) na população do MTOS. Q uando as lesões na cabeça, de escore AIS 3 e 4 (séria e grave) estavam associadas a outras lesões de escores AIS 4 e 5 (grave e crítica) a mortalidade elevou-se. O bservaram que em lesões crânio-encefálicas de escore AIS 3 a mortalidade foi 18,4\% e em lesões AIS 4 localizadas em outras regiões do corpo foi 13,1\%. Entretanto, quando essas lesões estavam presentes no mesmo paciente a mortalidade elevou-se para 41,7\%.

A presença de várias lesões em diferentes regiões corpóreas e de gravidade variada são freqüentes em pacientes de trauma. Neste estudo, a média de lesões por paciente foi 3,19, mas o efeito de suas combinações não foi verificado.

A face foi a segunda região corpórea com o maior número de lesões neste estudo. Classificada como uma das regiões do corpo mais atingidas, porém em imensa maioria (84,56\%) foram lesões leves (AIS 1) decorrentes de trauma contuso (80,40\%). Excluídas as lesões consideradas AIS1 em superfície externa na região da face, outras lesões de gravidade leve (AIS 1) localizaram-se especialmente nas estruturas oculares.

VIANNA FILHO et al. (1995) verificaram que em 652 casos de perfurações oculares atendidos em um no pronto-socorro do município de São Paulo, entre julho de 1988 e setembro de 1992, 159 (24,4\%) foram em razão de acidentes automobilísticos, destes somente nove pessoas afirmaram estar usando cinto de segurança no momento do acidente. Ressaltaram a importância de medidas preventivas como uso do cinto de segurança, pára-brisa com vidros laminados associadas à educação no trânsito.

A relação entre lesões oculares ou orbitais e o trauma grave foi verificada por PO ON; McCLUSKEY; HILL (1999) selecionando-se 178 (16\%) entre 1.119 pacientes de trauma admitidos em um hospital de Sydney na Austrália. Verificaram que o risco de 
perda da visão por trauma foi correlacionado fortemente por lacerações de pálpebra , lesões superficiais nos olhos, fraturas de base de crânio e órbita e a condição de ser condutor de veículo. Chamaram a atenção para a importância da avaliação oftalmológica precoce, do paciente grave nessas condições como parte das medidas para reduzir uma das principais causas de cegueira no mundo.

PELLETIER et al. (1998) ressaltaram a importância do exame dos olhos feito por oftalmologista em pacientes com lesões na cabeça e pescoço na vigência de sinais e sintomas potencialmente indicativos de lesão ocular, ainda na fase aguda do tratamento, para otimizar o tempo da abordagem cirúrgica e reduzir a incidência de disfunção visual decorrente de trauma.

Os MMII foram freqüentemente lesados e, quando considerados em conjunto com os MMSS pode-se verificar que as extremidades tiveram o maior número de lesões depois da região da cabeça. Tratavam-se de lesões leves, moderadas e sérias (AIS 1, 2 e 3) e decorrentes tanto de trauma contuso quanto penetrante. No entanto, as lesões em MMII foram mais freqüentes em trauma contuso e as em MMSS em trauma penetrante. Considerando outros dados relativos ao trauma penetrante como freqüência elevada de lesões em abdome, número de lesões em tórax (Tabela 05), o fato do trauma penetrante ter sido predominantemente decorrente do uso de arma de fogo e arma branca $(78,26 \%)$ (Tabela 04) e a relação dos MMSS com o abdome e o tórax (alvo da arma de fogo ou branca) é possível que os braços tenham-se tornado mais vulneráveis ao trauma penetrante que os MMII.

No estudo de LEBRÃO; MELLO JORGE; LAURENTI (1997) sobre morbidade hospitalar por causas externas no Brasil, foi constatado que o maior número de internação decorreu por lesões do tipo fratura e 84,5\% relacionaram-se aos membros.

A incidência elevada de lesões em membros nos eventos relacionados ao trauma contuso como acidentes de trânsito e quedas tem sido constatada em vários estudos. (KOIZUMI, 1985b; ; OTT et al., 1993; DALOSSI, 1993 ; WHITAKER, 1993; HANNAN et al., 1995; SOUSA; KOIZUMI, 1996; ; CALIL, 1997; MESQUITA FILHO , 1998; ANDRADE, 1998; HELLING et al., 1999). 
Muito embora a maioria das lesões em MMII e MMSS estejam classificadas como de gravidade leve (AIS1), moderado (AIS2) e séria (AIS3) no Manual AIS, estas podem determinar períodos longos de internação, ocorrência de complicações, aumento da mortalidade e incapacidade, notadamente, quando estão associadas a lesões em outras regiões do corpo (PO LLE et al., 1996; EASTRIDGE; BURGESE, 1997; PENG et al., 1999).

MCCLURE; D OUG LAS (1996) estudaram prospectivamente uma coorte de 2.312 pacientes de trauma com lesões leves que não necessitaram permanecer internados para 0 tratamento de seus agravos, na Austrália. Verificaram que $80 \%$ dos pacientes sofreram lesões leves (AIS1), principalmente em membros tanto superiores quanto inferiores. Os autores chamaram a atenção para a importância deste tipo de lesão, por determinar incapacidade temporária de adultos jovens e pela sua magnitude na morbidade por trauma.

Para avaliar o efeito da combinação de múltiplas lesões presentes no paciente de trauma, calculou-se o ISS com base nas lesões classificadas pela AIS. Torna-se importante salientar que a maioria dos tipos de causas externas $(61,42 \%)$ foi classificada em trauma contuso, seguidas de penetrante $(23,24 \%)$. As lesões resultantes (4.918) foram decorrentes, predominantemente, de trauma contuso $(75,79 \%)$, mais freqüentes na região da cabeça $(28,12 \%)$, seguidas da face $(22,00 \%)$ e MMII $(13,87 \%)$ sendo $41,32 \%$ de gravidade leve (AIS1), 23,22\% moderada (AIS2) e 22,77\% séria. A média de lesão por paciente foi 3,19. No trauma contuso, as regiões corpóreas com o maior número de lesões foram a cabeça $(33,83 \%)$ seguidas da face $(23,34 \%)$. No trauma penetrante, as regiões mais atingidas foram 0 abdome $(26,03 \%)$ e a face (17,95\%). Em relação à gravidade, verificou-se que lesões leves (AIS1) foram freqüentes na face $(45,03 \%)$ e as moderadas (AIS 2) em MMII (23,91\%). As lesões sérias(AIS 3), graves (AIS4) e críticas (AIS5) foram mais freqüentes na região da cabeça, 43,21\%, 75,00\% e 69,82\%, respectivamente. A única lesão AIS 6 localizou-se no tórax.

\subsubsection{GRAVIDADE DO TRAUMA PELO SISTEMA AIS/ ISS}


O ISS é um índice de trauma utilizado, freqüentemente, para mensurar de maneira objetiva os efeitos de múltiplas lesões em várias regiões do corpo que, caracteristicamente, ocorrem nos pacientes que sofrem trauma grave (CO PES et al., 1988 a,b).

A gravidade do trauma mensurada pelo ISS está fundamentada na gravidade das lesões anatômicas previstas no Manual AIS.

D os 1.542 pacientes com lesões classificadas pela AIS, foi possível calcular o ISS para praticamente a totalidade dos pacientes, 1.527 (99,02\%). O ISS não foi calculado para 15 (0,98\%) pacientes que apresentaram, somente, descrições genéricas das lesões ou código AIS 9, respeitando-se as regras desse índice.

Figura 09 - Pacientes internados ( $\mathrm{N}=1.527)$, segundo a gravidade do trauma (ISS), ICHCFMUSP, 1998.

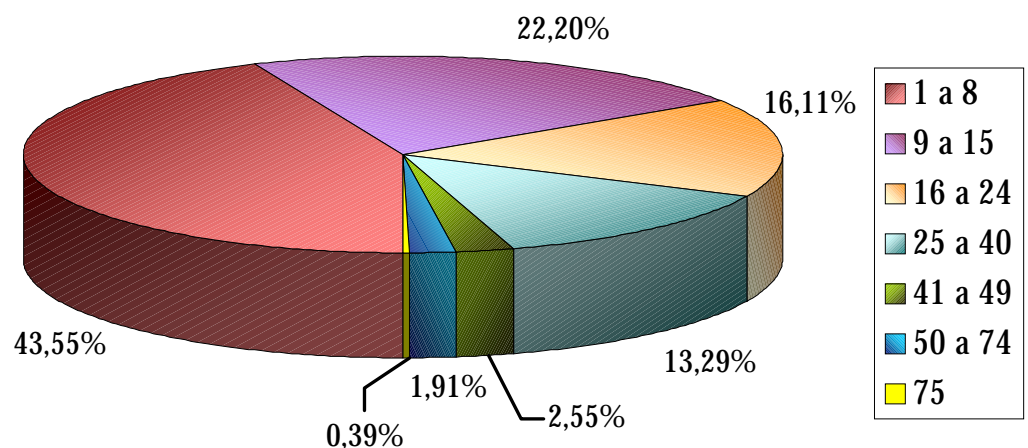

Conforme os dados da Figura 09, a maioria (65,75\%) dos pacientes obteve escores ISS abaixo de 16, observando-se 43,55\% classificados no intervalo ISS de 1 a 8 , seguidos de 22,20\% no intervalo ISS de 9 a15.

A possibilidade de classificar a gravidade do trauma de maneira objetiva utilizando-se uma linguagem comum, facilita comparar os resultados, medir diferenças entre populações estudadas e avaliar a qualidade da assistência. Entretanto, a definição dos níveis de gravidade do trauma é uma questão controversa. Em muitos estudos, os pesquisadores adotam 0 ISS $\geq 16$ definindo-0 como trauma importante, porque esse 
escore pode ser resultado de uma única lesão AIS 4, considerada grave,(por exemplo, 0 hematoma subdural pequeno ou $<100 \mathrm{ml}$ ) determinado com base nesse escore, cuja mortalidade é em torno de $10 \%$, um aumento gradativo da mortalidade por trauma.

Neste estudo, com vistas ao escore ISS 16, observou-se que a maioria $(65,75 \%)$ dos pacientes não foi considerada como sendo de trauma importante, mostrando concordância com outros estudos de morbi-mortalidade hospitalar.

DALOSSI (1993) analisou a gravidade do trauma (ISS) em 100 pacientes internados em razão de lesões contusas e penetrantes em um hospital de referência em emergência no município de São Paulo e constatou que o ISS de 47\% dos pacientes foi inferior a 16.

O estudo de CALIL (1997) verificou a gravidade do trauma em pacientes internados por sofrerem acidente de trânsito, observou que 58,64\% dos pacientes obtiveram ISS abaixo de 16.

Os resultados de CHAMPION (1990b) sobre a análise de 80.544 pacientes de trauma de 139 hospitais da América do Norte, também, revelaram que no tipo de trauma contuso e penetrante $61,7 \%$ dos pacientes foram classificados em escores ISS abaixo de 15.

Nos dados de YATES; WOODFORD; HOLLIS (1992) a maioria (83,9\%) dos 14.648 pacientes de trauma que foi internada em 33 hospitais do Reino Unido, obteve escores ISS abaixo de 16.

Nos dados apresentados por MOORE (1995) referentes a 91 centros de trauma nível I e 56 de nível II, observou-se que 70\% das admissões em centro de trauma I foram de pacientes com ISS $\leq 15$. Esse resultado foi apontado pelo autor como sendo o reflexo do encaminhamento de pacientes considerados com trauma importante no pré-hospitalar, segundo os critérios de triagem, quando de fato não eram. A ocorrência desses casos não indica falha nos critérios de triagem. Sua ocorrência está relacionada à precaução em garantir assistência em centros de trauma aos pacientes que possam ter lesões graves ocultas 
Tabela 07 - Pacientes internados, segundo gravidade do trauma (ISS) e condição de saída hospitalar, IC-HCFMUSP, 1998.

\begin{tabular}{|c|c|c|c|c|c|c|}
\hline \multirow[b]{3}{*}{ ISS } & \multicolumn{6}{|c|}{ CONDIÇÃO DE SAÍDA } \\
\hline & \multicolumn{2}{|c|}{ Sobreviventes } & \multicolumn{2}{|c|}{ Ó bitos } & \multicolumn{2}{|c|}{ Total } \\
\hline & $\mathrm{N}$ & $\%$ & $\mathrm{~N}$ & $\%$ & $\mathrm{~N}$ & $\%$ \\
\hline 1 a 8 & 662 & 50,73 & 3 & 1,35 & 665 & 43,55 \\
\hline 9 a 15 & 334 & 25,59 & 5 & 2,25 & 339 & 22,20 \\
\hline 16 a 24 & 215 & 16,48 & 31 & 13,96 & 246 & 16,11 \\
\hline 25 a 40 & 87 & 6,67 & 116 & 52,25 & 203 & 13,29 \\
\hline 41 a 49 & 3 & 0,23 & 36 & 16,22 & 39 & 2,55 \\
\hline 50 a 74 & 4 & 0,30 & 25 & 11,27 & 29 & 1,91 \\
\hline 75 & - & - & 6 & 2,70 & 6 & 0,39 \\
\hline Total & 1305 & 100,00 & 222 & 100,00 & 1527 & 100,00 \\
\hline
\end{tabular}

Segundo os dados da Tabela 07, denominou-se de sobreviventes os pacientes com os tipos de saída alta hospitalar, transferência para outro hospital, alta a pedido e evasão do hospital.

D entre os sobreviventes, a maioria (76,32\%) possuía escore ISS < 16, o porcentual mais elevado foi verificado no intervalo ISS de 1 a 8 (50,73\%) seguido do intervalo de 9 a 15 (25,59\%). Além disso, observaram sete sobreviventes com escores ISS elevados, três no intervalo de 41 a 49 e quatro no intervalo de 50 a 74.

No grupo de óbitos quase a totalidade $(96,40 \%)$ obteve ISS $\geq 16$, a maioria (52,25\%) concentrou-se no intervalo ISS de 25 a 40.

O valor da média do ISS na população foi 12,49 com desvio-padrão de 12,75. 0 valor médio do ISS obtido entre os sobreviventes foi 8,98 com desvio-padrão de 8,60 e 0 obtido entre os óbitos foi 33,06 com desvio-padrão de 13,7.

Ainda em relação ao ISS, observou-se a distribuição de pacientes, conforme o tipo de trauma para verificar a existência de características diferentes entre os grupos. 
Tabela 08 - Pacientes internados, segundo gravidade (ISS) e tipo de trauma, ICHCFMUSP,1998.

\begin{tabular}{ccccccccccc}
\hline & \multicolumn{10}{c}{ TIPO DE TRAUMA } \\
\cline { 2 - 12 } ISS & $\mathrm{N}$ & $\%$ & $\mathrm{~N}$ & $\%$ & $\mathrm{~N}$ & $\%$ & $\mathrm{~N}$ & $\%$ & $\mathrm{~N}$ & $\%$ \\
\hline 1 a 8 & 425 & 41,59 & 184 & 44,77 & 33 & 53,23 & 23 & 71,88 & 665 & 43,55 \\
9 a 15 & 211 & 20,65 & 109 & 26,52 & 15 & 24,19 & 4 & 12,50 & 339 & 22,20 \\
16 a 24 & 198 & 19,37 & 41 & 9,98 & 7 & 11,29 & - & - & 246 & 16,11 \\
25 a 40 & 135 & 13,21 & 59 & 14,36 & 6 & 9,68 & 3 & 9,38 & 203 & 13,29 \\
41 a 49 & 30 & 2,94 & 7 & 1,70 & - & - & 2 & 6,24 & 39 & 2,55 \\
50 a 74 & 21 & 2,04 & 7 & 1,70 & 1 & 1,61 & - & - & 29 & 1,91 \\
75 & 2 & 0,20 & 4 & 0,97 & - & - & - & - & 6 & 0,39 \\
\hline Total & 1022 & 100,00 & 411 & 100,00 & 62 & 100,00 & 32 & 100,00 & 1527 & 100,00 \\
\hline
\end{tabular}

De acordo com os dados da Tabela 08 verificou-se que 0 padrão da distribuição de pacientes, conforme a gravidade em cada tipo de trauma foi semelhante. A maioria possuía ISS abaixo de 15 independente do tipo de trauma

A média obtida no trauma contuso foi 13,08 variando entre 1 e 75 com desviopadrão de 12,69, no penetrante foi 11,97 variando entre 1 e 75 com desvio-padrão de 13,24, em queimadura foi 8,48 variando entre 1 e 50 com desvio-padrão de 9 e em outros tipos de trauma foi 7,94 variando entre 1 e 43 com desvio-padrão de 11. A média dos valores ISS entre o trauma contuso e o penetrante foi próxima, assim como a média do tempo de permanência no hospital cinco dias para ambos, variando entre zero horas e 157 dias com desvio-padrão de 12 dias para contuso e variando entre zero horas e 61 dias com desvio-padrão 8 dias para o penetrante.

A média do ISS em queimadura foi baixa nesta série, entretanto a média do tempo de permanência foi alta, 26 dias variando entre 8 horas a 135 dias com desvio-padrão de 30 dias. No grupo outros tipos de trauma, embora a média do ISS tenha sido baixa $(7,94)$ como a de queimaduras, os pacientes permaneceram menos tempo no hospital, na média seis dias, variando entre zero horas a 157 dias com desvio-padrão de 13 dias. 
Por outro lado, se a média for analisada de acordo com a condição de saída hospitalar e a gravidade em cada tipo de trauma observa-se que, entre os sobreviventes, houve declínio nítido em seus percentuais conforme o aumento da intensidade da gravidade, independente do tipo de trauma.

A média do ISS no trauma contuso para sobreviventes foi 9,71 variando entre $1 \mathrm{e}$ 50 com desvio-padrão de 8,96 e para óbitos foi 33,63 variando entre 1 e 75 com desviopadrão de 12,77 . No trauma penetrante, a média para sobreviventes foi 7,86 variando entre 1 e 43 com desvio-padrão de 7,82 e para óbitos 33,03 variando entre 10 e 75 com desvio-padrão de 15,28. Em queimadura, a média dos sobreviventes foi 7,14 variando entre 1 e 29 com desvio-padrão de 7,23, para óbitos 21,00 variando entre 1 e $50 \mathrm{com}$ desvio-padrão de 16,98. No grupo outros tipos de trauma, a média para sobreviventes foi 3,52 variando entre 1 e 3 com desvio-padrão de 3,70, para óbitos 31,80 variando entre 25 e 43 com desvio-padrão de 9,33. 
Figura 10 (A-D) - Pacientes internados, segundo tipo de trauma, condição de saída hospitalar e gravidade do trauma (ISS), IC-HCFMUSP, 1998.

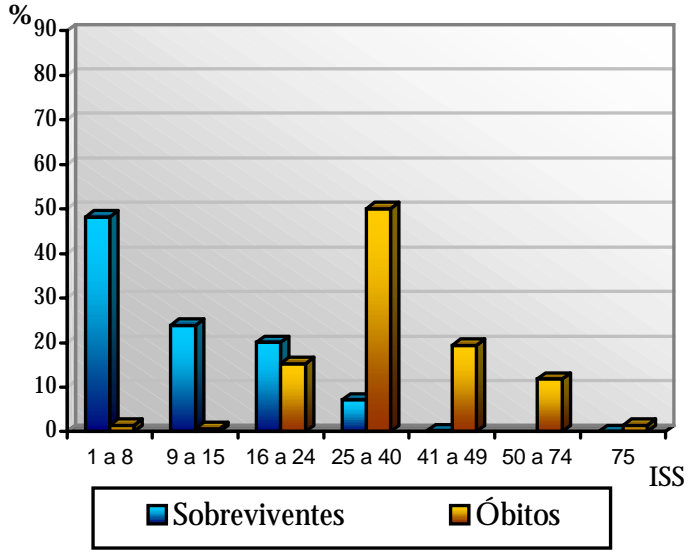

A Contuso ( $\mathrm{n}=1022)$

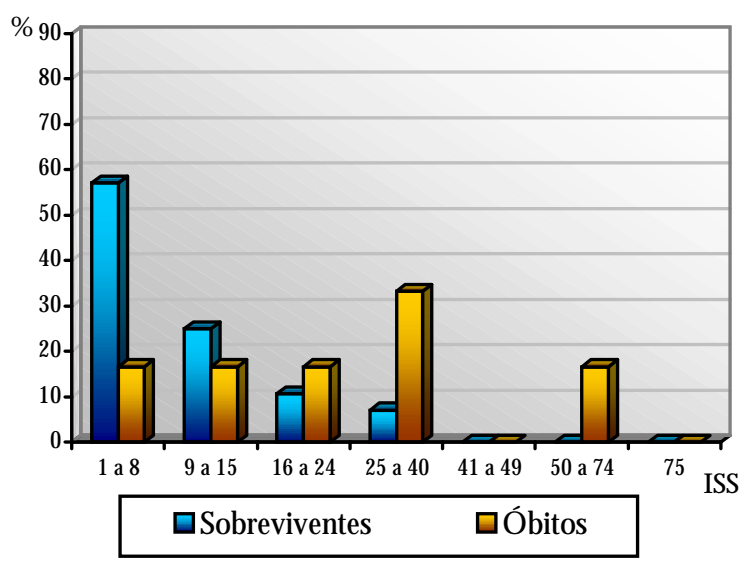

C Q ueimadura $(\mathrm{n}=62)$

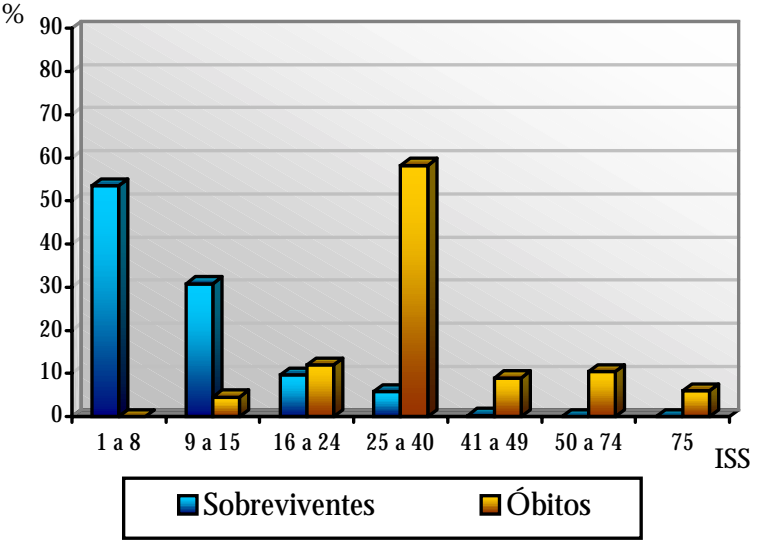

B Penetrante $(\mathrm{n}=411)$

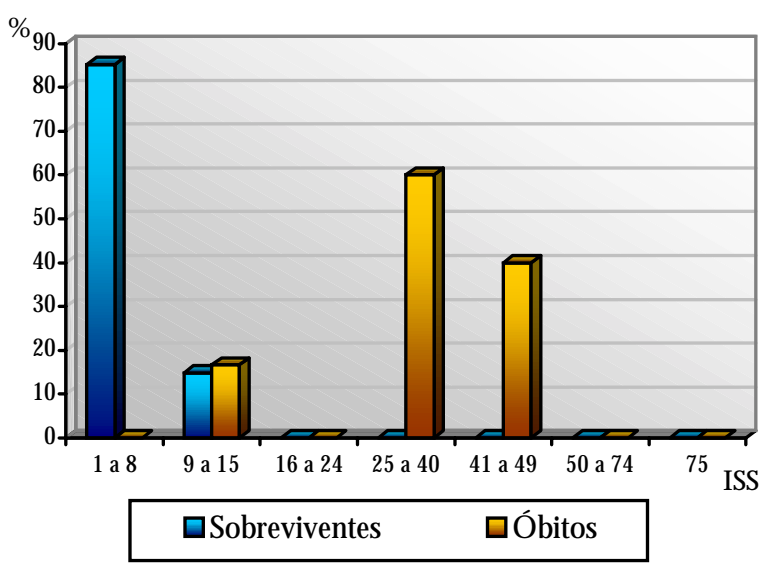

D Outros $(\mathrm{n}=32)$

Em relação aos pacientes que morreram, observou-se maior concentração no intervalo ISS de 25 a 40, como consta na Figura 10 (A-D), em todos os tipos de trauma.

Os percentuais mais elevados de óbitos em escores ISS de 1 a 8 e 9 a 15 foram observados no grupo queimaduras e outros tipos de trauma.

Examinando-se a relação entre escores ISS e a distribuição de óbitos conforme 0 tipo de trauma e idade, COPES et al. (1988b) constataram a ocorrência de concentrações de casos de óbitos em determinados escores ISS. Analisando o fato puderam concluir que a freqüência de óbitos estava relacionada à composição dos três escores AIS no cálculo 
do ISS. Nos escores ISS que incluíam pontuação AIS de maior gravidade em relação ao escore que o antecedia, observaram maior porcentual de óbitos. Os autores exemplificaram o observado com os escores ISS 14 e 16. Para o primeiro, a composição dos escores AIS foi "3,2,1" e o porcentual de óbitos foi 1,1\%; para o segundo, "4,0,0" e 0 porcentual de óbitos foi 14,3\% em razão da existência de um escore AIS 4. Além disso, os autores verificaram que não há como obter todos os escores ISS (1 a 75) por meio das combinações possíveis de três escores AIS. Isso significa, por exemplo, que não há como obter um ISS 15. Partindo desta observação, os autores propuseram intervalos aos escores ISS levando-se em consideração os de maior número de óbitos e também a definição do escore AIS mais elevado em cada intervalo ISS, como é apresentado a seguir:

\begin{tabular}{|ll|}
\hline Intervalo ISS & Lesão de escore AIS mais elevado na composição do ISS \\
$\begin{array}{l}\text { a } 8 \\
9 \text { a } 15\end{array}$ & AIS 2 \\
16 a 24 & AIS 3 \\
\hline $\begin{array}{l}25 \\
40\end{array}$ & AIS 4 \\
41 a 49 & AIS 4 e AIS 5 \\
50 a 66 & Duas AIS 5 e uma AIS 4 \\
\hline 75 & AIS 6 ou três AIS 5 \\
\hline
\end{tabular}

Neste estudo, observou-se porcentual elevado de óbitos, praticamente, nos mesmos escores ISS verificados por COPES et al. (1988b), o que resultou em distribuição, também, semelhante das freqüências dos óbitos (Tabela 07 e Figura 10) nos intervalos recomendados pelos referidos autores.

A existência de óbitos em escores ISS baixos, verificados nos dados da Tabela 07 e nos dados da Figura 10, pode indicar falhas do índice, como também pode estar relacionada a fatores do tipo qualidade dos dados, condição prévia de saúde do paciente ao evento traumático, demora no atendimento pré-hospitalar, tendo em vista tratar-se de um índice anatômico (COPES et al. 1988b; CHAMPION et al. 1990a; ZOLTIE; D O MBAL, 1993; RUTLED GE, 1996a). 
Analisada a gravidade do trauma obtida das lesões anatômicas, constatou-se que a maioria $(65,75 \%)$ da população do estudo foi classificada com escores ISS<16. Considerando-se a evolução do paciente, verificou-se que no grupo sobreviventes, $76,32 \%$ tinham ISS<16, mas no grupo óbitos $96,40 \%$ possuíam ISS $\geq 16$. Observou-se pequena diferença entre a média do ISS no trauma contuso $(13,08)$ e no penetrante $(11,97)$. Em queimadura foi 8,48 e em outros tipos de trauma 7,94. Mas quando observado o ISS conforme a condição de saída, constatou-se diferença nos valores obtidos entre sobreviventes e óbitos em cada grupo de trauma.

Com vistas à análise da probabilidade de sobrevida estimada pelo TRISS, que inclui o ISS, o RTS e a idade do paciente e considerando que a condição do paciente na fase pré-hospitalar pode influenciar o resultado, verificou-se a gravidade do trauma, obtida da variação fisiológica, por meio dos escores RTS.

\subsubsection{GRAVIDADE DO TRAUMA PELO RTS (FASE PRÉ - HOSPITALAR)}

Q uando o RTS é aplicado na fase pré-hospitalar, é mantido em seu valor absoluto, resultante da somatória dos pontos obtidos em cada parâmetro avaliado neste índice (ECGl, FR e PAS). Para diferenciar o RTS utilizado na fase pré-hospitalar (valor absoluto) do RTS calculado para compor o TRISS, denominou-se de RTS- triagem (RTSt) àquele aplicado no pré-hospitalar.

Os dados do RTS-t na Tabela 09 referem-se àqueles aferidos por bombeiros, médicos ou enfermeiros durante 0 atendimento pré-hospitalar que foram recuperados do banco de dados do COBOM e das fichas de atendimento das USA e Águia obtidas no SAMU-SP. 
Tabela 09 - Pacientes internados segundo, os escores RTS-t, da fase pré-hospitalar e condição de saída hospitalar (n=228), IC-HCFMUSP, 1998.

\begin{tabular}{ccccccc}
\hline & \multicolumn{3}{c}{ COND IÇÃO DE SAÍDA } \\
\cline { 2 - 7 } RTS-t* & $\mathrm{N}$ & $\%$ & $\mathrm{~N}$ & $\%$ & $\mathrm{~N}$ & $\%$ \\
\hline 0 & 2 & 6,25 & 30 & 93,75 & 32 & 100,00 \\
7 & - & - & 2 & 100,00 & 2 & 100,00 \\
8 & 1 & 50,00 & 1 & 50,00 & 2 & 100,00 \\
9 & 2 & 33,33 & 4 & 66,67 & 6 & 100,00 \\
10 & 10 & 76,92 & 3 & 23,08 & 13 & 100,00 \\
11 & 32 & 91,43 & 3 & 8,57 & 35 & 100,00 \\
12 & 131 & 94,93 & 7 & 5,07 & 138 & 100,00 \\
\hline Total & 178 & 78,07 & 50 & 21,93 & 228 & 100,00 \\
\hline
\end{tabular}

*Não houve freqüência nos escores RTS-t de 1 a 6.

D o total de 464 pacientes internados que foram atendidos pelo SAMU-SP (Tabela 09), $228(49,14 \%)$ possuíam registro completo dos dados do RTS-t. Entre estes, 138 (60,53\%) foram avaliados e receberam pontuação RTS-t 12, dos quais 131 (94,93\%) pacientes sobreviveram ao evento traumático e 7 (5,07\%) morreram.

Entre os 32 pacientes com escore zero verificou-se que 30 (93,75\%) faleceram e 2 $(6,25 \%)$ sobreviveram.

A correlação dos escores RTS-t (absolutos) com mortalidade foi verificada por Champion et al. (1989) com base nas medidas fisiológicas obtidas de 2.166 pacientes de trauma. Os resultados revelaram que $97,2 \%$ dos casos de óbito e a maioria dos pacientes com trauma importante (ISS $\geq 16$ ) obteve escores RTS-t $\leq 11$, observando-se elevação do porcentual de óbitos conforme os valores dos escores diminuíram.

Neste estudo, observou-se a mesma tendência verificada por CHAMPIOM et al. (1989a), entre escores RTS-t e óbito, entretanto os percentuais de óbito foram mais elevados em cada escore no presente estudo. Este resultado pode estar relacionado à diferença de perfil e do número de casos observados em relação aos de CHAMPIOM et al. (1989a). 
Apesar da forte correlação do RTS com sobrevida e mortalidade, é importante ressaltar que índices fisiológicos, assim como este sofrem influência de variabilidade temporal, propiciando o aparecimento de resultados tanto falso negativo como falso positivo. Na fase pré-hospitalar, quando a aplicação do índice tem a função de triagem de pacientes aos hospitais, conforme a gravidade do trauma, a existência desses resultados pode gerar prejuízos tanto aos pacientes como aos hospitais. Isso significaria aumento da morbi-mortalidade em trauma pelo fato dos pacientes graves não terem sido encaminhados a hospitais adequados e pela utilização desnecessária de recursos em pacientes em razão da falha do índice (MORRIS et al., 1986; BOYD et al., 1987; CHAMPION et al. 1990a).

Segundo LONG; BACHULIS; HYNES (1986), um critério ideal de triagem deveria ser $100 \%$ acurado e ausente de resultado falso negativo ou falso positivo, mas isso é impossível. 0 critério mais próximo do ideal seria 80 a $90 \%$ acurado, inexistência de falso negativo e 15 a $20 \%$ de falso positivo. Considerando as falhas de triagem inerentes na fase pré-hospitalar e um porcentual razoável de falso positivo, poder-se-ia reduzir as chances de subestimar a gravidade do paciente e não encaminhá-lo a um centro de trauma. Para alcançar esse padrão, os autores recomendaram a composição de dados fisiológicos e mecanismos do trauma nos protocolos de triagem de pacientes na fase préhospitalar.

Os resultados do estudo de COTTINGTON et al. (1988) em 2.057 pacientes para avaliar o desempenho do TS ao identificar os de trauma importante (ISS $>15$ ou $>20$ ) também indicaram que, a triagem baseada somente no índice fisiológico resulta em casos falsos negativos ou valor preditivo negativo baixo. D esse modo, sugerem a associação do mecanismo do trauma, região corpórea da lesão, particularmente, tórax e abdome e a avaliação fisiológica para redução dos casos falso negativo em triagem.

O "American College of Surgeons" preconiza 0 algoritmo para triagem de pacientes de trauma na fase pré-hospitalar, observando-se em primeiro lugar os dados fisiológicos (RTS-t), mas compondo-os também com o tipo de lesão, em segundo lugar 0 mecanismo do trauma ou circundantes, em terceiro lugar e por último, a idade, existência de doença ou gravidez. (ACS, 1986, 1999a). Em geral, a prioridade é a redução dos casos 
falsos negativos, porque podem resultar em mortes preveníveis ou morbidade decorrente da demora da assistência definitiva. Uma taxa de 5 a 10\% de falsos negativos é considerada inevitável e está associada com 30 a $50 \%$ de casos falsos positivos (ACS, 1999a).

O processo de triagem de 26.025 pacientes aos centros de trauma em mais de 15 hospitais em Oregon (EUA), no período de dois anos foi analisado por ZIMMERGEMBECK et al. (1995) tendo como referência o ISS. Os autores verificaram que os pacientes graves (ISS $\geq 16$ ) que não foram transportados ao centro de trauma, relacionaram-se a pacientes idosos com lesão única. Por outro lado, o transporte de pacientes de gravidade leve (ISS $<9$ ) ao centro de trauma foi relacionaram-se aos fatores intoxicações, obesidade ou lesão em face ou cabeça.

Os resultados dos estudos de JAGGER et al. (1984) e JURKOVICH et al. (1992) demonstraram a influência do álcool na alteração do nível de consciência, resultando em superestimação da gravidade do trauma nas primeiras seis horas pós-evento. Esse fator pode contribuir para elevação dos casos falsos positivos considerando que, um dos critérios de triagem de pacientes no pré-hospitalar é o nível de consciência, avaliado pela ECGl, que poderá estar alterado pela influência do álcool e não pela gravidade da lesão propriamente dita.

Neste estudo, os dois pacientes que obtiveram escore RTS-t zero e sobreviveram eram jovens (16 e 29 anos). As causas dos eventos ocorridos: ao de 16 anos foi afogamento e ao outro, queda de moto. Ambos apresentaram parada cardiorrespiratória no local do evento. 0 paciente de 29 anos obteve ISS 19, para o outro não há valor ISS por tratar-se de afogamento. Ambos foram transferidos a outro hospital, estes casos não se trataram de resultados falsos positivos, tendo em vista a condição clínica no local do evento, e por terem sido transferidos e considerados sobreviventes, segundo o critério adotado no tipo de saída neste estudo.

A ocorrência de óbito em pacientes com escore RTS-t 12, indicativo de condição fisiológica inalterada ou normal, pode resultar em falso negativo. Fatores relacionados ao paciente, ao tipo de lesão e ao tempo de atendimento pré-hospitalar aliados à triagem feita 
com base, unicamente, no critério fisiológico, propiciam a ocorrência desse tipo de resultado.

D os sete pacientes que obtiveram escore RTS-t 12 e evoluíram com óbito (Tabela 09) todos tiveram ISS $\geq 16$, indicativo de trauma importante. Embora 0 resultado tenha sido o óbito, sob o ponto de vista da triagem de pacientes graves a um hospital terciário e referência para trauma, o encaminhamento foi correto. 0 tempo de atendimento préhospitalar de cinco desses sete pacientes variou de 22 a 72 minutos, exceto uma criança que sofreu queimadura, todos tiveram de trauma contuso e os escores ISS variaram de 21 a 50. Entre os pacientes, havia uma criança de sete anos, três adultos entre 30 e 49 anos e três idosos com idade acima de 70 anos, e dois deles possuíam doenças cardiovasculares. Dois pacientes faleceram com menos de dez horas de permanência no hospital, outros dois faleceram entre 48 e 96 horas e três, depois de um mês.

No estudo de CHAMPION et al. (1989a), os pacientes que obtiveram escores $\leq 11$ permaneceram mais tempo internados, tanto em unidade de terapia intensiva quanto no hospital. Aos que obtiveram escore 12. A média de permanência foi oito e três dias, respectivamente.

Neste estudo, excluindo-se os escores 12 com 94,93\% de sobreviventes e zero com 93,75\% de óbitos, observou-se que nenhum paciente obteve escores de 6 a 1. Nos escores 10 e 11 o porcentual de sobreviventes é predominante, entretanto no escore 80 porcentual de óbitos e sobreviventes foi igual. Os dois pacientes que obtiveram escore 7 faleceram.

Em relação aos dados do RTS-t, chama a atenção o fato de, somente, metade dos pacientes atendidos na fase pré-hospitalar possuírem registro desses dados, uma vez que, tratam-se de parâmetros, freqüentemente, adotados e preconizados pelo ACS (1986, 1999) para triagem pré-hospitalar. Além disso, esses dados, também, são importantes quando se deseja comparar os resultados da assistência pré-hospitalar prestada em nosso meio com resultados de outros serviços.

Tendo-se em vista os resultados da análise da gravidade do trauma com base em índices fisiológicos e anatômicos, a estimativa de probabilidades de sobrevida levando em consideração essas duas variáveis é apresentada a seguir. 


\subsection{PROBABILIDADE DE SOBREVIDA (Ps) ESTIMADA PELO TRAUMA AND INJURY SEVERITY SCORE (TRISS)}

D o total de pacientes com ISS calculado ( $\mathrm{n}=1.527)$, foram excluídos da análise do TRISS aqueles que não possuíam um ou mais dados necessários para o cálculo da Ps. Os pacientes que vieram transferidos de outros hospitais para o IC-HCFMUSP, fizeram parte desse grupo porque os dados da avaliação inicial, do primeiro hospital que os atendeu, não constavam do prontuário do paciente. Além disso, excluíram-se aqueles de origem desconhecida, porque não foi possível concluir se 0 primeiro atendimento que 0 paciente recebeu foi no IC-HCFMUSP. Convém relembrar que os pacientes que sofreram queimadura e os classificados em outros tipos de trauma, embora possuíssem 0 ISS calculado, também, foram excluídos do cálculo da Ps, pois a metodologia TRISS é aplicada somente aos pacientes de trauma contuso e penetrante.

Desse modo, neste estudo o cálculo da Ps utilizando-se 0 método TRISS foi possível somente aos pacientes que possuíam as seguintes condições:

- estar classificado no grupo de trauma contuso ou penetrante (n=1.433),

- ter 0 ISS calculado $(\mathrm{n}=1.433)$,

- não ter sido transferido de outro hospital ou de procedência ignorada (n=801),

- possuir todos os componentes para o cálculo do RTS, mensurados no atendimento inicial no IC-HCFMUSP ( $\mathrm{n}=241)$.

As exclusões efetuadas encontram-se apresentadas a seguir. 


\begin{tabular}{|l|c|}
\hline PACIENTE S EXCLUIDOS & N \\
\cline { 2 - 2 } Transferidos de outros hospitais & 550 \\
Procedência ignorada & 82 \\
\cline { 2 - 2 } Q ueimadura & 62 \\
O utros tipos de trauma & 32 \\
\hline Dados do RTS incompletos & 560 \\
TOT AL & 1286 \\
\hline
\end{tabular}

Excluindo-se os 632 pacientes transferidos ou de procedência ignorada, os 94 pacientes de queimadura e outros tipos de trauma, o principal motivo da exclusão de 560 pacientes da análise TRISS foi a falta de um ou mais dados dos componentes do RTS. Entre estes, o valor absoluto da FR, verificado durante 0 atendimento inicial foi preponderante e não foi registrado em 553 pacientes. A ECGl de 133 pacientes e a PAS de 126 pacientes também não estavam registradas.

Neste estudo, a ausência de registros de um ou mais componentes do RTS foi constatada tanto nos dados da fase pré-hospitalar quanto da hospitalar. A porcentagem da falta de registro em cada uma das fases foi bastante elevada, 50,86\% na fase pré-hospitalar e 69,91\% na hospitalar.

A exclusão de pacientes em razão da ausência de um ou mais dados do RTS, especialmente, a FR para o cálculo do TRISS não tem sido uma peculiaridade dos pacientes deste estudo. Outros autores também relataram a necessidade de excluir pacientes pelo mesmo motivo (STEWART; LANE; STEFANITS,1995; LANE et al., 1996).

YATES; WOODFORD; HOLLIS (1992) ao analisarem dados de 33 hospitais do Reino Unido para verificar a efetividade da assistência ao paciente traumatizado usando as normas do MTOS, observaram que a FR foi o dado não registrado mais freqüente variando entre $41,3 \%$ e $100 \%$ do casos nos hospitais analisados.

GARBER et al. (1996), quando compararam os resultados dos pacientes de trauma contuso tratados em hospitais de Ontário no Canadá, utilizando o TRISS, consideraram como uma das limitações mais significativas do método a necessidade de excluir cerca de 
40 \% dos casos de trauma mais graves, em razão da ausência de registro da FR e do componente verbal da ECGl.

Neste estudo, de 801 pacientes internados que poderiam ter o TRISS calculado, somente 241 (30,09\%) puderam ter a Ps estimada por meio desse método.

D os 241 pacientes da amostra, 194 (80,50\%) eram do sexo masculino e a média de idade foi 32,9 anos e variando de 1 a 89 anos com desvio-padrão de 15,50.

D o total de pacientes da amostra, 181 (75,10\%) eram de trauma tipo contuso e 60 $(24,90 \%)$ do tipo penetrante.

Tabela 10 - Distribuição dos pacientes da amostra $(\mathrm{n}=241)$, segundo a gravidade (ISS) e o tipo de trauma, IC-HCFMUSP, 1998.

\begin{tabular}{lcccccc}
\hline & \multicolumn{7}{c}{ TIPO DE TRAUMA } \\
\cline { 2 - 7 } ISS & \multicolumn{2}{c}{ Contuso } & \multicolumn{2}{c}{ Penetrante } & \multicolumn{2}{c}{ Total } \\
\hline 1 a 8 & 68 & 37,57 & 16 & 26,67 & 84 & 34,85 \\
9 a 15 & 39 & 21,55 & 7 & 11,67 & 46 & 19,10 \\
16 a 24 & 30 & 16,57 & 7 & 11,67 & 37 & 15,35 \\
25 a 40 & 23 & 12,71 & 19 & 31,66 & 42 & 17,43 \\
41 a 49 & 12 & 6,63 & 5 & 8,33 & 17 & 7,05 \\
50 a 74 & 8 & 4,42 & 3 & 5,00 & 11 & 4,56 \\
75 & 1 & 0,55 & 3 & 5,00 & 4 & 1,66 \\
\hline Total & 181 & 100,00 & 60 & 100,00 & 241 & 100,00 \\
\hline
\end{tabular}

Nos dados da Tabela 10 Observa-se, que a maioria ( 53,95\%) dos pacientes recebeu escores ISS abaixo de 16, e essa tendência foi notada mais nitidamente no grupo de trauma contuso do que no de trauma penetrante, $59,12 \%$ e 38,34\%, respectivamente. No trauma penetrante, $43,33 \%$ dos pacientes tinham escores ISS entre 16 e 40, ou seja maior proporção de pacientes com trauma importante.

Na amostra estudada, a mortalidade foi elevada (32,78\%). 
Tabela 11 - Distribuição de pacientes da amostra $(\mathrm{n}=241)$, segundo a gravidade do trauma (ISS) e a condição de saída, ICHCFMUSP, 1998.

\begin{tabular}{lcccccc}
\hline & \multicolumn{6}{c}{ CONDIÇÃO DE SAIDA } \\
\cline { 2 - 7 } & \multicolumn{2}{c}{ Sobreviventes } & \multicolumn{2}{c}{ Ó bitos } & \multicolumn{2}{c}{ Total } \\
ISS & $\mathrm{n}$ & $\%$ & $\mathrm{n}$ & $\%$ & $\mathrm{n}$ & $\%$ \\
\hline 1 a 8 & 84 & 51,85 & - & - & 84 & 34,85 \\
9 a 15 & 44 & 27,16 & 2 & 2,53 & 46 & 19,10 \\
16 a 24 & 24 & 14,81 & 13 & 16,46 & 37 & 15,35 \\
25 a 40 & 9 & 5,56 & 33 & 41,77 & 42 & 17,43 \\
41 a 49 & - & - & 17 & 21,52 & 17 & 7,05 \\
50 a 74 & 1 & 0,62 & 10 & 12,66 & 11 & 4,56 \\
75 & - & - & 4 & 5,06 & 4 & 1,66 \\
\hline Total & 162 & 100,00 & 79 & 100,00 & 241 & 100,00 \\
\hline
\end{tabular}

Os escores ISS entre os sobreviventes e os óbitos foram assim distribuídos, 79,01\% dos sobreviventes com escores abaixo de 16 e 97,47\% dos óbitos obtiveram escores $\geq 16$. Além disso, no grupo de óbitos houve maior concentração de casos (41,77\%) nos escores ISS entre 25 e 40, como apresentado na Tabela 11.

Uma panorama geral dos resultados da amostra com base nas normas do MTOS para estimar a probabilidade de sobrevida pelo TRISS pode ser observada a seguir.

\subsubsection{METOd OLOGia "PRELIMINARY OUTCOME-BASED EVALUATION" - PRE}

Posicionando-se os escores ISS e RTS de cada paciente da amostra na Figura 11, pode-se verificar graficamente 0 resultado individual, comparando-0 com 0 padrão adotado pelo MTOS (TRISS) e identificar os resultados inesperados. 
Figura 11 - Pacientes de trauma contuso e penetrante $(\mathrm{n}=241)$, segundo o ISS e RTS em relação ao limite de 50\% de probabilidade de sobrevida estimada pelo TRISS, IC-HCFMUSP, 1998.

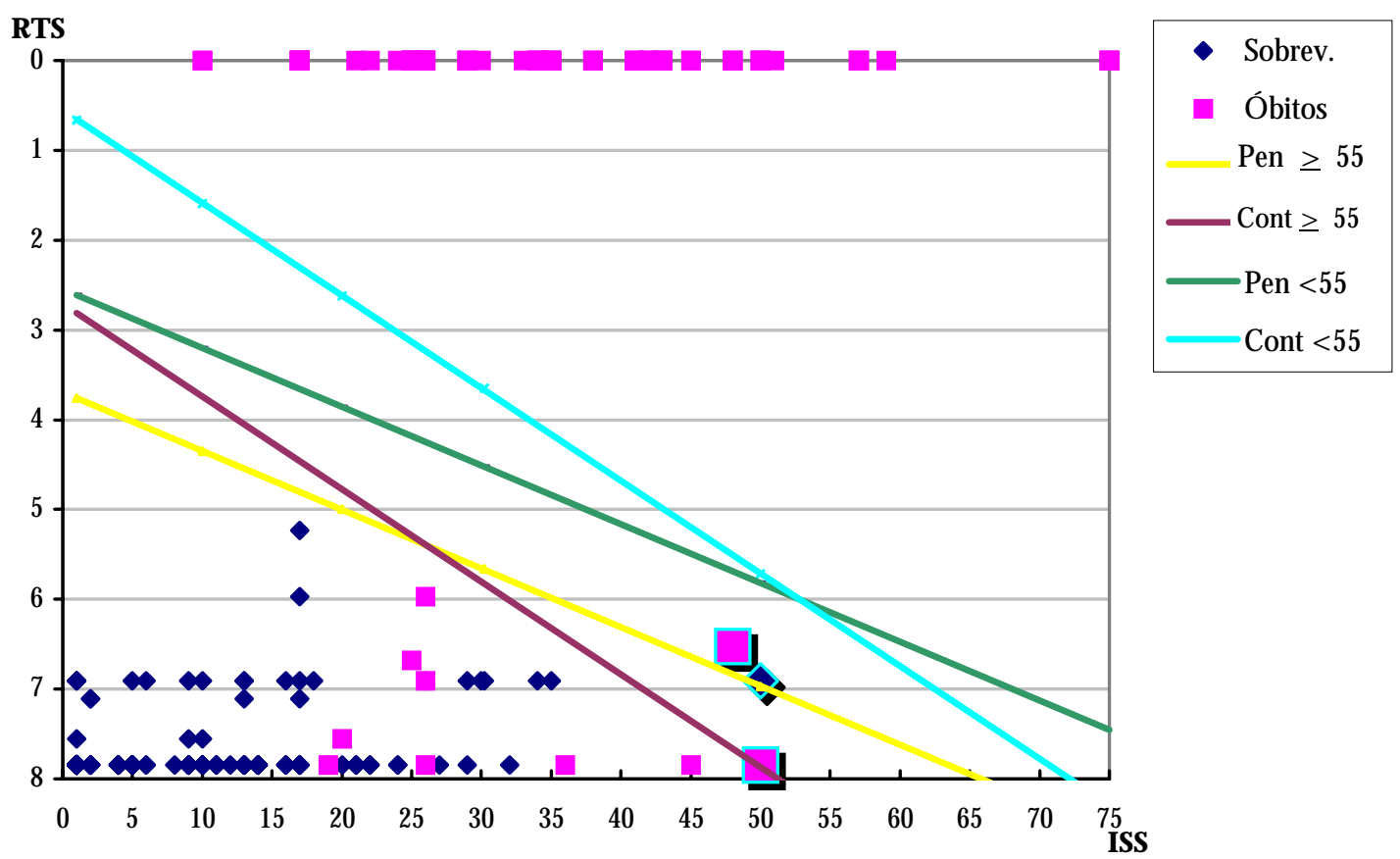

Utilizando-se a metodologia PRE (Figura 11) não foi observada ocorrência de sobrevida inesperada (pacientes com Ps $<0,50$ e que sobreviveram) em nenhuma categoria analisada. Mesmo o sobrevivente posicionado sobre a linha amarela (trauma penetrante $\geq 55$ anos) não se trata de sobrevida inesperada, pois o paciente pertencia ao grupo de trauma contuso como está marcado pela cor azul ao redor do seu identificador na Figura 11. Mas ocorreram 10 mortes inesperadas (óbitos com Ps >0,50).

Chamou a atenção a distribuição de óbitos na Figura 11, mesmo que não tenham sido mortes inesperadas, pois foi observado que pacientes com Ps $<0,50$ todos receberam escore RTS zero, independente do ISS. O escore RTS zero é indicativo de parada cardiorrespiratória, ou seja, a somatória da ECGl foi 3 pontos $(\mathrm{AO}=1, \mathrm{MRV}=1$, MRM=1), com ausência da PAS e da FR . Considerando que os valores do RTS foram obtidos no atendimento inicial, é importante ressaltar que esses pacientes foram admitidos em parada cardiorrespiratória, uma condição desfavorável e de difícil reanimação do paciente. 
A finalidade da metodologia PRE é possibilitar a identificação dos resultados inesperados de forma simples e rápida para se proceder a análise desses casos. Portanto, tendo em vista a existência de dez mortes inesperadas na Figura 11, as características desses pacientes foram descritas para facilitar a análise.

\section{PACIENTE 1}

Sexo: masculino

Idade: 30 anos

Tipo de trauma: contuso

A tendimento pré-hospitalar : SIM (águia) tempo de atendimento :nc

Período de permanência:5h46

RTS:7,84

ISS:19

TRISS:0,99

Lesões: Cabeça: AIS 3

Extremidades e cintura pélvica: AIS 3 e AIS 2

Externa: AIS 1

O bs.: evoluiu com choque hemorrágico e parada cardiorrespiratória.

\section{PACIENTE 2}

Sexo: masculino

Idade: 37 anos

Tipo de trauma: contuso

A tendimento pré-hospitalar : SIM (águia) tempo de atendimento :nc

Período de permanência:3h22

RTS:7,84

ISS: 26

TRISS:0,98

Lesões: Tórax: duas AIS 3 e uma AIS 4

Extremidades e cintura pélvica: AIS 3

Externa: AIS 1

O bs.: evoluiu com hemorragia traumática e choque a esclarecer. 


\section{PACIENTE 3}

Sexo: masculino

Idade: 33 anos

Tipo de trauma: contuso

A tendimento pré-hospitalar : SIM (UR) tempo de atendimento :1h11 (preso

Período de permanência:5h10

RTS:7,84

Lesões: Cabeça: AIS 5

ISS:50

em ferragem)

Tórax: AIS3

Abdome e conteúdo pélvico: quatro AIS 2 e uma AIS 4

Extremidades e cintura pélvica: duas AIS 3 e quatro AIS 2

$\mathrm{O}$ bs.: parada cardiorrespiratória nos raios X e óbito durante a laparotomia

\section{PACIENTE 4}

Sexo: masculino

Idade: 30 anos

Tipo de trauma: contuso

A tendimento pré-hospitalar : SIM (UR) tempo de atendimento : $22 \mathrm{~min}$.

Período de permanência:4 dias

RTS:7,84

ISS:45

TRISS:0,89

Lesões: Cabeça: AIS 5 e AIS 3

Pescoço: AIS 2

Tórax: uma AIS 4 e duas AIS 3

Abdome e conteúdo pélvico: quatro AIS 2

\section{PACIENTE 5}

Sexo: masculino

Idade: 37 anos

Tipo de trauma: contuso

Atendimento pré-hospitalar : SIM(águia) tempo de atendimento : nc

Período de permanência:2 dias

RTS:7,84

ISS:36

TRISS:0,95

Lesões: Cabeça: AIS 4, AIS 3 e AIS 2

Face: AIS1

Abdome e conteúdo pélvico: AIS 2

Extremidades e cintura pélvica: uma AIS 4, duas AIS 3 e três AIS 2 O bs.: parada cardiorrespiratória durante a cirurgia ; coagulação intravascular disseminada e falência de múltiplos órgãos 
PACIENTE 6

Sexo: masculino

Idade: 47 anos

Tipo de trauma: contuso

A tendimento pré-hospitalar : SIM (águia) tempo de atendimento :nc

Período de permanência:1h55

RTS:6,52

ISS:48

TRISS:0,69

Lesões: Cabeça: AIS 4 e AIS 3

Tórax: duas AIS 4 e uma AIS 3

Abdome: AIS 4 e AIS 3

Extremidades e cintura pélvica: três AIS 3 e quatro AIS 2

O bs.: evoluiu com choque hipovolêmico.

\section{PACIENTE 7}

Sexo: masculino

Idade: 69 anos

Tipo de trauma: contuso

A tendimento pré-hospitalar : SIM (UR) tempo de atendimento : 1 h16

Período de permanência:2 dias

RTS:6,90

ISS: 26

Lesões: Cabeça: AIS 5, AIS 4, AIS 3 e AIS 2

TRISS:0,77

Externa: AIS 1

PACIENTE 8

Sexo: feminino

Idade: 59 anos

Tipo de trauma: contuso

A tendimento pré-hospitalar : não

Período de permanência:1 dia

RTS:5,96

ISS:26

Lesões: Cabeça: três AIS 5

TRISS:0,61

Externa: AIS 1

O bs.: hipertensão arterial e diabetes. 


\section{PACIENTE 9}

Sexo: masculino

Idade: 54 anos

Tipo de trauma: penetrante

A tendimento pré-hospitalar : SIM (águia) tempo de atendimento : nc.

Período de permanência: 9 dias

RTS: 7,55

ISS: 20

TRISS: 0,97

Lesões: Abdome: duas AIS 4 e uma AIS 3

Externa : AIS 2

O bs.: choque séptico.

\section{PACIENTE 10}

Sexo: masculino

Idade: 20 anos

Tipo de trauma: penetrante

A tendimento pré-hospitalar : SIM (UR) tempo de atendimento : 25min.

Período de permanência: 1 dia

RTS: 6,67

ISS: 25

Lesões: Abdome: AIS 5, AIS 4, duas AIS 3 e uma AIS 2

TRISS: 0,92

O bs.: choque hemorrágico.

Entre os dez pacientes com resultado inesperado, ou seja, que morreram mesmo tendo Ps estimada pelo TRISS > 50\%, nove eram do sexo masculino e jovens, somente dois pacientes tinham idade acima de 55 anos. Entre esses, observou-se a existência de múltiplas lesões na mesma região corpórea ou em diferentes regiões. Quando existem lesões na mesma região corpórea, o ISS não reflete a gravidade real do paciente visto que esse índice considera somente uma lesão, a de maior escore, de três regiões corpóreas diferentes. Ilustrando com a paciente número oito, observa-se que, sua morte inesperada relacionou-se ao ISS 26, obtido conforme as regras do ISS, por considerar somente uma lesão de AIS 5 (crítica) na região da cabeça e uma de AIS 1 (leve) na região externa. Entretanto, a paciente tinha registro de mais duas lesões de AIS 5 na região da cabeça, além daquela que foi considerada para cálculo do ISS. Nitidamente, percebe-se uma das principais falhas do ISS apontadas por vários autores (CHAMPION et al., 1990a; KARMY-JONES et al., 1992; OSLER, 1993; CHAMPION et al 1996; OSLER; BAKER.; LONG, 1997;). Nos nove pacientes restantes considerados como mortes inesperadas, todos sofreram mais de uma lesão em cada região traumatizada, além daquela considerada no cálculo do ISS. 
Ainda em relação aos resultados inesperados, dos dez pacientes, cinco não apresentaram variações dos parâmetros fisiológicos considerados no RTS, no momento do atendimento inicial na sala de emergência, assim sendo alcançaram o escore máximo. Verificou-se que eram pacientes com idade entre 30 e 37 anos, jovens que caracteristicamente mascaram sua condição real, por serem capazes de compensação fisiológica diante de perdas maciças de volume. Todos os cinco pacientes foram atendidos na fase pré-hospitalar, três foram transportados pelo helicóptero e dois pela UR. Ao utilizar o escore ISS 16 como ponto de corte e indicativo de trauma importante, observou-se que esses pacientes são exemplos de resultados falso negativos na avaliação inicial, ou seja, sem alteração fisiológica do ponto de vista do RTS, mas com trauma importante (ISS $\geq 16$ ), condição que envolve uma avaliação complexa com possibilidade de insucesso.

É importante ressaltar que os resultados analisados foram obtidos tendo como base os coeficientes da população estudada pelo MTOS para o cálculo do TRISS.

\subsubsection{METODOLOGIA "DEFINITIVE OUTCOME-BASED EVALUATION"- DEF}

Considerando os grupos de sobreviventes e óbitos, verificou-se por meio da DEF que os valores de "Z" indicaram que houve diferença estatisticamente significante $(\mathrm{p}<0.05)$, entre a amostra estudada e 0 grupo controle (MTOS). 0 valor de "Z" para 0 grupo de sobreviventes foi -3,4032 e o valor de "Z" para os óbitos foi +3,4032.

Tendo em vista que " $Z$ " mostrou diferença significante na amostra estudada foram calculados os valores de " $\mathrm{W}$ ".

Para o grupo de sobreviventes, o valor de " $W$ " foi -3,1862. Isso indica que, em cada 100 pacientes de trauma tratados, três não evoluíram satisfatoriamente em relação ao grupo controle (MTOS). Portanto, no grupo de óbitos, de acordo com o valor de "W" $(+3,1862)$, verificou-se que houve três óbitos a mais em relação ao MTOS, em cada 100 pacientes. 
Ao verificar os valores de "Z" e " $W$ ", considerando-se o tipo de trauma, observou-se que os valores obtidos pelo grupo de trauma penetrante foram muito mais elevados que os verificados em trauma contuso, como pode ser verificado a seguir.

\begin{tabular}{lcccc}
\hline \multicolumn{3}{c}{ Contuso $(\mathrm{n}=181)$} & \multicolumn{3}{c}{ Penetrante $(\mathrm{n}=60)$} \\
\hline \multicolumn{5}{c}{ Condicão de sáda } \\
& Sobrevivente(n=139) & Ó bito(n=42) & Sobrevivente(n=23) & Ó bito(n=37) \\
\hline valores & -2.6711 & +2.6711 & -7.9021 & +7.9021 \\
\hline "Z" & -3.0955 & +3.0955 & -19.87 & +19.87 \\
"W" &
\end{tabular}

Baseados nas normas do MTOS verificou-se que os resultados da amostra foram estatisticamente diferentes com o padrão MTOS. No entanto, é preciso considerar que nos coeficientes aplicados não foram incluídos pacientes tratados em hospitais brasileiros, portanto, ao utilizar as normas do MTOS, em nosso meio, deve-se analisar os resultados obtidos com cautela.

Assim, a amostra deste estudo com todos os dados para o cálculo do TRISS e que foi comparada com os resultados do MTOS, foi também analisada com vistas à obtenção de coeficientes apropriados a ela.

Para verificar a representatividade da amostra, comparou-se com o grupo de pacientes que potencialmente poderia ter sido incluído na análise do TRISS. As variáveis idade, sexo, tipo de trauma e a mortalidade, utilizados para a comparação entre os dois grupos estão apresentados a seguir. 


\begin{tabular}{|c|c|c|c|c|}
\hline \multicolumn{2}{|c|}{ AMOSTRA } & \multirow[t]{2}{*}{$\mathrm{n}=801$} & \multirow[t]{2}{*}{$\mathrm{n}=241$} & \multirow{2}{*}{$\begin{array}{l}\text { Nível descritivo } \\
\text { (p) }\end{array}$} \\
\hline VARIÁVEL & CONDIÇÃO & & & \\
\hline \multirow[b]{2}{*}{ Idade(média) } & Contuso & 34,36 & 34,00 & 0,7221 \\
\hline & Penetrante & 28,95 & 29,70 & 0,9460 \\
\hline \multirow[b]{2}{*}{ Sexo } & Masculino & $81,77 \%$ & $80,50 \%$ & 0,6096 \\
\hline & Feminino & $18,23 \%$ & $19,50 \%$ & 0,6069 \\
\hline \multirow{2}{*}{ Tipo de trauma } & Contuso & $76,78 \%$ & $75,10 \%$ & 0,5368 \\
\hline & Penetrante & $30,24 \%$ & $33,15 \%$ & 0,3253 \\
\hline \multirow[b]{2}{*}{ Mortalidade } & Sobrevivente & $81,15 \%$ & $67,22 \%$ & $<0,0001$ \\
\hline & Óbito & $23,23 \%$ & $32,78 \%$ & 0,0004 \\
\hline
\end{tabular}

Notou-se que os dois grupos foram estatisticamente iguais em relação a variável idade ( $p>0,05)$, sexo $(p>0,05)$ e mecanismo do trauma $(p>0,05)$.

Em relação à mortalidade, os dois grupos foram diferentes $(p=0,0004)$. Porém esta diferença não seria suficientemente capaz de alterar a magnitude dos coeficientes calculados.

A gravidade do trauma (ISS) também foi comparada entre os dois grupos (Tabelas 10 e 12).

Tabela 12 - Distribuição de pacientes potenciais para análise do TRISS (n=801), segundo a gravidade e o tipo de trauma, IC-HCFMUSP, 1998.

\begin{tabular}{ccccccc}
\hline & \multicolumn{4}{c}{ TIPO DE TRAUMA } & \multicolumn{2}{c}{ Total } \\
\cline { 2 - 7 } ISS & $\mathrm{N}$ & $\%$ & $\mathrm{~N}$ & Penetrante & $\mathrm{N}$ & $\%$ \\
\hline 1 a 8 & 229 & 37,24 & 77 & 41,40 & 306 & 38,20 \\
9 a 15 & 130 & 21,14 & 41 & 22,04 & 171 & 21,35 \\
16 a 24 & 130 & 21,14 & 21 & 11,29 & 151 & 18,85 \\
25 a 40 & 82 & 13,33 & 33 & 17,74 & 115 & 14,36 \\
41 a 49 & 22 & 3,58 & 6 & 3,23 & 28 & 3,50 \\
50 a 74 & 20 & 3,25 & 4 & 2,15 & 24 & 3,00 \\
75 & 2 & 0,33 & 4 & 2,15 & 6 & 0,75 \\
\hline Total Global & 615 & 100,00 & 186 & 100,00 & 801 & 100,00 \\
\hline
\end{tabular}


Os dados da Tabela 12 mostram que a maioria (59,55\%) dos pacientes tiveram escores ISS < 16. Essa tendência foi observada tanto em trauma contuso (58,38\%) quanto no trauma penetrante $(63,44 \%)$. Conforme já apresentado na Tabela 10 , em trauma penetrante houve maior porcentagem de pacientes com ISS $\geq 16$ comparado ao grupo da tabela 12. Entretanto, verificou-se que não houve diferença estatisticamente significante da gravidade do trauma entre os dois grupos $(p=0,43)$.

Considerando a amostra representativa, processou-se a análise descritiva das variáveis sexo e tipo de trauma desses pacientes, segundo suas condições de saída do hospital, ou seja sobrevivente ou óbito.

Em relação à variável sexo, constatou-se que não houve diferença na distribuição de óbitos em ambos os sexos $(\mathrm{p}=0,127)$. Quanto ao tipo de trauma, percebeu-se que os pacientes com trauma penetrante apresentaram maior propensão à morte em relação ao trauma contuso $(\mathrm{p}<0,001)$.

Observou-se diferença nos escores médios de RTS $(p<0,001)$ e ISS $(p<0,001)$ entre sobreviventes e óbitos, mas não houve diferença entre as médias de idade nesses dois grupos $(p=0,823)$, como pode ser verificado a seguir.

\begin{tabular}{clccccc}
\hline Variável & Condição & Freqüência & Média & $\begin{array}{c}\text { Desvio- } \\
\text { padrão }\end{array}$ & $\begin{array}{c}\text { Erro-padrão } \\
\text { da média }\end{array}$ & $\begin{array}{c}\text { Nível descritivo } \\
\text { (p) }\end{array}$ \\
\hline Idade & Sobreviventes & 162 & 33,13 & 16,32 & 1,28 & 0,823 \\
& Ó bitos & 79 & 32,66 & 13,75 & 1,55 & $(\mathrm{~ns})$ \\
\hline \multirow{2}{*}{ RTS } & Sobreviventes & 162 & 7,68 & 0,39 & 0,03 & $<0,001$ \\
& Ó bitos & 79 & 0,92 & 2,45 & 0,27 & \\
\hline \multirow{2}{*}{ ISS } & Sobreviventes & 162 & 8,89 & 8,89 & 0,70 & $<0,001$ \\
& Ó bitos & 79 & 35,77 & 15,04 & 1,69 & \\
\hline \hline
\end{tabular}

As variáveis tipo de trauma, RTS e ISS que se mostraram diferentes entre sobreviventes e óbitos foram consideradas na análise de regressão logística para obtenção dos coeficientes de estimação da probabilidade de sobrevida dos pacientes da amostra deste estudo. 
Os coeficientes derivados da regressão logística para tipo de trauma, RTS, ISS e 0 intercepto e seus respectivos erros-padrão, razão de chances e nível descritivo (p) estão apresentados a seguir.

\begin{tabular}{ccccc}
\hline Variável & Coeficiente & Erro-padrão & Razão de chances & Nível descritivo $(\mathrm{p})$ \\
\hline Mecanismo & 2,3155 & 1,1350 & 10,1301 & 0,0413 \\
RTS & 1,0082 & 0,3143 & 2,7407 & 0,0013 \\
ISS & $-0,1696$ & 0,0425 & 0,840 & 0,0001 \\
Intercepto & $-3,3396$ & 2,517 & - & - \\
\hline
\end{tabular}

Assim, a probabilidade de sobrevida dos pacientes da amostra do estudo em função de tipo de trauma, RTS e ISS foi calculada com a seguinte fórmula:

$$
P s=\frac{1}{1+e^{-b}}
$$

onde $b=-3,3396+2,3155$ (contuso)+1,0082(RTS) $-0,1696$ (ISS)

quando aplicado em trauma penetrante não se aplica 0 coeficiente de valor 2,3155.

Para obter maior precisão nas estimativas, ajustou-se um único modelo contendo a variável tipo de trauma como preditora.

Convém salientar que os coeficientes do MTOS não estão baseados na população, mas foram derivados tendo em vista mais de 170.000 pacientes de trauma internados.

Novamente, verificou-se 0 resultado individual graficamente posicionando-se os escores ISS e RTS de cada paciente para identificar os resultados inesperados, mas desta vez foram usados os coeficientes ajustados para a amostra deste estudo. Para melhor observação dos resultados, os grupos de pacientes foram apresentados conforme os tipos de trauma, contuso e penetrante, separadamente. Outrossim, para facilitar a identificação e comparação dos grupos que foram analisados utilizando-se os coeficientes do MTOS e os derivados da amostra deste estudo, denominou-se o último de TRISS-hc. 
Figura 12 - Pacientes internados com trauma contuso $(n=180)$, segundo o ISS e RTS em relação ao limite de 50\% de probabilidade de sobrevida estimada pelo TRISS-hc, IC-HCFMUSP, 1998.

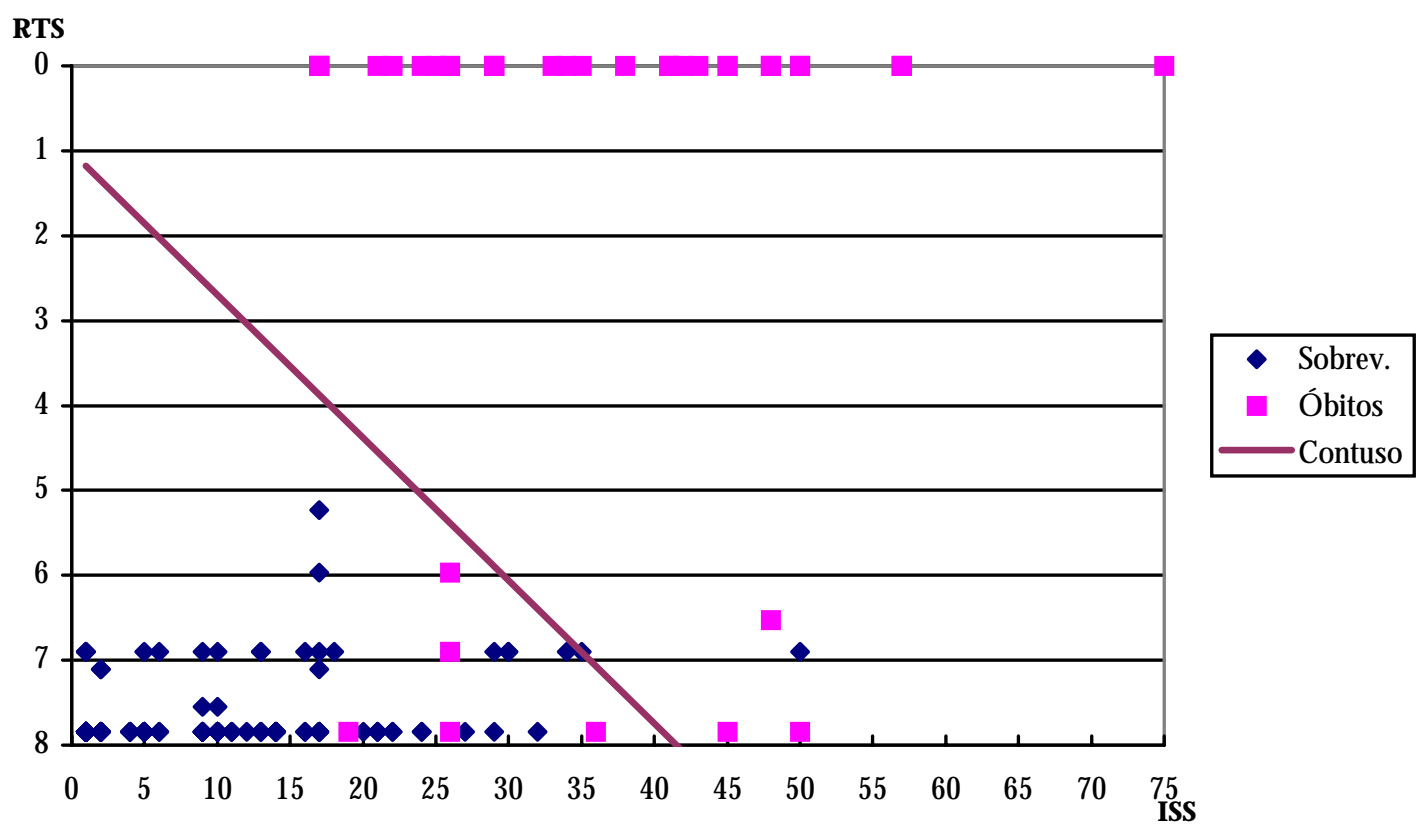

Figura 13 - Pacientes internados com trauma penetrante $(n=60)$, segundo o ISS e RTS em relação ao limite de 50\% de probabilidade de sobrevida estimado pelo TRISS-hc, IC-HCFMUSP, 1998.

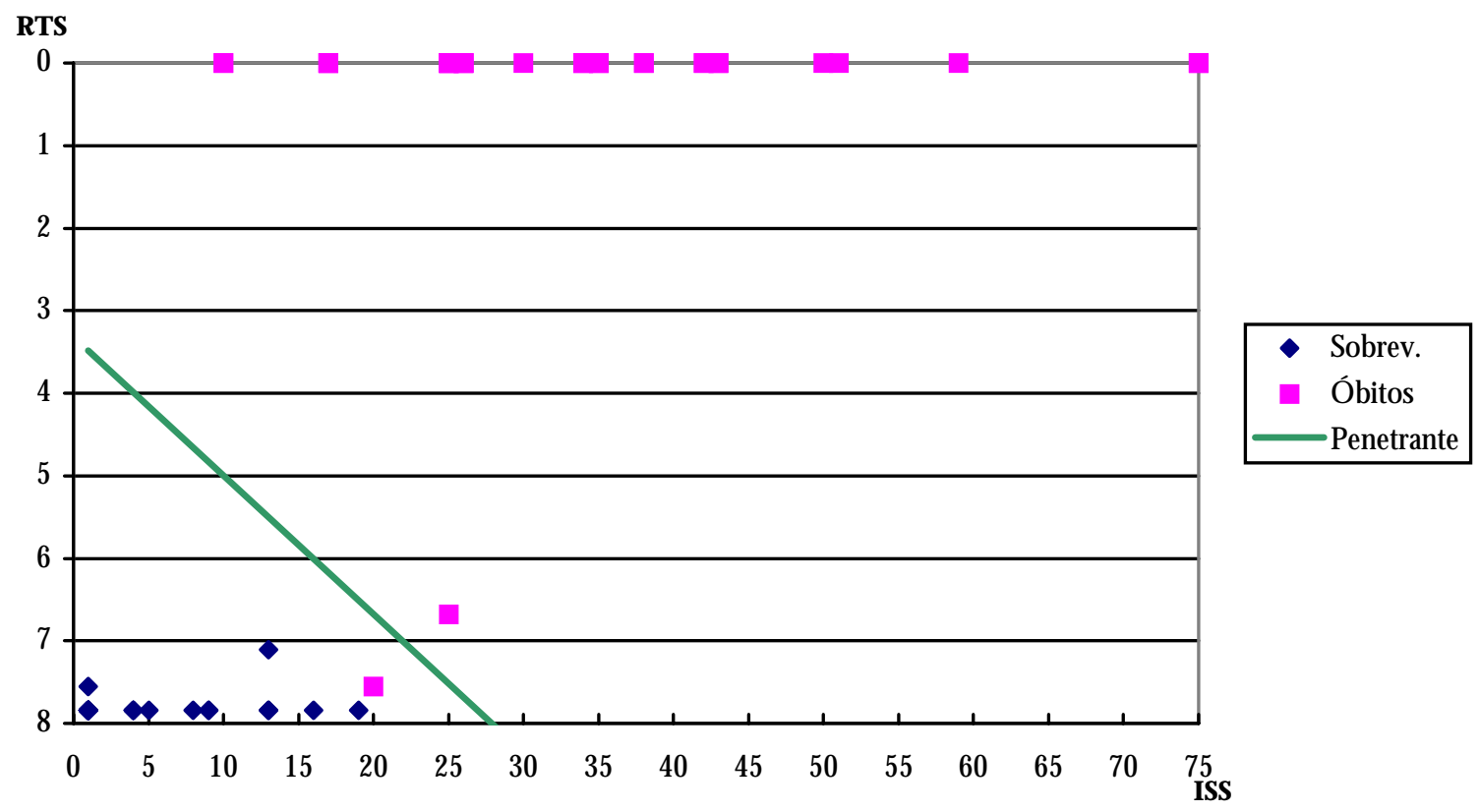


Pela Figura 12 foi possível verificar que, com a utilização de coeficientes ajustados na obtenção do TRISS-hc, os resultados individuais foram diferentes no grupo de pacientes com trauma contuso, em relação àqueles observados com o uso dos pesos do MTOS (TRISS). Excluídos os pacientes de trauma penetrante, verificou-se a ocorrência de cinco mortes inesperadas pelo com o TRISS-hc. Além disso, observou-se uma sobrevida inesperada indicativa de resultado positivo para a assistência prestada.

Com o ajuste, ocorreram cinco mortes inesperadas, esses são, potencialmente, merecedores de revisão pelos pares (peer review) para identificar e analisar a(s) causa(s) de insucesso, considerando o sistema de atendimento integrado ao traumatizado como um todo.

Em relação aos resultados do grupo de pacientes com trauma penetrante (Figura 13), verificou-se que a linha indicadora de Ps de 50\% obtida com o TRISS-hc restringiu drasticamente a área para Ps $>50 \%$ do trauma penetrante, o que significa a redução da chance de sobreviver nesse tipo de trauma. Nesse grupo observou-se uma morte inesperada, não houve casos de sobrevida inesperada.

$\mathrm{Na}$ amostra de pacientes utilizada para derivar os coeficientes do TRISS-hc, percebeu-se que a mortalidade foi elevada (32,78\%). Entre os pacientes de trauma contuso ( $n=181$ ), o porcentual de mortos foi $23,20 \%$ e entre os de trauma penetrante $(n=60)$, esse valor foi 2,5 vezes maior $(61,67 \%)$, o que influenciou os coeficientes ajustados para esse grupo.

O valor da razão de chances de 10,13 é indicativa de que a chance de óbito em trauma penetrante foi dez vezes a chance de óbito em trauma contuso na amostra.

Convém ressaltar que todos os 60 pacientes com trauma penetrante da amostra fizeram parte do grupo de agressões enquanto causas externas, sendo 41 por meio de arma de fogo. Entre os 37 casos de óbitos, 35 sofreram agravos por terem sido atingidos por arma de fogo. Os dados chamam a atenção por envolverem lesões provocadas intencionalmente com elevada mortalidade.

A adoção de duas grandes categorias, trauma contuso e penetrante, mascararam variações das taxas de mortalidade entre os diferentes tipos de eventos. 0 fato foi observado por CAYTEN et al. (1991) que compararam resultados inter-instituições de 
oito hospitais americanos. Assim, no trauma penetrante a mortalidade e o valor de "Z" de locais com grandes proporções de pacientes com ferimento por arma de fogo foram comparados, desfavoravelmente, com hospitais que possuem percentuais mais elevados de pacientes feridos por arma branca. Em trauma contuso, a peculiaridade foi observada no grupo de quedas (excluída a de altura) que caracteristicamente ocorre em pessoas do sexo feminino, idosas acometidas por fraturas isoladas, que resultam em internações prolongadas. Em vista destas peculiaridades, os autores sugerem a utilização de coeficientes específicos nos grupos que possuem diferentes taxas de mortalidade.

Outra observação feita por CAYTEN et al. (1991) relacionou-se à falha na predição de resultados em pacientes com múltiplas lesões graves na mesma região corpórea, comum em ferimento por arma de fogo em abdome, conseqüência esta determinada pela regra do ISS, um dos componentes do TRISS.

CORNWELL et al. (1998) também verificaram que o TRISS não distingue os pacientes acometidos por arma de fogo daqueles por arma branca no trauma penetrante, o que resulta em Ps superestimada ao grupo com ferimento produzido por arma de fogo. A constatação foi feita após a análise de 39 casos de lesões penetrantes em abdome por arma de fogo considerados mortes inesperadas, pelo TRISS, identificadas entre 848 pacientes admitidos em hospital norte-americano. Na revisão feita pelos pares das 39 mortes inesperadas, 38 foram consideradas como não preveníveis e somente, um caso, como potencialmente prevenível. A razão apresentada pelos autores à limitação do TRISS nesse tipo de paciente estava relacionada à regra do ISS que não considera múltiplas lesões em uma única região corpórea. Para melhorar a predição dos resultados, sugeriram o cálculo de coeficientes específicos ao TRISS ajustados às diferentes modalidades em cada tipo de trauma.

A ampla utilização do TRISS para avaliação da assistência em trauma possibilita verificar vantagens e desvantagens em sua aplicação. Mas a busca por um instrumento ou a melhoria dos existentes capazes de mensurar a qualidade da assistência em trauma tem sido uma constante por estudiosos envolvidos na área.

Considerando a existência de diferenças entre a população do MTOS e a da província de Ontário no Canadá, LANE et al. (1996) derivaram coeficientes para 0 
TRISS, específicos para analisarem os resultados de pacientes atendidos em 12 centros de trauma na província em questão. Os valores de "Z" para trauma contuso variaram de 10,26 a +1,84 utilizando-se os coeficientes do MTOS. Ajustando-se à população de Ontário os valores de "Z" variaram de -4,12 a +2,78. A adequação dos coeficientes permitiu uma avaliação de desempenho mais apropriada entre os centros de trauma da própria província.

A mensuração do desempenho entre instituições por meio da utilização de modelos estatísticos pressupõe, em primeiro lugar, a verificação da distribuição dos fatores de risco relacionados à mortalidade da população a ser estudada. Uma vez constatada a semelhança desses fatores entre os grupos, será possível aplicar o modelo e comparar a mortalidade observada com a estimada, ou seja, como se tivesse sido atendida na instituição que serviu de base ao modelo estatístico. Por outro lado, dados que não são próprios à metodologia estatística, não significam falha do método ou da assistência prestada, mas simplesmente características diferentes entre as populações que se deseja comparar (Jones, 1995abc).

Por vezes, a identificação de resultados inesperados por meio do TRISS, leva à constatação das limitações do próprio método.

Os resultados inesperados identificados com o uso do TRISS em três centros de trauma nível I dos EUA foram analisados por KARMY-JO NES et al. (1992). D o total de 2.023 pacientes, 50 foram considerados resultados inesperados pelo TRISS. A análise processada pelo grupo de auditores, feita em cada instituição, considerou 26 mortes e 1 sobrevida inesperada discordantes com os 50 pacientes identificados pelo TRISS. Entre as 26 mortes inesperadas, 13 casos foram discordantes em decorrência da limitação do ISS e nove pela subestimação da gravidade da lesão pela AIS 85. A limitação do ISS apontada pelos autores relacionou-se à própria regra. Como o ISS considera somente uma lesão, a de maior escore, de três diferentes regiões corpóreas, a gravidade real do paciente era subestimada na vigência de outras lesões na mesma região, por vezes mais graves que as consideradas para o cálculo do ISS. Q uanto a AIS 85, foram apontadas algumas lesões crânio-encefálicas que não eram previstas na versão utilizada. A sobrevida inesperada verificada pelo TRISS, mas não aceita pelos auditores foi em razão da constatação do uso 
de curare e benzodiazepínico na fase pré-hospitalar, resultando em RTS baixo. Contudo, os autores consideraram válida a utilização do TRISS no processo de avaliação da qualidade da assistência, visto que a revisão dos casos pelos pares pode ser feita com base na identificação objetiva e padronizada de resultados inesperados.

Uma nova proposta para melhorar o poder preditivo do ISS foi apresentada por BAKER (1997), denominada de New Injury Severity Score (NISS). Trata-se de uma proposta para melhorar o poder preditivo do ISS. Partindo-se da premissa de que o ISS considera lesões com maior AIS em três diferentes regiões do corpo, surge conflito com 0 princípio fundamental em trauma, pois as lesões mais graves devem ser priorizadas em relação às menos graves. Para corrigir esta falha, o NISS propõe um novo cálculo para mensurar a gravidade do trauma: a soma dos quadrados dos três escores mais elevados, independente da região do corpo (O SLER et al., 1997).

Observou-se os casos de trauma contuso, estimados como morte inesperada pelo TRISS-hc, considerando a proposta de BAKER (1997). Os cinco casos eram pacientes com múltiplas lesões em uma ou várias regiões corpóreas. Assim, pode-se constatar que ao levar em consideração os escores AIS mais elevados para o cálculo do NISS, todos tiveram os valores NISS superiores aos do ISS. 0 exemplo mais nítido foi a paciente com o número 8, cujo ISS foi 26 e o NISS 75, pois outras duas lesões de escores AIS 5 na região da cabeça, foram consideradas.

Para melhorar as limitações relacionadas ao ISS, ao RTS e à variável idade no TRISS, foi proposto o ASCOT. O nde o ISS foi substituído pelo Anatomic Profile que valoriza lesões e regiões corpóreas que influenciam a Ps, dessa forma, atribui pesos maiores para essas variáveis. A proposta inclui uma estratificação mais detalhada de faixas etárias que se relacionam melhor com mortalidade (CHAMPION et al., 1990a; COPES et al., 1990).

Uma das limitações ao uso do TRISS, freqüentemente, relatada nos estudos é a ausência de algum(s) parâmetro(s) do RTS. Entre os mais problemáticos está a FR e/ ou a resposta verbal da ECGl. 
Neste estudo, a ausência da FR foi o principal motivo de exclusão de pacientes para análise da Ps por meio do TRISS. Do total de 801 pacientes potencialmente classificáveis para a análise, 553 não tinham esse dado registrado.

Tendo em vista que as normas do MTOS foram derivadas com base em variáveis fisiológicas obtidas durante 0 atendimento inicial do paciente no centro de trauma, aqueles que desejam utilizar a metodologia TRISS, obedecem a mesma sistemática adotada pelo MTO S para reproduzir os dados e evitar tendenciosidades.

A fidelidade em reproduzir os dados com o rigor do MTOS resulta na exclusão de pacientes, por vezes, graves. Isso ocorre em razão da existência de serviços de atendimento pré-hospitalar que realizam procedimentos como entubação endotraqueal, administração de sedativos, curares necessários aos pacientes graves que interferem na obtenção da FR e na avaliação da ECGl.

Assim, como as variáveis do RTS são verificadas na admissão do paciente no centro de trauma, as variações ocorridas no atendimento pré-hospitalar não são consideradas. Mesmo que as variáveis tivessem sido obtidas antes da execução dos procedimentos pela equipe do pré-hospitalar.

Tendo em vista a ampla utilização da ECGl e preocupados com a exclusão de pacientes nas avaliações da assistência ou o desconhecimento da forma alternativa para contornar essa dificuldade, que poderia influenciar os resultados dos estudos, pesquisadores têm verificado a confiabilidade da aplicação e as formas alternativas. Observaram a existência de variações na conduta para obtenção de respostas e todos salientaram a importância do treinamento e a uniformização do padrão a ser adotado na impossibilidade de obtenção de algum indicador da ECGl (ROWLEY ;FIELD ING , 1991; MENEGAZZI et al., 1993; MARION; CARLIER, 1994b; MARION, 1994a; BUECHLER et al., 1998; ALVES, 1998).

Índices de trauma foram testados em pacientes de trauma na Alemanha para verificar a validade de sua utilização naquele meio, por BOUILLON et al. (1997). A proposta incluiu também a adoção dos valores da ECGl e ou da FR obtidos pelo médico durante 0 atendimento pré-hospitalar. Esta opção foi escolhida pelos autores porque 0 estudo foi realizado em um sistema de trauma desenvolvido e eficiente. Observando-se 
que os índices mostraram correlação com os resultados percebidos, os autores recomendaram a utilização de dados fisiológicos obtidos na fase pré-hospitalar para 0 RTS compor o TRISS.

A utilização do RTS obtido na fase pré-hospitalar, como alternativa para se processar o cálculo do TRISS parece ser uma solução viável. Contudo, há necessidade desses dados estarem registrados para que possam ser recuperados. Neste estudo, só, aproximadamente, metade dos pacientes que foram atendidos na fase pré-hospitalar, possuíam tais dados registrados.

Outra alternativa para aplicar o TRISS em pacientes sem a variável FR ou um componente da ECGl foi apresentada por Harviel et al.(1989), consistiu na utilização do escore máximo e mínimo da variável no RTS (zero e quatro). Portanto, o paciente terá duas Ps calculadas pelo TRISS, a mínima e a máxima. Com esses valores posicionados no gráfico PRE será possível observar aqueles com resultados inesperados. Casos em que a faixa da Ps estimada recair sobre a linha da Ps 50\% deverão ser revisados.

HANNAN et al.(2000) aplicaram dois modelos preditores de mortalidade para pacientes internados em decorrência de acidente de veículo a motor baseado na resposta verbal (ECGl) e FR. Concluíram que a inclusão ou não das variáveis influenciaram pouco ou quase nada a capacidade preditiva de mortalidade nos modelos estudados. Entretanto, constataram que a entubação endotraqueal foi o melhor preditor de mortalidade na população estudada.

A dificuldade na obtenção do indicador "resposta verbal" da ECGl resultou em alternativas apresentadas e confirmadas por vários pesquisadores. Basicamente, trata-se da utilização da variável "resposta motora" ou da composição desta com a variável "abertura ocular". Os autores dos estudos confirmam a capacidade preditiva dessas modalidades alternativas que permitem avaliar pacientes entubados e incluí-los na análise do TRISS (MERED ITH et al., 1995, 1998; RUTLEDGE et al., 1996b; RO SS et al.,1998).

OFFNER et al. (1992) foram os precursores do uso de uma variação na composição dos dados fisiológicos para compor o TRISS. Da ECGl seria utilizada somente a resposta motora, por ser o dado de melhor predição do resultado e do RTS somente a PAS. Os autores observaram que a sensibilidade, a especificidade e 0 erro de 
classificação da nova proposta foram semelhantes $(57,0 \%, 98,9 \%$ e 3,6\%) às verificadas no TRISS $(58,8 \%, 99,3 \%$ e 3,0\%).

A proposta de OFFNER et al.(1992) é uma maneira de reduzir o viés de seleção que ocorre quando da utilização do TRISS por excluir pacientes entubados, sedados ou curarizados que freqüentemente são os mais graves. A denominada de "TRISS-like" foi testada por vários autores e por mostrar desempenho semelhante e, às vezes, melhor que o próprio TRISS está sendo apontada como um índice promissor para avaliação da assistência em trauma (STEWART et al., 1995; GARBER et al., 1996; GARBER et al., 1997).

LANE et al. (1997) além de utilizar o "TRISS-like" em Ontário no Canadá para comparar os resultados entre 11 centros de trauma, ajustou os coeficientes para a população do estudo. Comparando os resultados obtidos por meio do TRISS-like com os obtidos pelo TRISS, observaram que os novos coeficientes foram mais acurados na predição de resultados.

$O$ estudo de LANE et al. (1997) foi considerado por JURKOVICH; MOCK (1999) um importante exemplo de limitação do uso da base de dados do MTOS como referência de norma nacional ou internacional. Características regionais específicas podem distorcer resultados obtidos por meio de instrumentos construídos com base em outra população, portanto nem sempre estarão ajustados às peculiaridades do grupo em estudo.

Considerando-se o tamanho da amostra utilizada para derivar os coeficientes do TRISS-hc, recomenda-se que pesquisas que incluam um maior número de pacientes sejam realizadas.

Com base nas observações de COTTINGTON; SUFFLEBARGER; TOWNSEND (1989), é prudente levar em consideração os fatores que influenciam 0 poder da estatística "Z" em detectar diferenças entre a sobrevida observada e estimada, tais como a magnitude e direção da diferença, a distribuição das probabilidades de sobrevida e o tamanho da amostra estudada.

Os modelos matemáticos para predição de resultado são os recursos utilizados para avaliação e comparação da assistência, utilizando-se um meio objetivo e de 
linguagem uniforme. No entanto, dependendo do critério adotado, os dados sob análise podem gerar resultados tendenciosos.

CLARK (1999) aponta algumas fontes de viés em estudos de trauma. Por exemplo, a exclusão de pacientes com determinada característica, pacientes com fratura em quadril que freqüentemente ocorre em idosos, pode resultar em mortalidade e morbidade diferentes quando comparadas com estudos que incluem esse grupo de pacientes, consistindo-se em viés de seleção. Um exemplo de viés de informação relaciona-se à dificuldade de obtenção da ocorrência de óbito, logo após a alta hospitalar ou transferência do paciente, e caso seja de ocorrência freqüente em um grupo, poderá distorcer a diferença do resultado. Para reduzir as chances de ocorrência de viés, especialmente de seleção e de informação, o autor recomenda que os critérios de inclusão e exclusão sejam cuidadosamente padronizados e explícitos em qualquer tipo de estudo multiinstituicional ou não e também na construção da base de dados. O bserva ainda que qualquer comparação numérica entre grupos de pacientes exige cuidadosa análise da qualidade e existência dos dados para daí, se possível, proceder a comparação.

As análises sobre avaliação da assistência em trauma que utilizam base de dados estruturadas para a metodologia TRISS que permitiram comparação entre os resultados com as normas do MTOS foram analisados por JURKOVICH; MOCK (1999). O objetivo foi verificar se a base de dados é um meio apropriado para avaliar a eficácia em serviços de trauma. Entre os 11 estudos analisados, os autores identificaram as causas que limitam a validade e a generalização dos achados, os erros na codificação da lesão e fatores que determinam variações da gravidade do trauma presentes nessas bases de dados.

Segundo SAMPALIS et al. (1995) a validade do ISS depende da qualidade da informação sobre a lesão registrada no prontuário do paciente. A inexistência de registro da lesão, a falta de detalhes específicos e a codificação AIS errada podem gerar escores ISS subestimados.

KRAMER et al. (1995) compararam a qualidade do resumo clínico de alta e o prontuário, em relação a natureza da lesão e gravidade do trauma, de 83 pacientes internados em 14 hospitais. Discrepâncias importantes sobre a distribuição, natureza e 
gravidade das lesões foram constatadas entre essas duas fontes de dados. No resumo clínico de alta não havia registro de 52\% das lesões intracranianas, 30\% das fraturas de coluna, 28\% das lesões torácicas, $15 \%$ das fraturas de crânio, pélvica e membros superiores e $5 \%$ de fraturas em membros inferiores. Consequentemente, a gravidade do trauma calculada com base nas lesões, foi discordante entre estas duas fontes de dados, principalmente no grupo de pacientes mais graves. Os autores verificaram que o uso do resumo clínico de alta não se mostrou adequado para quantificar e mensurar a gravidade da lesão e do trauma, por ser um registro com propósitos voltados, principalmente, para cálculos de custos e reembolso.

A obtenção de um padrão para comparação de resultados em trauma e mesmo a comparação de resultados entre instituições tem sido um desafio. Tratando-se de um evento multifacetado que resulta em inúmeras combinações, é necessário que outros paradigmas sejam desenvolvidos para alcançar o estado da arte na comparação dos dados do paciente traumatizado.

Neste estudo, o fator limitante para a avaliar os resultados da assistência com o uso do TRISS foi a inexistência do registro de dados utilizados para seu cálculo. A ausência de dados para mensurar a gravidade do trauma relacionou-se, essencialmente, à inexistência de dados fisiológicos tanto os obtidos na fase pré-hospitalar quanto na hospitalar. Sob ponto de vista anatômico, a gravidade do trauma pôde ser mensurada para, praticamente, a totalidade dos pacientes com lesões previstas no Manual AIS, desconsideradas aqui quanto à qualidade dos dados.

A aplicação do TRISS na amostra deste estudo revelou dez casos de morte inesperada identificados pela metodologia PRE. Além disso, os valores da estatística "Z" tanto para pacientes com trauma contuso $(2,67)$ quanto penetrante $(7,90)$ foram indicativos de que a amostra foi estatisticamente diferente da população do MTOS. Da mesma forma, os valores de "W" para trauma contuso $(3,09)$ e para penetrante $(19,87)$ indicaram resultados clínicos diferentes na amostra deste estudo em relação ao MTOS. Mas ajustando-se os coeficientes do TRISS à amostra estudada, observou-se resultados diferentes por meio do método PRE. Em trauma contuso, ocorreram cinco mortes 
inesperadas e uma sobrevida inesperada. Em trauma penetrante, houve uma morte inesperada e não se observou sobrevida inesperada.

Espera-se que este estudo ofereça subsídios para ações preventivas e melhoria da qualidade da assistência aos pacientes hospitalizados em decorrência das causas externas. 


\section{Conclusões}




\section{CONCLUSÕES}

Os resultados deste estudo referentes a 1.781 pacientes de causas externas internados no IC-HCFMUSP no ano de 1998, permitiram as conclusões que se seguem.

Os principais tipos de causas externas que determinaram a hospitalização da população estudada, foram os acidentes de transporte, as agressões e as quedas. Os eventos com o maior porcentual em cada grupo citado foram, respectivamente, atropelamento, agressão por arma de fogo e queda de altura. A população foi constituída, predominantemente, por pacientes do sexo masculino e mais da metade eram jovens entre 15 e 39 anos. Os pacientes foram, principalmente, provenientes diretos da cena do evento e transferidos de outros hospitais. Entre os que vieram direto da cena do evento, a maioria recebeu atendimento pré-hospitalar e foi transportada principalmente pela UR. 0 tempo de atendimento pré-hospitalar das unidades do SAMU-SP foi, na maioria das vezes, entre 31 e 60 minutos. A mortalidade hospitalar foi 12,63\%, o porcentual de óbitos com menos de 1 hora de permanência foi 33,78\% e mais da metade ocorreu nas primeiras 24 horas.

A maioria dos pacientes foi acometida por tipos de causas externas classificadas em trauma contuso, seguido de penetrante.

A análise da gravidade da lesão com base na AIS foi possível para grande parte da população(86,58\%) com agravos decorrentes de causas externas que resultaram em lesões classificáveis pelo sistema adotado. As lesões foram 4.918, decorrentes na maioria das vezes de trauma contuso, mais freqüentes na região da cabeça, seguidas da face. A média de lesão por paciente foi 3,19. As lesões foram predominantemente de gravidade leve (AIS1), moderada (AIS2) e séria (AIS3). No trauma contuso, as regiões corpóreas com 0 maior número de lesões foram a cabeça sobretudo com lesões sérias (AIS 3), graves (AIS4) e críticas (AIS5); seguida da face, freqüentemente, com lesões leves (AIS1). No trauma penetrante, as regiões mais atingidas foram 0 abdome, em geral, com lesões moderadas (AIS2) e a face. A gravidade do trauma (ISS) foi verificada para, praticamente, a totalidade dos pacientes, 1.527 (99,02\%), com lesões classificadas pela AIS. Constatou-se 
que a maioria da população foi classificada com escores ISS $<16$. O grupo de sobreviventes, predominantemente, obteve escore ISS $<16$, e quase a totalidade do grupo de óbitos obteve ISS $\geq 16$. Houve pequena diferença entre as médias do ISS no trauma contuso $(13,08)$ e no penetrante $(11,97)$. A média do ISS em queimadura foi 8,48 e em outros tipos de trauma foi 7,94. A média do ISS entre sobreviventes e óbitos em cada tipo de trauma foi diferente.

A gravidade do trauma na fase pré-hospitalar, com o uso do RTS-t, pôde ser verificada somente para metade dos pacientes que receberam atendimento antes de chegarem ao IC, por inexistência de registro desses dados. Quase a totalidade dos sobreviventes obteve escore 12 e os óbitos em quase sua totalidade receberam zero.

O fator limitante para o cálculo do TRISS foi a inexistência de dados fisiológicos que compõe o método.

A probabilidade de sobrevida estimada pelo TRISS pôde ser calculada somente para uma amostra de 241 pacientes que possuíam registros de todos os dados necessários para seu cálculo. Nessa amostra, foram verificados dez casos de morte inesperada identificados pela metodologia PRE. O s valores da estatística " $Z$ " e "W" para o grupo de pacientes com trauma contuso e penetrante foram indicativos de que a amostra foi estatisticamente diferente da população do MTOS. Ajustados os coeficientes do TRISS para a amostra estudada, observou-se por meio do método PRE que, em trauma contuso, ocorreram cinco mortes inesperadas e uma sobrevida inesperada. Em trauma penetrante, ocorreu uma morte inesperada e não houve casos de sobrevidas inesperadas. 
Anexos 
ANEXO I

Triage Score

\begin{tabular}{|l|l|c|}
\hline \multicolumn{1}{|c|}{ variável } & \multicolumn{1}{c|}{ resposta } & escore \\
\hline Expansão torácica & normal & 0 \\
\hline & superficial & 2 \\
\hline & com tiragem & 2 \\
\hline & ausente & 3 \\
\hline
\end{tabular}

\begin{tabular}{|l|l|l|}
\hline Enchimento capilar & normal $(<2$ Seg) & 0 \\
\hline & lentificado (>2 Seg) & 2 \\
\hline
\end{tabular}

\begin{tabular}{|l|l|c|}
\hline Abertura ocular & espontânea & 0 \\
\hline & ao estímulo verbal & 1 \\
\hline & ao estímulo doloroso & 2 \\
\hline & não abre & 3 \\
\hline
\end{tabular}

\begin{tabular}{|l|l|c|}
\hline Resposta verbal & orientado & 0 \\
\hline & confuso & 1 \\
\hline & plavras impróprias & 2 \\
\hline & sons incompreensíveis & 3 \\
\hline & não responde & 4 \\
\hline
\end{tabular}

\begin{tabular}{|l|l|c|}
\hline Resposta motora & obedece & 0 \\
\hline & retirada & 1 \\
\hline & decorticação & 2 \\
\hline & descerebração & 3 \\
\hline & não reage & 4 \\
\hline
\end{tabular}

\begin{tabular}{|l|l|}
\hline escore & Ps \\
\hline 0 & 0,99 \\
\hline 1 & 0,99 \\
\hline 2 & 0,98 \\
\hline 3 & 0,97 \\
\hline 4 & 0,96 \\
\hline 5 & 0,94 \\
\hline 6 & 0,91 \\
\hline 7 & 0,86 \\
\hline 8 & 0,80 \\
\hline 9 & 0,71 \\
\hline 10 & 0,61 \\
\hline 11 & 0,50 \\
\hline 12 & 0,39 \\
\hline 13 & 0,29 \\
\hline 14 & 0,21 \\
\hline 15 & 0,14 \\
\hline 16 & 0,09 \\
\hline
\end{tabular}




\section{ANEXO II}

TRAUMA SCORE - TS

\begin{tabular}{|c|c|c|c|c|c|}
\hline A) ECGl & B) PAS & $\begin{array}{c}\text { C) } \\
\text { Enchimento } \\
\text { Capilar }\end{array}$ & D) FR & $\begin{array}{c}\text { E) Expansão } \\
\text { torácica }\end{array}$ & Escore \\
\hline $14-15$ & & & & & 5 \\
\hline $11-13$ & $>90$ & & $10-24$ & & 4 \\
\hline $8-10$ & $70-90$ & & $25-35$ & & 3 \\
\hline $5-7$ & $50-69$ & Normal & $>35$ & & 2 \\
\hline $3-4$ & $<50$ & Lentificado & $<10$ & Normal & 1 \\
\hline & 0 & Ausente & 0 & $\begin{array}{c}\text { Superficial ou c/ } \\
\text { Tiragem }\end{array}$ & 0 \\
\hline & & & \multicolumn{5}{|c|}{$\mathrm{A}+\mathrm{B}+\mathrm{C}+\mathrm{D}+\mathrm{E}$} \\
\hline
\end{tabular}

Seus escores variam de 1 a 16

\begin{tabular}{|l|l|}
\hline escore & Ps \\
\hline 16 & 0,99 \\
\hline 15 & 0,98 \\
\hline 14 & 0,95 \\
\hline 13 & 0,91 \\
\hline 12 & 0,83 \\
\hline 11 & 0,71 \\
\hline 10 & 0,55 \\
\hline 9 & 0,37 \\
\hline 8 & 0,22 \\
\hline 7 & 0,12 \\
\hline 6 & 0,07 \\
\hline 5 & 0,04 \\
\hline 4 & 0,02 \\
\hline 3 & 0,01 \\
\hline 2 & 0,00 \\
\hline 1 & 0,00 \\
\hline
\end{tabular}


ANEXO III

FICHA DE COLETA DE DADOS - HC - RESGATE

NOME:

$\mathbf{N}^{\mathbf{0}}$ Prontuário:

\begin{tabular}{|l|l|lc|}
\hline $\begin{array}{l}\text { Sexo: } \\
\text { Cor: }\end{array}$ & Idade: & Causa Externa: & CID: \\
\hline
\end{tabular}

\begin{tabular}{|lll|}
\hline Data Entrada PS: & Data Alta Hospitalar: & Data Transferência: \\
Hora Entrada PS: & Hora Alta Hospitalar: & Hora Transferência: \\
Unidades(s) Internação: & & Transferido para: \\
\hline
\end{tabular}

\begin{tabular}{llc|}
\hline Direto da Cena? & Pré Hospitalar? & Qual? \\
Endereço do Evento: & Hora Evento: \\
Hospital de Origem: & Tempo no Hospital de Origem: \\
Tempo entre Evento/ Hospital até HC: & \\
\hline
\end{tabular}

Data Óbito: Hora Óbito: Local Óbito:
Causa Mortis no Resumo Clínico:
Causa Mortis no Recolhimento Cadáver:

\begin{tabular}{|l|}
\hline História de Entrada: \\
\end{tabular}

\begin{tabular}{|l|l|l|l|l|l|l|l|}
\hline Dados do Resgate no PS & Glasgow: & AO: & MRV: & MRM: & FR: & FC: & PA: \\
\hline Dados do Local de Origem & Glasgow: & AO: & MRV: & MRM: & FR: & FC: & PA: \\
\hline Dados de Entrada no PS & Glasgow: & AO: & MRV: & MRM: & FR: & FC: & PA: \\
\hline Dados 1a Avaliação do Neuro & Glasgow: & AO: & MRV: & MRM: & FR: & FC: & PA: \\
\hline DadosObtidos no Resgate & Glasgow: & AO: & MRV: & MRM: & FR: & FC: & PA: \\
\hline
\end{tabular}

\begin{tabular}{|l|l|l|l|l|}
\hline RTS no Hospital: & Score FR: & Score PAS: & Score Glasgow: & RTS: \\
\hline RTS no Resgate: & Score FR: & Score PAS: & Score Glasgow: & RTS: \\
\hline
\end{tabular}

\begin{tabular}{|l|l|l|l|l|}
\hline Horários & H. Chama: & H. Chega: & H. Sai: & H. Hospital: \\
\hline Unidade de Resgate & Helicóptero: & USA: & UR: & Outros: \\
\hline
\end{tabular}

\begin{tabular}{|c|c|}
\hline Álcor & Drogas: $\quad$ Doença Pré: \\
\hline
\end{tabular}


ANEXO III (continuação)

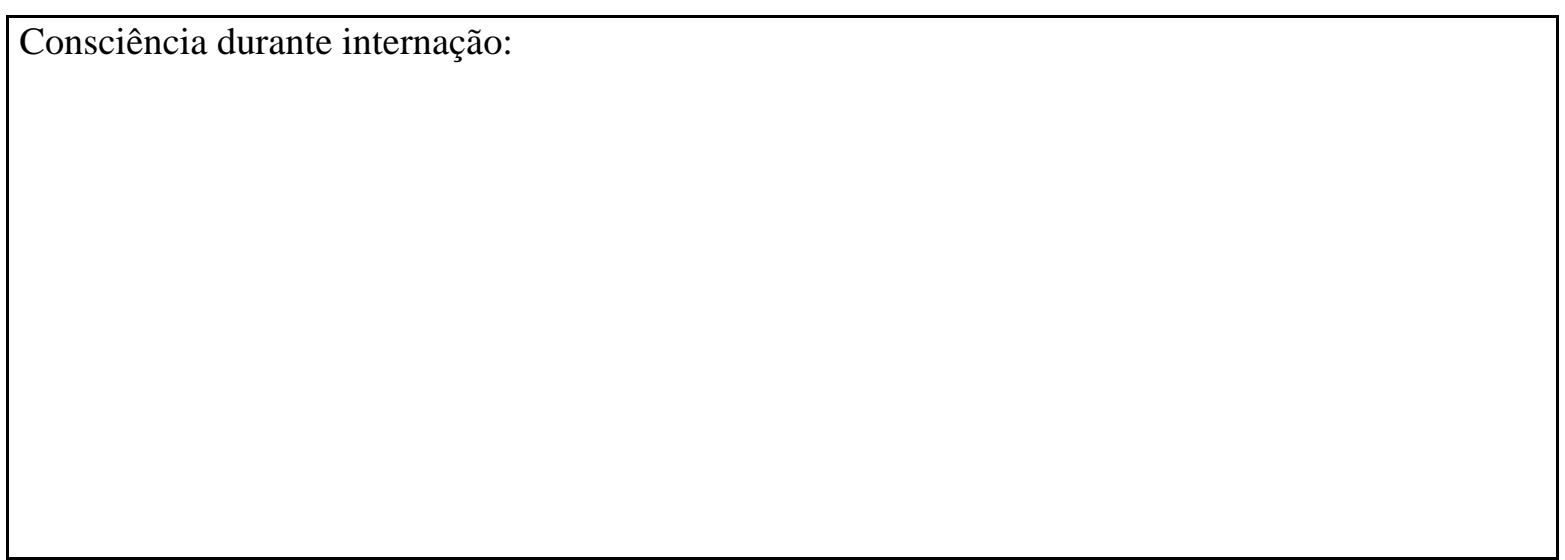

\begin{tabular}{|l|l|l|}
\hline Data & Lesão Anatômica & Código AIS \\
\hline & & \\
\hline & & \\
\hline & & \\
\hline & & \\
\hline & & \\
\hline & & \\
\hline & & \\
\hline & & \\
\hline & & \\
\hline & & \\
\hline & & \\
\hline & & \\
\hline & & \\
\hline & & \\
\hline & & \\
\hline & & \\
\hline & & \\
\hline & & \\
\hline
\end{tabular}


ANEXO IV

FICHA DE COLETA DE DADOS - IML

\begin{tabular}{|l|l|}
\hline NOME: & N. ${ }^{\circ}$ Prontuário HC : \\
\hline
\end{tabular}

\begin{tabular}{|l|l|l|}
\hline Sexo: & Idade: & Causa Externa: \\
Cor: & & \\
\hline
\end{tabular}

\begin{tabular}{|c|c|c|}
\hline B.O n.: & Laudo n. ${ }^{\circ}$ : & Data da Necropsia: \\
\hline Profissão: & Data do Óbito: & Data do Relatório: \\
\hline
\end{tabular}

Médico Solicitante do HC:

Endereço do paciente:

Morte sobreveio em virtude de:

Quesitos:

Primeiro (Houve morte?):

Segundo (Qual a causa?):

Terceiro (Qual a natureza do agente, instrumento ou meio que a produziu?):

Quarto (Foi produzida por meio de veneno, fogo, explosivo, asfixia ou tortura, ou por meio insidioso ou cruel?):

\begin{tabular}{|l|l|}
\hline Lesões Anatômicas & Código AIS \\
\hline & \\
\hline & \\
\hline & \\
\hline & \\
\hline & \\
\hline & \\
\hline & \\
\hline & \\
\hline
\end{tabular}


ANEXO IV (continuação)

Lesões Anatômicas

Código AIS 


\section{Referências Bibliográficas}




\section{REFERÊNCIAS BIBLIOGRÁFICAS}

ACOSTA, J.A. et al. Lethal injuries and time to death in a level I trauma center. J.Am.Coll.Surg. v.186, n.5, p.528-33, 1998.

AG RESTI, A. Categorical Data Analysis. Interscience, New Y ork, 1990

ALVES, D. Avaliação do nível de consciência pelo enfermeiro no senviço de emergência. São Paulo, 1998, 100p. Tese (Mestrado) - Departamento de Enfermagem, Universidade Federal de São Paulo.

AMERICAN COLLEGE OF EMERGENCY PHYSICIANS. Trauma care systems quality improvement guidelines. Ann.E merg.Med., v.12, n.6, p. 736-9, 1992.

AMERICAN COLLEGE OF SURGEONS - ACS. Committee on Trauma. Hospital and prehospital resources for optimal care of the injured patient. Bull.Am.Coll.Surg., v. 71, n.10, p.1-56, 1986.

AMERICAN COLLEGE OF SURGEONS - ACS. Committee on Trauma. Resources for optimal care of the injured patient: 1999. Chicago, American College of Surgeons,1999a.

AMERICAN COLLEGE OF SURGEONS - ACS. Committee on Trauma. Suporte Avançado de Vida no Trauma - SAVT: Programa para médicos. Trad. do Programa ATLS./ São Paulo/ , 1999b.

ANDERSEN, J. et al. Injury severity score, head injury, and patient wait days: contributions to extended trauma patient length of stay. J.Trauma, v.33, n.2, p.219-20, 1992.

AND RADE, S.M.. Acidentes de transporte terrestre em Londrina - Paraná: análise das vítimas, dos acidentes e das fontes de informação. São Paulo, 1998, 1840p. Tese (D outorado) - D epartamento de Epidemiologia, Faculdade de Saúde Pública, Universidade de São Paulo.

ARREO LA-RISA, C. et al. Trauma care systems in urban Latin America: the priorities should be prehospital and emergence room management. J.Trauma, v.39, n.3, p.457-2, 1995. 
ASSOCIATION FOR THE ADVANCEMENT OF AUTOMOTIVE MEDICINE - AAAM. The Abbreviated Injury Scale (AIS): 1990 Revision. D es Plaines, Illinois, 1990.

ASSOCIATION FOR THE ADVANCEMENT OF AUTOMOTIVE MEDICINE - AAAM. The Abbreviated Injury Scale (AIS) : 1990 Revision. Update 98. D es Plaines, Illinois, 1998

BAKER, S.P. et al. The Injury severity score: a method for describing patients with multiple injuries and evaluating emergency care. J.Trauma, v.14, n.3, p.187-96, 1974.

BAKER, S.P; O’NEILL, B. The Injury Severity Score: na uptade. J.Trauma, v.16, n.11, p.822-5, 1976.

BAKER, C.C. et al. Epidemiology of trauma deaths. Am.J.Surg. v.140, n.1, p.144-50, 1980.

BAKER, S.P. Injuries: the neglected epidemic: stone lecture, 1985 America Trauma Society Meeting. J.Trauma, v.27, n.4, p.343-8, 1987.

BAKER, S.P. Injuries in American a national disater. Trans.Stud.Coll.Physicians Phila., v.10, n.1/ 4, p.135-45, 1988.

BAKER, S.P. Advances and adventures in trauma. J.Trauma, v.42, n.3, p.369-73, 1997.

BARROS, J.L.P. et al. Avaliação do protocolo de traumatismo craniencefálico na unidade de terapia intensiva pediátrica do Hospital de Base do Distrito Federal. Arq. Bras. N eurocinurg., v.13, n.2, p.64-8, 1994.

BARSS, P. et al. Injury prevention: an international perspective epidemiology, surveillance and policy. Oxford , Oxford University Press, 1998

BAZZOLI, G.J. et al. Progress in the development of trauma systems in the United States: results of a national survey. JAMA, v.273, n.5, p.395-01, 1995.

BOUILLON, B. et al. Trauma score systems: Cologne validation study. J.Trauma, v.42, n.4, p.652-8, 1997.

BOYD, C.R. et al. Evaluating trauma care: the triss method. J.Trauma, v.27, n.4, p.370-8, 1987. 
BRASIL. Ministério da Saúde. Assessoria de Comunicação Social. Plano qüinquenal de saúde 1990/ 95: a saúde do Brasil novo. Brasilia, Centro de Documentação do Ministério da saúde, 1991.

BRASIL. Ministério da Saúde. Sistema de Informação Hospitalar do Sistema Único de Saúde. [CD-ROM] Brasília, 1999.

BRENNEMAN, F.D. et al. Measuring injury severity: time for a change? J.Trauma, v.44, n.4, p.580-2, 1998.

BUECHLER, C.M. et al. Variation among trauma centers' calculation of glasgow coma scale score: results of a nacional servey. J.Trauma, v.45, n.3, p.429-32, 1998.

BUSSAB, W. O .; MO RETTIN, P. A.. Estatística Básica. São Paulo, Ed. Atual, 1987.

CALES, R.H. Injury severy determination: requirementes, aproaches, and aplications. Ann.E merg.Med., v.14, n.12, p.1427-33, 1986.

CALIL, A.M. Natureza da lesão e gravidade do trauma segundo qualidade das vítimas de acidente de trânsito de veículo a motor. São Paulo, 1997. 134p. Dissertação (Mestrado) - Escola de Enfermagem, Universidade de São Paulo.

CAMERO N, P. et al. Major trauma in Australia: a regional analysis. J.Trauma, v.39, n.3, p.545$52,1995$.

CAYTEN, C.G. et al. Limitations of TRISS method for interhospital comparisons: a multihospital study. J.Trauma, v.31, n.4, p.471-82, 1991.

CAYTEN, C.G.; EVANS, W. Severity indices and their implications for emergency medical services research and evaluation. J.Trauma, v.19, n.2, p.98-102, 1979.

CHAMPION, H.R. et al. Assessment of injury: the Triage Index. Crit.Care Med., v. 8, n.4, p.201-8, 1980 .

CHAMPIO N, H.R. et al. Trauma Score. Crit.CareMed., v. 9, n. 9, p. 672-6, 1981.

CHAMPIO N, H.R. Field triage of trauma patients. Ann.Emerg.Med. v.11, n.3, p.160-1, 1982. 
CHAMPIO N, H.R et al. Trauma severy scoring to predict mortality. World J. Surg. v. 7, n. 1, p. 4-11, 1983.

CHAMPIO N, H.R. et al. A revision of the Trauma Score. J.Trauma, v. 29, n.5, p.623-9, 1989a.

CHAMPIO N, H.R. et al. Major Trauma in geriatric patients. Am.J.Publ.Health, v. 79, n.9, p.1278-82, 1989b.

CHAMPION, H.R. et al. A new characterization of injury severity. J.Trauma, v.30, n.5, p.53946, 1990a.

CHAMPION, H.R. et al. The major trauma outcome study: establishing mational norms for trauma care. J.Trauma, v. 30, n.11, p. 1356-65, 1990b.

CHAMPION , H.R. et al. Trauma scoring. In: MOORE, E.E. et al. Trauma. 2.ed Califórnia, Apleton \& Lange, 1991. cap. 4, p. 47-65.

CHAMPIO N, H.R. et al. Economic issues in trauma care. In: CARD ONA, V.D. et al. Trauma nursing: from ressucitation through rehabilitation. 2. ed. Philadelphia, W.B. Saunders, 1994. cap. 3, p.28-38.

CHAMPION, H.R.;SACCO,W.J.;COPES,W.S..Injury severity scoring again. J.Trauma, v. 38, n.5, p.94-5, 1995.

CHAMPION, H.R. et al. Improved predictions from a severity characterization of trauma (ASCOT) over Trauma and Injury Severity Score (TRISS): results of an independent evaluation. J.Trauma, v.40, n.1, p.42-9, 1996.

CHAVES, C.C. et al. A spectos epidemiológicos das vítimas de agressões físicas atendidas em um pronto socorro do município de São Paulo. Rev. Bras. Enf., v.40, n.2/ 3, p.106-0, 1987.

CIRICILLO, S.F. et al. Severity and outcome of intracranial lesions in pedestrians injurd by motor vehicles. J.Trauma., v.33, n.6, p. 899-3, 1992.

CIVIL, I.D . Patterns of injury in motor vehicle trauma. NZMed.J., v.99, n. 814, p. 905-6, 1986.

CIVIL, ID .; SCHWAB C.W. Clinical prospective injury severy scoring: when is it accurate? J.Trauma, v.29, n.5, p.613-4, 1989. 
CLARK. D.E. Comparing institutional trauma survival to a standard: current limitations and suggested alternatives. J.Trauma, v.47, n.3, p.S92-S8, 1999.

COHAD O N, F.; RICHER, E.; CASTEL, J.P. Head injuries: incidence and outcome. J.N. Sci., v.103, p.S27-S31, 1991. Supplement

COIMBRA, R.S.M. et al. Índices de trauma: o que são e porque devem ser usados. Rev.Col.Bras.Cinurg., v..24, n.4, p.255-63, 1997.

COLLI, B.O. et al. Características dos pacientes com traumatismo craniencefálico atendidos no hospital das Clínicas da Faculdade de Medicina de Ribeirão Preto. Arq.N europsiquiatr., v.55, n.1, p.91-100, 1997.

CONOVER, W.J. Practical nonparametric statistics. 3ed. New York, John Wiley \& Sons, 1999.

COPES, W.S. et al. A comparison of abbreviated injury scale 1980 and 1985 versions. J.Trauma, v.28, n.1, p.78-86, 1988a.

COPES, W.S. et al. The Injury Severity Score revisited. J.Trauma, v.28, n.1, p.69-77, 1988b.

COPES, W.S. et al. Progress in characterizing anatomic injury . J.Trauma, v.30, n.10, p.1200-7, 1990.

CORNWELL III, E.E et al. Lethal abdominal gunshot wounds at a level I trauma center: Analysis of TRISS (Revised Trauma Score and Injury Severity Score) fallouts. J.Am.Coll.Surg. v.187, n.2, p.123-9, 1998.

COTTINGTO N, E.M. et al. The utility of physiological status, injury site, and injury mechanism in identifying patients with major trauma. J.Trauma, v.28, n.3, p.305-11, 1988.

COTTINGTON, E.M.; SUFFLEBARGER, M.; TOWNSEND, R. The power of Z statistic: Implications for trauma research and quality assurance review. . J.Trauma, v.29, n.11, p.1509, 1989.

DALOSSI, T. Determinação precoce do nível de gravidade do trauma. São Paulo, 1993, 73p. Dissertação (Mestrado) - Escola de Enfermagem, Universidade de São Paulo. 
DESLANDES, S.F.; SILVA, C.M.F.P.da; UGÁ, M.A.D . O custo do atendimento emergencial às vítimas de violências em dois hospitais do Rio de Janeiro. Cad.Saúde Pública, v.14, n.2. p.287-99, 1998.

EASTRIDGE, B.J.; BURGESS, A.R. Pedestrian pelvic fratures: 5-year experience of a major urban trauma center. J.Trauma, v.42, n.4, p.695-00, 1997.

FERREIRA,C.S.W. Os serviços de assistência às urgências no Município de São Paulo: implantação de um sistema de atendimento pré-hospitalar. São Paulo, 1999, 110p. D issertação (Mestrado) - D epartamento de Medicina Preventiva, Faculdade de Medicina, Universidade de São Paulo.

FIUZA, R.M. Traumatismo craniencefálico em acidentes de motocicleta. Arq. Bras. N eurocinurg. v.7, n.4, p.191-01, 1988.

FLO RA, J.D. A method for comparing survival of burn patients to a standart survival curve. J.Trauma, v.18, n.10, p.701-5, 1978.

FREITAS, P.E. et al. Fatores de avaliação precoce da mortalidade em traumatizados de crânio com ênfase na escala de coma de G lasgow. J. Bras. N eurocirurg. v.2, n.2, p.53-9, 1990.

GARBER, B.G. et al. Validation of trauma and injury severity score in blunt trauma patients by using a Canadian trauma registry. . J.T rauma, v.40, n.5, p.733-7, 1996.

GAWRYSZEWSKI, V.P. A mortalidade por causas extemas no município de São Paulo, 1991. São Paulo, 1995, 184p. Tese (D outorado) - D epartamento de E pidemiologia, Faculdade de Saúde Pública, Universidade de São Paulo.

GENNARELLI, T.A. et al. Mortality of patients with head injury and extracranial injury treated in trauma centers. J.T rauma, v.29, n.9, p.1193-202, 1989.

GENNARELLI, T.A. et al. Comparison of mortality, morbidity, and severity of 59,713 head injured patirnts patients with 114,447 patients with extracranial injuries. J.Trauma, v.37, n.6, p.962-8, 1994.

GENNARI, et al. Trauma severity determined by clinical observations and autopsy findings - a preliminary study . In: ANNUAL CONFERENCE OF ASSOCIATION FOR THE 
ADVANCEMENT OF AUTOMOTIVE MEDICINE, 41, Orlando - Flórida, 1997. Proceedings. Orlando,FL, ASSOCIATION FOR THE ADVANCEMENT OF AUTO MOTIVE MEDICINE, 1997. P. 423-4.

GIBSO N, G. Indices of severity for emergency medical evaluative studies: reliability, validity, and date requirements. Int.J.H eath Serv., v.11, n. 4, p.597-621, 1981.

HANNAN, E.L. et al. Multivariate models for prediting survival of patients trauma from low falls: the impact of gender and pre-existing conditions. J.Trauma, v. 38, n.5, p. 697-04, 1995a.

HANNAN, E.L. et al. Validation of TRISS and ASCOT USING a non-MOTS Trauma Registry. J.Trauma, v. 38, n.1, p. 83-8, 1995b.

HANNAN, E.L. et al. Accounting for intubation status im predicting mortality for victims of motor vehicle crashes. . J.Trauma, v. 48, n.1, p. 76-87, 2000.

HARRUFF, R.C.; AVERY, A.; ALTER-PANDYA, A.S. Analysis of circumstances and injuries in 217 pedestrian traffic fatalities. Accid.Anal.Prev., v.30, n.1, p.11-20, 1998.

HARVIEL, J.D. et al. The effect of autopsy on injury severity and survival probability calculations. J.Trauma, v.29, n.6, p.766-2, 1989.

HELLING, T.S. et al. Low fall: an underappreciated mechanism of injury. J.Trauma, v.46, n.3, p.453-6, 1999.

HILL, A.B. et al. Chest trauma in a canadian urban setting - implications for trauma research in Canada. J.Trauma, v.31, n.7, p.971-3, 1991.

HOLLIS, S.; FOSTER, P. Standartized comparison of performance indicators in trauma: a new approach to case-mix variation. J.Trauma, v.38, n.5, p.763-6, 1995.

HOSMER, D.H.; LEMESHOW, S. Applied Logistic Regression. John Wiley \& Sons, New York, 1989.

IMAI, M.F.P. Avaliação da gravidade do traumatismo crânio-encefálico por índices anatômicos e fisiológicos. São Paulo, 1994, 73p. Dissertação (Mestrado) - Escola de Enfermagem, Universidade de São Paulo. 
IUNES, R.F. Acidentes e violência no Brasil.III Impacto econômico das causas externas no Brasil: um esforço de mensuração. Rev.Saúde Púb., v.31, n.4, p.38-46, 1997.

JAGGER, J. et al. Effect of alcohol intoxication on the diagnosis and apparent severity of brain injury. Neurosurgery, v.15, n.3, p.303-6, 1984.

JONES, J.M.; REDMOND, A.D.; TEMPLETON, J. Uses and abuses of statistical models for evaluating trauma care. . J.Trauma, v.38, n.1, p.89-93, 1995a.

JONES, J.M. et al. A multivariate analysis of factors related to the mortality of blunt trauma admissions to the North Staffordshire Hospital centre. J.Trauma, v.38, n.1, p.118-22, 1995b.

JONES, J.M. An approach to the analysis of trauma data having a response variable of death survival. J.Trauma, v.38, n.1, p.123-8, 1995c.

JO RCENSEN, K.. Use of Abbreviated Injury Scale in a hospital emergency room: potential for research in accident epidemiology. Acta Orthop.Scand., v.52, n.3, p.273-7,1981.

JURKOVICH, G. et al. Effects of alcohol intoxication on the initial assessment of trauma patients. Ann.Emerg.Med., v.21, n.6, p.704-8,1992.

JURKOVICH, G. J.; MOCK, C. Systematic review of trauma system effectiveness based on registry comparisons. J.Trauma, v.47, n.3, p.S46-S55, 1999.

KARMY-JONES, R. et al. Results of a multi-institutional outcome assessment: Results of a structured peer review of TRISS-designated unexpected outcomes. J.Trauma, v.32, n.2, p.196-03, 1992.

KOIZUMI, M.S. Aspectos epidemiológicos dos acidentes de motocicleta no Município de São Paulo, 1982. São Paulo, 1984. 140p. Tese (D outorado) - Faculdade de Saúde Pública, Universidade de São Paulo.

KOIZUMI, M.S. Acidentes de motocicleta no município de São Paulo, SP (Brasil). 1. Caracterização dos acidentes e das vítimas. Rev.Saúde Pública, v.19, n.5, p.475-89, 1985a.

KOIZUMI, M.S. Acidentes de motocicleta no município de São Paulo, SP (Brasil). 2. Análise da mortalidade. Rev.Saúde Pública., v.19, n.6, p.543-55, 1985b. 
KOIZUMI, M.S. Natureza das lesões nas vítimas de acidentes de motocicleta. São Paulo, 1990. 116p. Tese (Livre D ocência) - Escola de Enfermagem, Universidade de São Paulo.

KOIZUMI, M.S. Padrão das lesões nas vítimas de acidentes de motocicleta. Rev.Saúde Pública, v.26, n.5, p.306-15, 1992.

KOIZUMI, M.S. et al. Morbimortalidade por traumatismo crânio-enfefálico no município de São Paulo, 1997. Arq.N europsiquiatr. v.58, n.1, p.81-9, 2000.

KRAMER,C.F. et al. Adequacy of hospital discharge data for determining trauma morbidity patterns. J.Trauma, v. 39, n.5, p. 935-40, 1995.

LANE, P.L et al. An evaluation of O ntario trauma outcomes and the development of regional norms for trauma and injury severity score (TRISS) analysis. J.Trauma, v.41, n.4, p.731-4, 1996.

LANE, P.L et al. Trauma outcome analysis and the development of regional norms. Accid. Anal. Prev., v. 29, n.1, p. 53-6, 1997.

LEBRÃO, M.L. Utilização da classificação intemacional de doenças em informações de morbidade. São Paulo, Centro da O MS para a Classificação de D oenças em Português, (Série divulgação no 8), 1993.

LEBRÃO, M.L.; MELLO JORGE, M.H.P.; LAURENTI, R. Acidentes e violência no Brasil .II Morbidade hospitalar por lesões e envenenamentos. Rev.Saúde Pública, v.31, n.4, p.26-37, 1997.

LONG, W.B.; BACHULIS, B.L.; HYNES, G.D. Accuracy and relationship of mechanisms of injury, trauma score, and injury severity score in identifying major trauma. Am.J.Surg. v.151, n.5, p.581-84, 1986.

MANN, N.C. Assessing the effectiveness and optimal structure of trauma systems: a consensus among experts. J.T rauma, v.47, n.3, p.S69-S74, 1999. Supplement

MARION, D.W. The Glasgow Coma Scale score: contemporary application. Intensive Care World. v.11, n.3, p.101-2, 1994a. 
MARION, D.W.; CARLIER, P.M.. Problems with initial Glasgow Coma Scale assessment caused by prehospital treatment of patients with head injuries: results of a national survey. J.Trauma, v.36, n.1, p.89-95, 1994b.

MARTINS, E.T.; BRUGGEMANN, M.; COUTINHO, M. Estudo prospectivo de 200 casos de TCE grave na grande Florianópolis. Rev. Bras. Terap. Intens., v.9, n.4, p.175-80, 1997.

MASINI, M. Perfil epidemiológico do traumatismo crânio-encefálico no Distrito Federal em 1991. J.Bras.Neurocirug. v.5, n.2, p.61-8, 1994.

McCLURE, R.J., DOUGLAS, R.M. The public health impact of minor injury. Accid.Anal. Prev., v.28, n.4, p.443-1, 1996.

McDERMOTT, F.T. et al. Evaluation of medical management and preventability of death in 137 road traffic fatalities in Vitoria, Autralia: an overview. J.Trauma, v. 40, n.4, p. 520-35, 1996.

MEISLIN, H. et al. Fatal trauma: the modal distribution of time to death is a function of patient demographics and regional resources. J.T rauma, v.43, n.3, p.433-0, 1997.

MEISLIN, H. et al. Fatal injury: characteristics and prevention of deaths at the scene. J.Trauma, v.46, n.3, p.457-61, 1999.

MELLO JORGE, M.H.P.de. Mortalidade por causas violentas no Município de São Paulo. São Paulo, 1979. 281p. Tese (D outorado) - Faculdade de Saúde Pública, Universidade de São Paulo.

MELLO JORGE, M.H.P; LAURENTI, R. Acidentes e violência no Brasil / Apresentação/ . Rev.Saúde Pública, v.31, n.4, p.1-4, 1997.

MELLO JORGE, M.H.P. Acidentes e violência no Brasil. À guisa de conclusão. Rev.Saúde Pública, v.31, n.4, p.51-4, 1997b.

MELLO JORGE, M.H.P.; GAWRYSZEWSKI, V.P.; LATORRE, M.R.D.de O. Acidentes e violência no Brasil .I Análise dos dados de mortalidade. Rev.Saúde Pública., v.31, n.4, p.525, 1997. 
MENEGAZZI, J.J. et al. Reliability of the Glasgow Coma Scale when used by emergency physicians and paramedics. J.Trauma, v.34, n.1, p.46-8 1993.

MEREDITH, W. et al. Field triage of trauma patients based upon the ability to follow commands: a study in 29.573 injured patients. J.Trauma, v.38, n.1, p.129-35, 1995.

MEREDITH, W. et al. The conundrun of the Glasgow Coma Scale in intubed patients: a linear regression prediction of the Glasgow verbal score from the Glasgow eye and motor scores. J.Trauma, v.44, n.15 p.839-45, 1998.

MESQ UITA FILHO, M. A morbidade por acidentes de transito em Pouso Alegre, Minas Gerais. São Paulo, 1998. 163p. Dissertação (Mestrado) - Departamento de Medicina Preventiva, Universidade Federal de São Paulo.

MEYER, A.A.. D eath and disability from injury: a global challenge. J.Trauma, v.44, n.1, p.1-12, 1998.

MO ORE, E.E. Trauma systems, trauma centers, and trauma surgeons: opportunity in managed competition. . J.Trauma, v.39, n.1, p.1-11, 1995.

MORRIS, J. A. et al. The Trauma Score as triage tool in the prehospital setting. JAMA, v.256, n.10, p. 1319-25, 1986.

MOSENTHAL,A.C. Falls: epidemiology and strategies for prevention. J.Trauma, v.35, n.3, p.753-56, 1995

MULLINS, R.J;; MANN, N.C. Population-based research assessing the effectiveness of trauma systems. J.Trauma, v.47, n.3, p.S59-S66, 1999. Supplement

NATIONAL ASSOCIATION OF EMERGENCY MEDICAL TECHNICIANS NAEMT- Prehospital Trauma Life Support. Committee./ AMERICAN COLLEGE OF SURGEONS. Committee on Trauma. PHTLS: basic and advanced prehospital trauma life support. 4.ed. St. Louis, Mosby, 1999.

O FFNER, P.J. et al. Revision of TRISS for intubated patients. J.Trauma, v.32, n.1, p.32-5, 1992. 
ORGANIZAÇÃO MUNDIAL DA SAÚDE - OMS. Manual de classificação estatística internacional de doenças e problemas relacionados à saúde. 10. rev. São Paulo, Centro Colaborador da OMS para Classificação de D oenças em Português, 1998a. v.1.

ORGANIZAÇÃO MUNDIAL DA SAÚDE - OMS. Manual de classificação estatística internacional de doenças e problemas relacionados à saúde: manual de instruções 10 . rev. São Paulo, Centro Colaborador da OMS para Classificação de Doenças em Português, 1998b. v.2.

ORGANIZAÇÃO PANAMERICANA DA SAÚDE / ORGANIZAÇÃO MUNDIAL DA SAÚDE -OPAS/ O MS. Escritório de Representação no Brasil. A saúde no Brasil. Brasília, 1998.

OSLER, T. Injury severity scoring: perspectives in development and future directions. Am.J.Surgery, v.165, n.2A, p.43S-7S, 1993. Suplemento

OSLER, T.; BAKER, S.P.; LONG, W.. A modification of the Injury Severity Score that both improves accuracy and simplifies scoring. J.Trauma., v.43, n.6, p. 922-6, 1997.

OTT, E.A. et al. Acidentes de trânsito em área metropolitana da região sul do Brasil caracterização da vítima e das lesões. Rev.Saúde Pública., v.27, n.5, p.350-6, 1993.

PELLETIER, C.R. et al. Assesment of ocular trauma associated with head and neck injuries. J.Trauma., v.44, n.2, p. 350-4, 1998.

POOLE, G.V. et al. Abbreviated injury scale does not reflect the added morbidity of multiple lower extremity fractures. J.Trauma, v.40, n.6, p.951-5, 1996.

POON, A.; McCLUSKEY, P.J.; HILL, D.A. Eye injuries in patients with major trauma. J.Trauma., v.46, n.3, p. 494-9, 1999.

ROSENBERG, M.L. Conference on Injury in America: a summary. Public.Health.Rep., v. 102, n.6, p.577-676, 1987.

ROSS, E.S. et al. Efficacy of motor component of the Glasgow Coma Scale in trauma triage. J.Trauma., v.45, n.1, p. 42-4, 1999 
ROSEnBerg, M.L Violence is a public health problem. Trans.Stud.Coll. Physicians Phila., v.10, n.1/ 4, p. 147-68, 1988.

ROUX, G.I de. Violence in the Americas. JAMA, v. 271, n.10, p. 727, 1994.

ROWLEY, G.; FIELDING, K. Reliability and accuracy of Glasgow Coma Scale with experienced and inexperienced users. LANCET. v.337, n.2, p.535-8, 1991

RUTLEDGE, R. The injury severity score is unable to differentiate between poor care and severe injury. J.Trauma, v.40, n.6, p.944-50, 1996a.

RUTLEDGE, R. et al. Appropriate use of Glasgow Coma Scale in intubed patients: a linear regression prediction of Glasgow verbal score from Glasgow eye and motor scores. J.Trauma, v.41, n.3, p.514-22, 1996b.

SAMPALIS, J.S. et al. Preventable death classification: interrater reliability and comparison with ISS-based survival probablity estimates. Accid.Anal.Prev., v.27, n.2, p.199-6, 1995.

SAMPALIS, S.S. et al. Direct to tertiary trauma centers versus transfer from lower level facilities: impact on motality and morbity among patients with major trauma. J.Trauma., v.43, n.2, p. 288-96, 1997.

SANTOS, L.C.R. de. Lesão traumática da medula espinhal: estudo retrospectivo de pacientes internados no Instituto de Ortopedia e Traumatologia do Hospital das Clínicas da Faculdade de Medicina da Universidade de São Paulo entre 1982 e 1987. São Paulo, 1989. 101p. Dissertação (Mestrado) Escola de Enfermagem, Universidade de São Paulo.

SÃO PAULO (Estado). Sistema Integrado de Atendimento às Emergências do Estado de São Paulo: Projeto Resgate. São Paulo, s.d. / Mimeografado/

SÃO PAULO (Estado). Secretaria de Estado da Saúde. Plano de atendimento médico de urgência da Região Metropolitana PAMU: organização e fluxo. São Paulo, SES/ SMS, 1993./ Mimeografado/

SÃO PAULO (Cidade). Prefeitura do Município de São Paulo. Programa de Aprimoramento das Informações de Mortalidade no Município de São Paulo (PRO-AIM). Alguns aspectos da mortalidade no Município de São Paulo em 1998. São Paulo, 1999. 
SAUAIA, A. Epidemiology of trauma deaths: a reassessment. J.Trauma., v.38, n.2, p. 185-3, 1995.

SCALASSARA, M.B.; SOUZA, R.K.; SOARES, D.P.P. Características da mortalidade por acidentes de trânsito em localidades da região sul do Brasil. Rev.Saúde Pública., v.32, n.2, p.125-32, 1998.

SCHWAB, C.W. Violence: A merica's uncivil war. J.Trauma., v.35, n.5, p. 657-65, 1993.

SEMPLE, P. L.; BASS, D.H.; PETER, J. C. Severe head injury in children - a preventable but forgotten epidemic. S afr.Med.J., v.88, n.4, p.440-4, 1998.

SHACKFORD, S.R. et al. The epidemiology of traumatic death: a population-based analysis. Arch.Surg., v.128, p.571-5, 1993.

SMITH, E J. et al. Trauma scoring methods. Br.J.H osp.Med., v44, n.2, p.114-8, 1990.

SO SIN, D.M.; SACKS, J.J.; SMITH,S.M. Head injury - associated deaths in the United States from 1979 to 1986. JAMA, v. 262, n.16, p. 2251-5, 1989.

SO USA, R.M.; KOIZUMI, M.S. Recuperação das vítimas de traumatismo crânio-encefálico no período de 1 ano após o trauma. Rev.Esc.Enf.USP., v.30, n.3, p.484-500, 1996.

SOUZA, E.R. Homicídios no Brasil: o grande vilão da saúde pública. na década de 80 . Cad.Saúde Pública., v.10, n.1, p.45-60, 1994. Suplemento

STEWART, T.C.; LANE, P.L.; STEFANITS, T. An evaluation of patients outcomes before and after trauma center designation using trauma and injury severity score analysis. J.Trauma, v.19, n.6, p.1036-40, 1995.

STREAT, S.J.; CIVIL, I.D. Injury scaling at autopsy: the comparison with premortem clinical data. Accid.Anal.Prev., v.22, n.3, p.241-52, 1990.

TAYLOR, M.S.; SACCO, W.J.; CHAMPION, H.R. On the power of a method for comparing survival of trauma patients to a standart survival curve. Comput.Biol.Med. v.16, n.1, p.1-6, 1986. 
TEASDALE, G.; JENNETT, B.. Assessment of coma and impaired consciousness. Lancet., v.2, n.872, p. 81-4, 1974.

THOMPSON, J.; DAINS, J. Indices of injury development and status. Nurs.Clin.North Am., v.21, n.4, p.655-73, 1986.

TIRET, L. et al. The epidemiology of head trauma in Aquitane (France), 1986: A communitybased study of hospital admissions and deaths. Int.J. Epidemiol., v.19, n.1, 1990.

TRUNKEY, D.D. Overview of trauma. Surg.Clin.North Am., v.62, n.1, p.3-7, 1982.

TRUNKEY, D.D. Current status of trauma severity indices. J.Trauma, v.23, n.3, p.185-98, 1983a.

TRUNKEY,D.D . Trauma. Sci.Am., v.149, n.2, p.20-7, 1983b.

VASCO NCELLO S, E.A. Urban development and traffic accidents in Brazil. Accid.Anal.Prev., v.31, p.319-28, 1999.

VIANNA FILHO, R.C. et al. Estudo epidemiológico das perfurações oculares em acidentes automobilísticos. Arq.Bras.0 ftal., v.58, n.6, p.460-4, 1995.

VILALTA, J. et al. Epidemiología de los traumatismos craneoencefálicos. Banco de datos "Barcelona". O bjetivos, diseño y análisis de 584 casos. Rev. Esp. Anestesiol. Reanim., v.39, p.277-81, 1992.

WHITAKER, I.Y.; VIANNA, L.A.C. Aspectos epidemiológicos das vítimas de atropelamento, colisão, ferimentos por arma de fogo e arma branca relacionados ao atendimento préhospitalar. Acta Paul. Enf., v.4, n.2/ 4, p. 35-43, 1991.

WHITAKER, I. Y. Gravidade do trauma avaliada na fase pré-hospitalar - análise das vítimas de causas extemas atendidas pelo SAMU-RE SGATE-SP, 1991 São Paulo, 1993, 78p. Dissertação (Mestrado) - D epartamento de Enfermagem, Escola Paulista de Medicina. 
WHITAKER, I.Y.; KOIZUMI, M. S. Comparing injury severy at autposy with Glasgow Coma Scale at accident scene in traumatic brain inury. In: WORLD FEDERATION OF NEURO SCINCE NURSES - SIXTH QUADRENNIAL CONGRESS, Acapuilco, 1993. Program. Acapulco, WORD FEDERATION OF NEUROSCIENCE NURSES / WORD FEDERATION OF NEURO LOGICAL SO CIETIES, 1993. p. 14- 5. / resumo/

WHITAKER, I.Y. et al. Características das vítimas atendidas pela Unidade de Suporte Avançado do SAMU-RESGATE-SP. in CONGRESSO BRASILEIRO DA SOCIEDADE BRASILEIRA DE ATENDIMENTO INTEGRADO AO TRAUMATIZADO, 2. SIMPÓSIO INTERNACIONAL DE NEUROTRAUMATOlOGiA, 4. São Paulo, 1997. Programa oficial. São Paulo, SBAIT, 1997.

WHITAKER, I.Y .; GUTIÉRREZ, M.G.R.; KOIZUMI, MS. Gravidade do trauma avaliada na fase pré-hospitalar. Rev Ass Med Brasil, v 44, n.2, p.111-9, 1998.

WISNER, D.H. History and current status of trauma scoring sustems. Arch. Surg., v.127, n.3, p.111-7, 1992.

YATES, D.W; WOODFO RD , M.; HOLLIS, S. Preliminary analysis of care of injured patients in 33 British hospitals: first report of United Kingdom major trauma outcome study. BMJ, v.305, n.26, p.737-40, 1992.

YOUNGE, P.A. et al. Interpretation of the Ws statistic: application to an integrated system. J.Trauma, v.43, n.3, p.511-5, 1997.

YUNES, J.; RAJS, D. Tendencia de la mortalidad por causas violentas en la población general y entre los adolescentes y jóvenes de la Región de las Américas. Cad.Saúde Pública., v.10, n.1, p.88-125, 1994. Suplemento

ZIMMER-GEMBECK, M.J. et al. Triage in an established trauma systems. J.Trauma, v.39, n.5, p.922-8, 1995.

ZOLTIE, N.; D O MBAL, F.T. The hit and miss of ISS and TRISS. Br.M.J., v.307, n.6909, p.9069, 1993. 